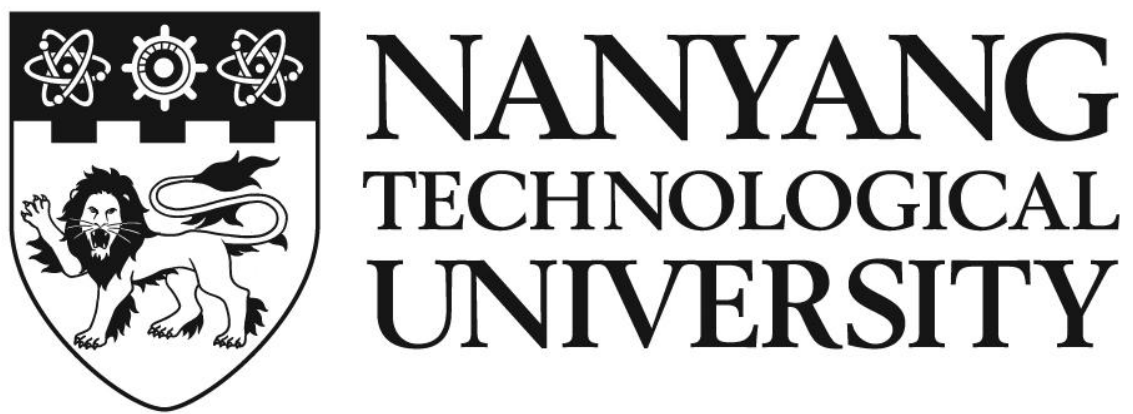

HETEROGENEOUS EXPECTATIONS AND HOUSING

MARKET

HUANG ZICHUN

SCHOOL OF SOCIAL SCIENCES 2017 


\section{HETEROGENEOUS EXPECTATIONS AND HOUSING MARKET}

\section{HUANG ZICHUN}

\section{School of Social Sciences}
A thesis submitted to the Nanyang Technological University in fulfillment of the requirement for the degree of Doctor of Philosophy




\section{Acknowledgements}

I am very grateful to my supervisors, colleagues, friends and family who were very supportive during the writing of my thesis.

First and foremost, I would like to express my greatest gratitude to my thesis supervisors, Associate Professor Chia Wai-Mun and Associate Professor Huang Weihong for their inspirational guidance and support. Their advice and encouragement extended beyond the scope of this dissertation. Without their guidance, this thesis could not have been completed.

I would also like to extend my sincerest thanks to Assistant Professor Tang Yang and Assistant Professor Bao Te for their constructive comments and insightful suggestions on the earlier drafts of this thesis.

I owe a debt of gratitude to friends and colleagues at the School of Humanities and Social Sciences, Nanyang Technological University. In particular, I would like to thank the students from my doctoral program and the team of students working under Associate Professor Chia Wai-Mun for their encouragement, support and useful comments.

Finally, I acknowledge my parents and husband for their encouragement, love and support throughout the years. 


\section{Contents}

Summary

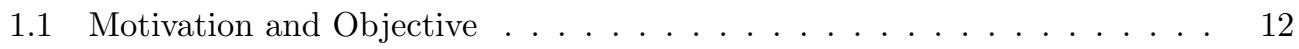

1.1.1 Exponential Bubble and Linear Trend . . . . . . . . . . . . . . . 14

1.2 Organization and Structure . . . . . . . . . . . . . . . 16

2 Literature Review $\quad 24$

2.1 Introduction . . . . . . . . . . . . . . . . . . 24

2.2 Literature on Housing Bubbles in the U.S. . . . . . . . . . . . . . 25

2.2.1 The Causes of Housing Bubbles . . . . . . . . . . . . . . 25

2.2.2 Housing Bubble Detection . . . . . . . . . . . . . 26

2.3 Literature on HAMs . . . . . . . . . . . . . . . . . . . 27

2.3.1 HAM in Housing Market . . . . . . . . . . . . . . . 29

2.3.2 HAM with Markov Regime-dependent Beliefs . . . . . . . . . . . 31

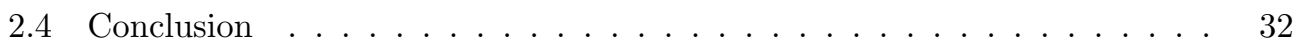




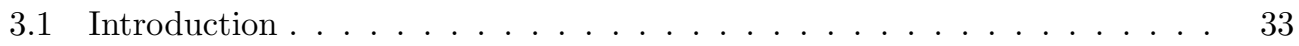

3.2 The Model . . . . . . . . . . . . . . . . . . . . . . . . . . 34

3.2.1 Evolutionary Selection of Expectations . . . . . . . . . . . . 37

3.2 .2 A Three-type Example . . . . . . . . . . . . . . . . . . . . . . . . 39

3.3 Results and Discussions . . . . . . . . . . . . . . . . . . . . . 41

3.3.1 Calculating the Fundamental Model Parameter . . . . . . . . . . 41

3.3.2 Estimating the HAM using Nonlinear Regression . . . . . . . . . . 43

3.3 .3 Estimation Results . . . . . . . . . . . . . . . . . 45

3.4 Factors Affecting the Formations of an Exponential Bubble . . . . . . . 47

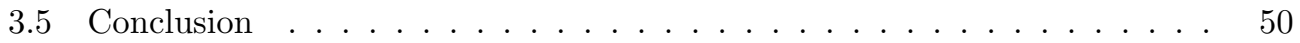

4 Housing Bubbles: Causes and Corrections under Heterogeneous Expec-

tations 52

$4.1 \quad$ Introduction . . . . . . . . . . . . . . . . . . . . . . . . . . 52

4.2 HAM under Market-correction-adjusted Fitness Measure Framework . . . 54

4.2.1 Market-correction-adjusted Fitness Measure . . . . . . . . . . . . 57

4.3 Results and Discussions . . . . . . . . . . . . . . . 63

4.3.1 Fundamental Price and Fundamental Model Parameters . . . . . . 63

4.3.2 Estimating the HAM using Nonlinear Regression . . . . . . . . 65

4.4 Predict the Timing of Market Switches . . . . . . . . . . . . . . 70

4.5 Dynamics and Policy Implications _. . . . . . . . . . . . . . . 74

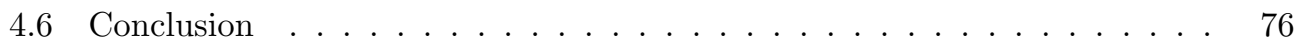


5 Boom-Bust Housing Price Dynamics under Markov Regime Switching 78

5.1 Introduction . . . . . . . . . . . . . . . 78

5.2 Model Description ...................... 79

5.2 .1 Speculators ......................... 80

5.2 .2 Consumers and Suppliers _. . . . . . . . . . . . . . . . 83

5.2.3 Market Structure . . . . . . . . . . . . . . . . 84

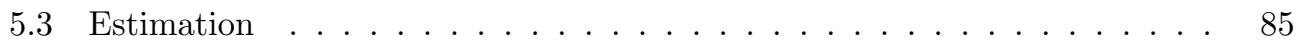

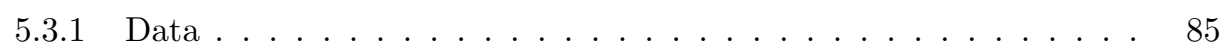

5.3.2 Maximum Likelihood . . . . . . . . . . . . . . . 87

5.3.3 Estimation Results . . . . . . . . . . . . . . . . 90

5.4 Empirical Implications . . . . . . . . . . . . . . . . . . . . . . . 94

5.4.1 Factors Affecting the Average Increasing (Decreasing) Speed . . . 95

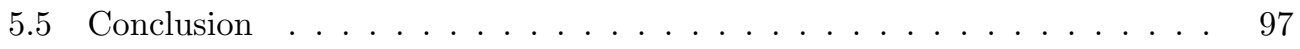

6 Conclusion and Future Work $\quad 99$

$\begin{array}{ll}\text { A Computing the Nonlinear Least Squares Estimator } & 103\end{array}$

B Robust Check: Neighbor States 105

C Robust Check: Fundamental Price is the Long-run Average of the Housing Prices 109

D A Modified Version of the Markov Regime Switching Model: Only Bringing in Speculative Motives

E Use Monthly data in the regression in Chapter 5 


\section{List of Tables}

1.1 Estimation results of $p_{t}=p_{0}+b t+c t^{2}+\epsilon_{t} \ldots \ldots \ldots \ldots \ldots \ldots 22$

3.1 Values used for the fundamental process $\ldots \ldots \ldots \ldots \ldots$

3.2 Estimation results for the three-agent HAM, 1975:1-2006:7 . . . . . . 46

4.1 Summary of the values used in the estimation . . . . . . . . . . 65

4.2 Estimates for the booms and busts of the two patterns, 1975:1-2015:3. . . 66

$5.1 \quad$ Summary statistics . . . . . . . . . . . . . . . . . . . . 87

5.2 Estimates for the regime switching HAM, 1975Q1-2015Q1 . . . . . . . 91

B.1 Estimation results for the three-agent HAM, 1975:1-2015:3 . . . . . . . . 106

C.1 Estimates for the model with a long-term-average fundamental price, 1975:1-

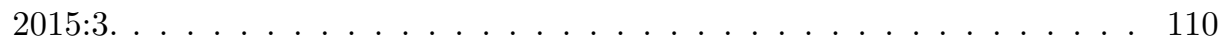

D.1 Estimates for the regime switching HAM, 1975Q1-2015Q1 . . . . . . 115

E.1 Estimates for regime switching model, 1975M1-2015M3. . . . . . . . . 118 


\section{List of Figures}

1.1 Dynamics of housing prices in 42 state in the U.S. . . . . . . . . . . 21

1.2 Dynamics of housing prices in Arizona . . . . . . . . . . . . . . . . 23

1.3 Dynamics of housing prices in Minnesota . . . . . . . . . . . . 23

3.1 Relative deviations and estimated fractions of agents in the formation of an exponential bubble ..................... 47

3.2 Relative deviations and estimated fractions of agents in the formation of a

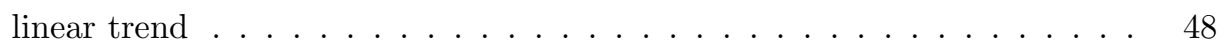

3.3 Sensitivity of $x_{t}$ to the transition speed between different strategies, $\beta^{*} \quad$. 49

3.4 Sensitivity of $x_{t}$ to the beliefs parameter of trend followers, $\phi_{3} \ldots \ldots$

3.5 Sensitivity of $x_{t}$ to the gross return of risk free asset relative to houses, $R^{*} \quad 51$

4.1 Forecasted relative deviation, $x_{t}$, by BHM-type model from Sep 2005 . . 53

4.2 Relative deviations and fractions of three types of agents in Arizona housing

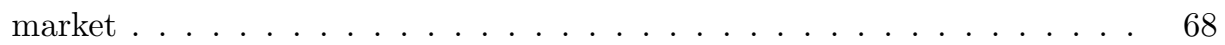

4.3 Relative deviations and fractions of three types of agents in Minnesota housing market . . . . . . . . . . . . . . . . 70

4.4 Forecast relative deviation, $x_{t}$, by my HAM and BHM-type model when the dividing point is Sep $2005 \ldots \ldots \ldots$. . . . . . . . . . . . 71 
4.5 Forecast relative deviation, $x_{t}$, by my HAM and BHM-type model when the dividing point is Oct $2005 \ldots \ldots \ldots$. . . . . . . . . . . 72

4.6 Forecast relative deviation, $x_{t}$, by my HAM and BHM-type model when the dividing point is Nov 2005 . . . . . . . . . . . . . 73

4.7 Forecast relative deviation, $x_{t}$, by my HAM and BHM-type model when the dividing point is Dec $2005 \ldots \ldots \ldots$. . . . . . . . . . 73

4.8 Bifurcation diagrams showing the long run behaviour for Arizona as a function of the bifurcation parameter $R^{*} \ldots \ldots \ldots$. . . . . . 75

5.1 Housing price index in the US from 1975Q1 to 2015Q1 . . . . . . . . 86

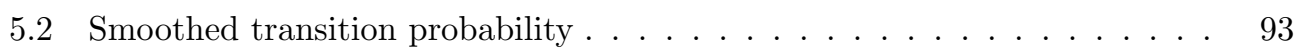

5.3 Housing price index and classified boom regimes . . . . . . . . . . . 94

5.4 The effects of the transition probability, $P_{1,1}$, on the housing price dynamics 96

5.5 The effects of the chartists' beliefs parameter in the boom regime, $\beta_{c, 1}$, on the housing price dynamics $\ldots \ldots \ldots$. . . . . . . . . . . 97

5.6 The effects of the chartists' beliefs parameter in the bust regime, $\beta_{c, 2}$, on the housing price dynamics $\ldots \ldots \ldots$. . . . . . . . . . . . . . 98

B.1 Relative deviations and fractions of three types of agents in California's housing market . . . . . . . . . . . . . . . . . 107

B.2 Relative deviations and fractions of three types of agents in Iowa's housing market . . . . . . . . . . . . . . . . . 108

C.1 Relative deviations and fractions of three types of agents in Arizona housing market using a long-term-average fundamental price . . . . . . . . . . . 111

C.2 Relative deviations and fractions of three types of agents in Minnesota housing market using a long-term-average fundamental price . . . . . . . 112 
D.1 Smoothed transition probability . . . . . . . . . . . . . . . 117

D.2 Housing price index and classified boom regimes . . . . . . . . . 117 


\section{Executive Summary}

This thesis studies the boom-bust housing price dynamics under heterogeneous expectations. I mainly focus on three key questions: (1) Why some housing prices form an exponential pattern and others follow a linear trend? (2) How to provide an explanation not only for the formation but also for the subsequent collapse of an exponential bubble and a linear trend jointly within the same framework? (3) How do different market conditions affect the trading behavior of market participants in the US housing market?

Using Freddie Mac housing price index from the United States, Chapter 1 classifies the dynamics of housing prices on its rising trend into two patterns: an exponential pattern and a linear pattern. An exponential bubble is a housing price bubble that grows exponentially before it bursts. A linear trend is a housing price trend that increases slowly in a linear pattern before it collapses.

In Chapter 3, I then develop a three-heterogeneous agent model (HAM) consisting of fundamentalists, chartists and naive agents to show that, without any exogenous shocks, the formations of the two different housing price patterns could have some endogenous origin. To estimate the model, I conduct a nonlinear regression using monthly housing market data in two representative states, Arizona and Minnesota, from Jan 1975 to Jul 2006. The estimated parameters measuring the heterogeneity and switching behaviour are statistically significant, confirming the co-existence of the three types of investors and that they are interacting between each other. More importantly, the formation of exponential bubbles and linear trends could be explained by the interactions between heterogeneous agents. Exponential bubbles could be primarily driven by the dominance of the chartists while a linear growth in housing prices could be due to systematically constant proportions of each type of agents. Sensitivity analysis suggests that a housing price movement is more likely to be of an exponential type when we have more frequent transition between trading strategies, stronger belief in the housing trend and smaller gross return on risk-free asset relative to housing.

Existing studies only analyze how an exponential bubble and a linear trend are formed or crash in isolation; they rarely look into the formation and the collapse of the two price patterns jointly within the same setup. Moreover, the model in Chapter 3 (BHMtype model) cannot predict the timing of market switches (Bolt et al., 2014). Chapter 4 develops a HAM with an evolutionary selection mechanism based on market-correctionadjusted fitness measure and offers a potential explanation not only for the formation 
but also for the subsequent collapse of an exponential bubble and a linear trend since the mid of 2006. One important feature of my HAM is that investors not only cluster to the heuristics which enjoyed better performance in the recent past, but also act based on the expectations that the market is more inclined to reverse when the current price deviates further from its fundamentals. Result 1 is that (1) while the formation of an exponential bubble is primarily due to the dominance of chartists, a linear trend can be explained by stable proportions of each type of agents, and (2) the collapse of both an exponential bubble and a linear trend could be driven mainly by the activations of fundamentalists. Result 2 shows that compared to BHM-type (Boswijk et. al., 2007) heterogeneous agent models, our HAM exhibits better forecasting accuracy in terms of predicting the timing of market switches when the dividing point is from Nov 2005 to Feb 2006. The policy implications in Result 3 suggest that a policy maker can stabilize the market through higher interest rate and property tax rate.

Chapter 5 proposes a simple heterogeneous agent model with Markov chain regimedependent beliefs for the U.S. real estate market. The demand for housing is divided in a real component and a speculative component consisting of fundamentalists, chartists and noise traders. Within the Markov-switching framework, the beliefs of chartists and noise traders are modeled to be regime-dependent. I estimate the model using the quarterly housing price data from 1975Q1 to 2015Q1 ${ }^{1}$. My Finding 1 is that the model matches well with the boom and bust periods in the U.S. housing market. Finding 2 shows the evidence of time-varying behavioural heterogeneity within-group. To be more specific, chartists form trend following expectation in the boom periods while take contrarian strategy in the bust periods, and noise traders are much more sensitive to external news in the bust state than in the boom state. My finding 3 suggests that the housing price increases (decreases) more drastically when the probability of staying in the boom (bust) state is larger and the bandwagon (contrarian) expectation of chartists is stronger.

\footnotetext{
${ }^{1}$ I use quarterly data instead of monthly Freddie Mac housing price data, because the estimated parameters using the monthly data are not significant. It is possible that market participants expect that the change in the relative deviations between the housing prices and the fundamental housing prices within a month is small, so the model cannot distinguish a trend follower from a contrarian. See Appendix E for details.
} 


\section{Chapter 1}

\section{Introduction}

\subsection{Motivation and Objective}

Real estate markets undergo episodes of dramatic changes. In the United States housing market, for instance, prices peaked in early 2006, started to drop in 2006 and 2007, and reached new lows in 2012. On December 30, 2008, the S\&P/Case Shiller home price index reported its largest price drop in its history with home prices declining by a record high of $18 \%$ from the previous year.

The aim of this thesis is to analyze the boom and bust of the U.S. real estate market. A housing price bubble is defined as a situation when the growth rate of a price series is not supported by changes in its fundamentals (Stiglitz, 1990). This issue is of particular importance because housing market bubbles are considered to be one of the leading indicators on financial instability and even crises ((Leamer, 2007). According to general consensus, the primary cause of recession in December of 2007 that subsequently led to the global financial crisis of 2007-2009 is credit crisis arising from the bursting of the housing bubble in the United States (McDonald and Stokes, 2013). Moreover, a bursting housing price bubble could lead to a decrease in the value of household wealth ${ }^{1}$, resulting in a severe negative impact on consumption and GDP (Mikhed and Zemcik, 2007 and

\footnotetext{
${ }^{1}$ Primary and other residential property constituted almost $39 \%$ of the total assets in the portfolios of US families, according to the 2004 Survey of Consumer Finances (see Bucks et al., 2006).
} 
2009). Therefore, it is crucial to have a good understanding on how bubbles are formed in the housing market.

Many academic studies have emerged in an attempt to explain how the housing bubbles have been fueled up. Generally, these studies can be classified into two main strands, with one attributes the exceptionally high appreciation rates of housing prices to various exogenous factors such as low interest rate policy (Schwartz et al., 2009; Taylor, 2007; McDonald and Stokes, 2013) or loose credit standards (Krugman, 2009) and the other on the role of irrational exuberance defined as a heightened state of speculative fervor (Shiller, 2005 and 2009).

While the first strand of literature clearly has virtues and contributions in explaining the house price fluctuations, most of them have neglected the potentially important endogenous origin in the dynamics of housing prices. The second strand of literature, on the other hand, offers some slightly different insights. Shiller (2005 and 2009) argues that it is the speculative behavior of market participants that repeatedly leads to stunning price movements in housing markets.

According to this strand of literature, all market participants, including government regulators, mortgage lenders, investment bankers, credit rating agencies, foreign investors, insurance companies and finally home owners, who contributed to the housing bubble acted on an universal assumption that home prices would continue to increase. It is this assumption that led them into making decisions that created the housing bubble. First, government regulators could not find any justifiable reasons to control rising home prices as there were no historical records for any drastic falls in housing prices since the Great Depression. Second, mortgage lenders who saw low default rates would continue to offer mortgages with adjustable mortgage rates, as long as housing prices continued to increase. Third, investment bankers would be keen to issue highly leveraged mortgage-backed securities and these securities would perform as expected if housing prices kept rising. Fourth, credit rating agencies would give these securities a triple-A rating. Fifth, with such high rating, foreign investors would keep pouring money into these mortgage-backed securities. Sixth, insurance companies would also find it well to sell credit default swaps to investors in these securities. Finally, home buyers would continue to buy homes even though the 
monthly payment was getting unbearable as they assumed that they would be able to soon sell the home for a profit or refinance the loan when the adjustable rate increased. Putting these together, the housing price climbed remarkably fast in the early 2000s and peaked in the first quarter of 2006 before it collapsed soon in the same year.

Most real estate studies referred to above generally concentrate on the empirical analysis, rarely building the theoretical models. To fill in the gap in the existing literature, this thesis first builds a three-agent heterogeneous agent model (HAM) consisting of fundamentalists, trend followers and naive agents to show that, without any exogenous shocks, housing price bubbles could have some endogenous origin.

\subsubsection{Exponential Bubble and Linear Trend}

Figure 1.1 shows the Freddie Mac house price index in 42 states in the U.S. from Jan $1993^{2}$ to Mar 2013. The figure shows that the dynamics of housing price on its rising trend can be visually classified into two patterns. For the 18 states in Pattern 1, housing prices were relatively stable throughout most of the 1990s, and then they began a rapid increase until they reached the peak around the mid of 2006. On the other hand, the increase of the housing prices in the 24 states in Pattern 2 was relatively modest. They rose slowly and approximately linearly before they collapsed. So I classify the dynamics of housing price on its rising trend into an exponential pattern and a linear trend. An exponential bubble reveals housing price that grows exponentially before it bursts, while a linear trend shows housing price trend that increases steadily over time demonstrating a linear trend before it collapses.

I further classify the two price patterns statistically. If there is a linear trend, the generating process of the data looks like

$$
p_{t}=p_{0}+b t+\epsilon_{t}
$$

\footnotetext{
${ }^{2}$ We choose Jan 1993 as the starting point in order to avoid the influence of the housing price bubbles before 1993 .
} 
If there is an exponential bubble, the data generating process should look like

$$
p_{t}=p_{0}+b t+c t^{2}+\epsilon_{t} .
$$

This means I can use the above equation to identify an exponential bubble and a linear trend. For example, we can run the regression. A significant and large $c$ is indication for the existence of an exponential bubble, while an either insignificant or small $c$ is indication for the existence of a linear trend.

For each state, I use monthly Freddie Mac house price index from Jan 1993 to the sample peak to run the regression. Table 1 reports the estimation results. For the states where housing prices form an exponential pattern, the parameter $c$ is significant and positive. While for the states where housing prices form a linear pattern, the parameter $c$ is either insignificant or small (some are even negative). So using these regression results we can identify an exponential bubble and a linear trend.

Table 1.1 reports the rate of change from 1993 to 2003, the rate of change from 1993 to the sample peak, the $t$-statistic and the $p$-value for the each state. The housing price movements in the 18 states in Pattern 1 are classified as exponential bubbles according to the $t$-tests. The gap between the rate of change from 1993 to $2003, \mu_{1}$, and the rate from 1993 to the sample peak, $\mu_{0}$, is relatively large. More importantly, the $p$-values of these states are below 0.05, indicating that rate of change from 1993 to the sample peak, $\mu_{0}$, is significantly larger than the rate of change from 1993 to $2003, \mu_{1}$. So the dynamics of these 18 states can be classified as exponential patterns. On the contrary, the housing price movements in the 24 states in Pattern 2 are classified as linear trends according to the $t$-tests. The gap between the rate of change from 1993 to $2003, \mu_{1}$, and the rate from 1993 to the sample peak, $\mu_{0}$, is relatively small. More importantly, the $p$ values of the 24 states in Group 2 are larger than 0.05. It indicates that the rate of change from 1993 to 2003 is not significantly different from the rate of change from 1993 to the sample peak. The housing price movement of these states could be relatively stable, demonstrating a linear increasing trend.

In the following analysis, I use the housing price dynamics in Arizona as a typical example of an exponential bubble and the housing price dynamics in Minnesota as a typical 
example of a linear trend. Figures 1.2 and 1.3 show the housing prices in Arizona and Minnesota. Then, the price in Arizona began a rapid increase. It reached its peak in the second quarter of 2006, over 210 percent higher than what it had been in the first quarter of 1993. In Minnesota, however, the increase was relatively modest. The housing price was also peaked in the second quarter of 2006 but at this level, it was only 144 percent higher than what was observed in the first quarter of 1991.

\section{$1.2 \quad$ Organization and Structure}

In order to examine whether housing price bubbles can be formed in the absence of any external shocks, in Chapter 3, I then proceed to construct a HAM that consists of fundamentalists, chartists and naive agents to explore whether the interaction of agents with different beliefs can affect the dynamics of the housing prices and subsequently the formation of exponential bubbles and linear trends. The fundamentalists believe in meanreversion of house price towards the benchmark fundamental price, which is derived from fundamental relations between housing price and rental, the chartists either take trend following strategy or contrarian strategy, and the naive agents adopt naive expectations to forecast future prices. An evolutionary selection mechanism based on relative recent past performances governs the interactions of agents with different forecasting rules. A strategy could attract more agents if it performed better than other strategies in the recent past. As our three-type HAM is a nonlinear evolutionary switching model, I use nonlinear least squares (NLLS) to estimate its parameters.

Using this HAM framework, I wish to address the following questions. First, could behavioral heterogeneity exist in the U.S. real estate market? If so, how do agents with different beliefs switch between strategies? Second, could the two housing price patterns be the outcomes of evolutionary switching between different agents in the market? Third, why did the price patterns in some states demonstrate an exponential price trend while the others revealed only a linear growing pattern?

In our nonlinear regression, I find some interesting results. First, I see that for the two markets demonstrating an exponential bubble and a linear trend, the estimated pa- 
rameters measuring the heterogeneity and switching behavior are statistically significant. This finding not only confirms the co-existence of the three types of agents in the housing market but also shows that they are interacting between each other. Second, the price patterns of both an exponential bubble and a linear trend could be generated by the evolutionary switching mechanism between agents so the dynamics of housing price could have at least some, if not all, endogenous origin. In particular, while the formation of an exponential bubble is driven mainly by the dominance of chartists, a linear price trend is attributed to the systematically constant proportions of each type of agents. Third, our simulation experiments suggest that the housing price is more likely to rise exponentially when there are more frequent transition between trading strategies, stronger belief in the housing trend and smaller gross return on risk-free asset relative to housing.

Compared to the existing literature, our study provides new insights in two aspects. First, I not only classify the U.S. housing price trends into two seemingly different patterns, namely an exponential trend and a linear trend, but also offer an endogenous explanation for the formation of different housing price trends. While some studies have attempted to use HAM to examine the booms and busts in the housing market, such as Bolt et al. (2014), none of them has presented how the two patterns are formed within the same framework. Second, our study can be seen as one of the few attempts to provide an empirical validation to test for the behavioral heterogeneity in the housing market using actual data. These few include the work of Kouwenberg and Zwinkels (2014) who estimate a HAM for the U.S. housing market, showing that the fractions of fundamentalists and trend followers are usually equal, while trend followers dominate in the booming periods. Their study, however, does not offer possible explanations for the formation of both types of price trends within the same framework. Eichholtz et al. (2015) estimate a HAM using housing price data along the Herengracht in Amesterdam with a price adjustment rule based on excess demand, while ours is a temporary equilibrium pricing model.

Most studies in previous literature only analyze how the two price patterns are formed or crash in isolation. They rarely look into the formation and the subsequent collapse of an exponential bubble and a linear trend jointly within the same framework. In addition, the model in Chapter 3 (BHM-type model) cannot predict the timing of market switches (Bolt et al., 2014). In Chapter 4, I fill the gap in the literature by constructing a three-type 
heterogeneous agent model (HAM) under a market-correction-adjusted fitness measure framework to provide an explanation not only for the formation but also for the collapse of an exponential bubble and a linear trend within the same setup and demonstrate how each of the price patterns is formed and how they crash mainly through the interactions of fundamentalists, chartists and naive agents in the housing market. The market-correctionadjusted fitness measure governs how the investors choose their forecasting rules. On one hand, agents will cluster to the strategies that performed better in the recent past. On the other hand, participants believe the further the price deviates from its fundamental price, the more likely the market corrections is going to occur.

I estimate the model using monthly housing market data from two representative states, Arizona and Minnesota, from Jan 1975 to Mar 2015. A few interesting findings follow. Result 1, while the formation of an exponential bubble could be due to the activations of trend followers, a linear trend is explained by a constant proportion of each type of agents, and the collapse of both an exponential bubble and a linear trend could be driven mainly by the activations of fundamentalists. Result 2, by adopting the marketcorrection-adjusted fitness measure, our nonlinear HAM is able to roughly predict the timing of market corrections. Compared to the existing HAMs using realized-profit fitness measure, such as BHM-type (Boswijk et. al., 2007) heterogeneous agent models, our nonlinear HAM exhibits better forecasting accuracy in the timing of market switches when the dividing point is from Nov 2005 to Feb 2006. Result 3, bifurcation diagrams from the model suggest that these is a role for policy makers to stabilise the market by increasing interest rate and raising property tax rate.

The contribution of this study is two-fold. First, our model uses an evolutionary selection mechanism based on market-correction-adjusted fitness measure which governs the interactions of agents with different forecasting rules. Under this framework, investors not only cluster to the heuristics which enjoyed better performance in the recent past, but also act based on the expectations that the market is more inclined to reverse when the current price deviates further from its fundamentals. On the contrary, in the frequently applied fitness measure in the HAM literature, the realized-profit fitness measure, investors usually consider only one single factor, that is, the relative performance of each heuristics, when choosing their forecasting rules. Second, our study can be seen as one of 
the few attempts to forecast the timing of market switches. While some have attempted to use HAM to predict the price trend in financial market or real estate market, such as Boswijk et al. (2007) and Chiarella et al. (2012), none of them has forecasted when the market switches would occur. In contrast, I show that the exponential bubble demonstrates likelihood to burst since Nov 2005, which fits the actual price movement relatively well as the actual housing price started to drop in early 2006. So my model can provide early warnings when the market is approaching a turning point.

Most HAM studies assume that heterogeneous agents expect the prices to evolve as a linear or a linearly auto-regressive process, although the price is modeled as a non-linear dynamic system. However, they may have neglected the possibility that the boom-bust housing price dynamics could affect agents' expectations. Recent real estate literature documents the influence of regime switching on investors' behaviors. For instance, Nneji et al. (2013) show that the U.S. housing market switches among three states, namely a bubble state, a steady state and a crash state, and that investors' behaviour varies with these market conditions. Chia et al. (2014) estimate a Markov regime switching HAM for the Australia housing market. Their results suggest that the market switches between two aggregate states, a boom state and a bust state, and that investors adapt their strategies over time based on various market conditions.

Motivated by previous literature, Chapter 5 proposes a simple HAM with Markov chain regime-dependent beliefs for the U.S. real estate market. The demand for housing is divided into a real component and a speculative component consisting of fundamentalists, chartists and noise traders. While fundamentalists trade on mean-reversion, chartists use either the trend following strategy or the contrarians strategy. Noise traders' demand is assumed to follow a normal distribution. I assume two aggregate states, a boom state and a bust state, for the housing market and that their switches follow a two-state Markov regime switching process. Within the Markov-switching framework, the beliefs of chartists and noise traders are modeled to be regime-dependent.

By estimating the Markov regime switching HAM using the quarterly housing market data $^{3}$ in the U.S. from 1975Q1 to 2015Q1, I show that the model matches well with the boom and bust periods in the real estate market. More interestingly, I find evidence of

\footnotetext{
${ }^{3}$ We obtain this series from Federal Housing Finance Agency.
} 
time-varying behavioural heterogeneity within-group. In particular, chartists form trend following expectations in the boom periods while take contrarian strategies in the bust periods, and noise traders are much more sensitive to external news in the bust regime than in the boom regime. In addition, our simulation results suggest that the housing price increases (decreases) more drastically when the probability of staying in the boom (bust) regime is larger and the bandwagon (contrarian) expectation of chartists is stronger.

Our study can be seen as one of the few attempts to investigate the time-varing within group behavioural heterogeneity by estimating a HAM with Markov chain regime-dependent beliefs. One of these few is Chiarella et al. (2012) which estimate a Markov regime switching HAM for the U.S. stock market using S\&P 500 data from January 2000 to June 2010, and their estimation results match well with the boom and bust periods in the U.S. stock market. In contrast to their work which only considers the speculative demand, our HAM for the U.S. real estate market is constructed to include the real demand and real supply as well. Chia et al. (2014) use the Australian housing market data from 1982Q1 to 2013Q2 to estimate a HAM with Markov regime-switching based a on temporary equilibrium framework, while the model I have is a market-maker framework model.

The remaining of the thesis is organized as follows. Chapter 2 provides literature review on studies and issues related to housing price bubbles. I also give literature review on heterogeneous agent model (HAM) in general. Chapter 3 explores the potentially important endogenous origin of an exponential bubble and a linear trend. Chapter 4 examines the formations and collapses of the two price patterns jointly using a HAM under a marketcorrection-adjusted fitness measure framework. Chapter 5 studies time-varying within group behavioural heterogeneity in boom-bust housing price dynamics by constructing a HAM with Markov chain regime-dependent beliefs. Chapter 6 offers some conclusions. 
Pattern 1
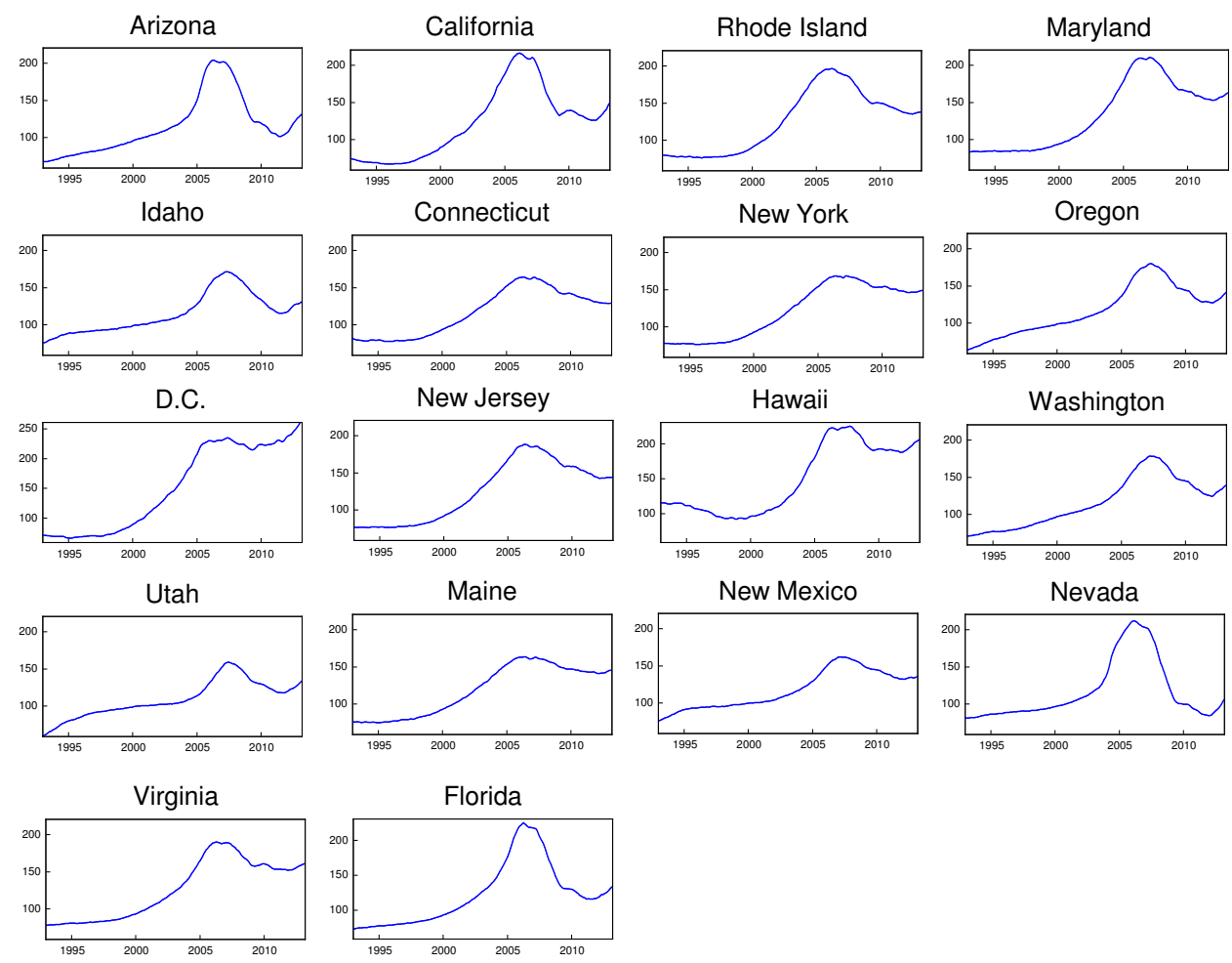

\section{Pattern 2}
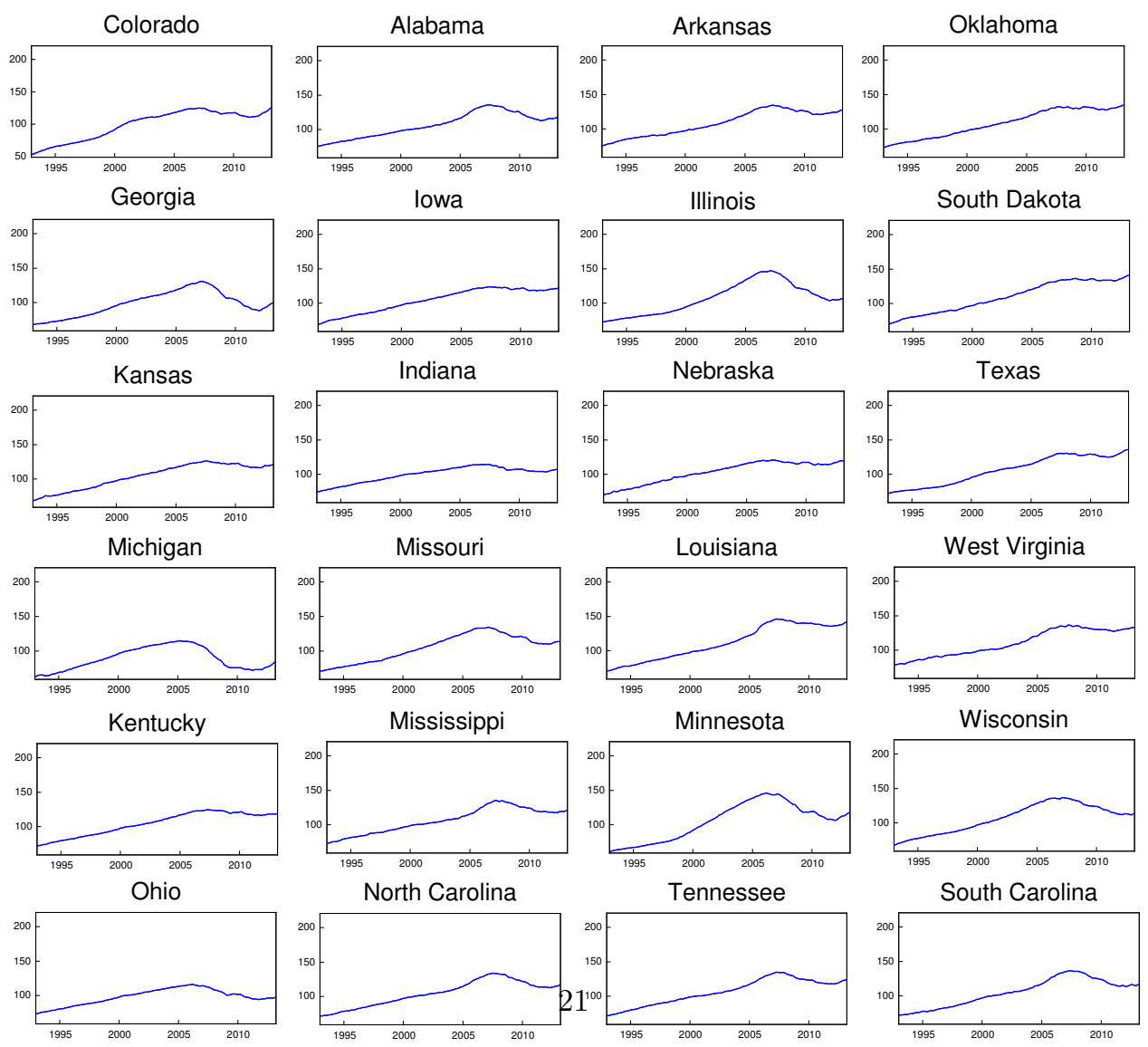

Figure 1.1: Dynamics of housing prices in 42 state in the U.S. 
Table 1.1: Estimation results of $p_{t}=p_{0}+b t+c t^{2}+\epsilon_{t}$.

\begin{tabular}{|c|c|c|c|}
\hline & $p_{0}$ & $b$ & $c$ \\
\hline \multicolumn{4}{|c|}{ States where housing prices form an exponential pattern: } \\
\hline Arizona & $79.4996(0.0000)^{* * *}$ & $-0.3947(0.0000)^{* * *}$ & $0.0064(0.0000)^{* * *}$ \\
\hline Calif & $80.7310(0.0000)^{* * *}$ & $-0.8180(0.0000)^{* * *}$ & $0.0106(0.0000)^{* * *}$ \\
\hline Conne & $9(0.0000)^{* * *}$ & $-0.3407(0.0000)^{* * *}$ & $0.0056(0.0000)^{* * *}$ \\
\hline D.C. & $00)^{* * *}$ & $9030(0.0000)^{* * *}$ & $0.0120(0.0000)^{* * *}$ \\
\hline Florida & $88.2708(0.0000)^{* * *}$ & $-0.7566(0.0000)^{* * *}$ & $0.0094(0.0000)^{* * *}$ \\
\hline Haw & $137.9348(0.0000)^{* * *}$ & $-1.5732(0.0000)^{* * *}$ & $0.0127(0.0000)^{* * *}$ \\
\hline Idaho & $3(0.0000)^{* * *}$ & $-0.2707(0.0000)^{* * *}$ & $0.0040(0.0000)^{* * *}$ \\
\hline Maine & $1(0.0000)^{* * *}$ & $-0.2380(0.0000)^{* * *}$ & $0.0051(0.0000)^{* * *}$ \\
\hline Mar. & $9(0.0000)^{* * *}$ & $-0.8306(0.0000)^{* * *}$ & $0.0095(0.0000)^{* * *}$ \\
\hline Neva & $1(0.0000)^{* * *}$ & $-0.8323(0.0000)^{* * *}$ & $0.0093(0$. \\
\hline New & k* & $-0.5235(0.0000)^{3}$ & $0.0075(0.0000)^{* * *}$ \\
\hline New & & $-0.1696(0.00$ & 0.0 \\
\hline $\mathrm{Ner}$ & & & \\
\hline Oreg & & & ) $* * *$ \\
\hline Rhe & & -0 & 0.0 \\
\hline Utah & & $2(0.002$ & )*** \\
\hline Vir & & & \\
\hline Washington & $77.4900(0.0000)^{* * *}$ & -0.1845( & \\
\hline \multicolumn{4}{|c|}{ States where housing prices form a linear pattern: } \\
\hline Arkansas & & 01204 & $* * *$ \\
\hline $\mathrm{Col}$ & & & \\
\hline & $* * *$ & )*** & )*** \\
\hline & $* * *$ & $2(0.0000)^{* * *}$ & )*** \\
\hline Iov & & $2(0.00$ & \\
\hline & & $1(0.00$ & \\
\hline & $*$ & $* * *$ & $* * *$ \\
\hline & $00)^{* * *}$ & $0.4505(0.0000)^{* * *}$ & $-0.0004(0.0000)^{* * *}$ \\
\hline & $00)^{* * *}$ & $0.4962(0.0000)^{* * *}$ & $0.0002(0.2830)$ \\
\hline & & $0.1942(0.0000)^{* * *}$ & )*** \\
\hline & & $0.2282(0.000$ & )*** \\
\hline & $* * *$ & $0.3380(0.0000)^{* * *}$ & $-0.0002(0$. \\
\hline North & $(0.0000)^{* * *}$ & $0.2048(0.0000)^{* * *}$ & $0.0007(0.0000)^{* * *}$ \\
\hline Ohio & $5(0.0000)^{* * *}$ & $0.2967(0.0000)^{* * *}$ & $-0.0001(0.0000)^{* * *}$ \\
\hline $\mathrm{Ok}$ & 74.9 & $0.1986(0.0000)^{* * *}$ & $0.0006(0.0000)^{* * *}$ \\
\hline & $0) * * *$ & $0.2133(0.0000)^{* * *}$ & $0.0008(0.0000)^{* * *}$ \\
\hline Sou & $72.8376(0.0000)^{* * *}$ & $0.2333(0.0000)^{* * *}$ & $0.0006(0.0000)^{* * *}$ \\
\hline Ten & $(0.0000)^{* * *}$ & $0.2067(0.0000)^{* * *}$ & $0.0007(0.0000)^{* * *}$ \\
\hline & & $0.2165(0.0000)^{* * *}$ & $0.0006(0.0000)^{* * *}$ \\
\hline Wisconsin & $69.0307(0.0000)^{* * *}$ & $0.2682(0.0000)^{* * *}$ & $0.0008(0.0000)^{* * *}$ \\
\hline
\end{tabular}




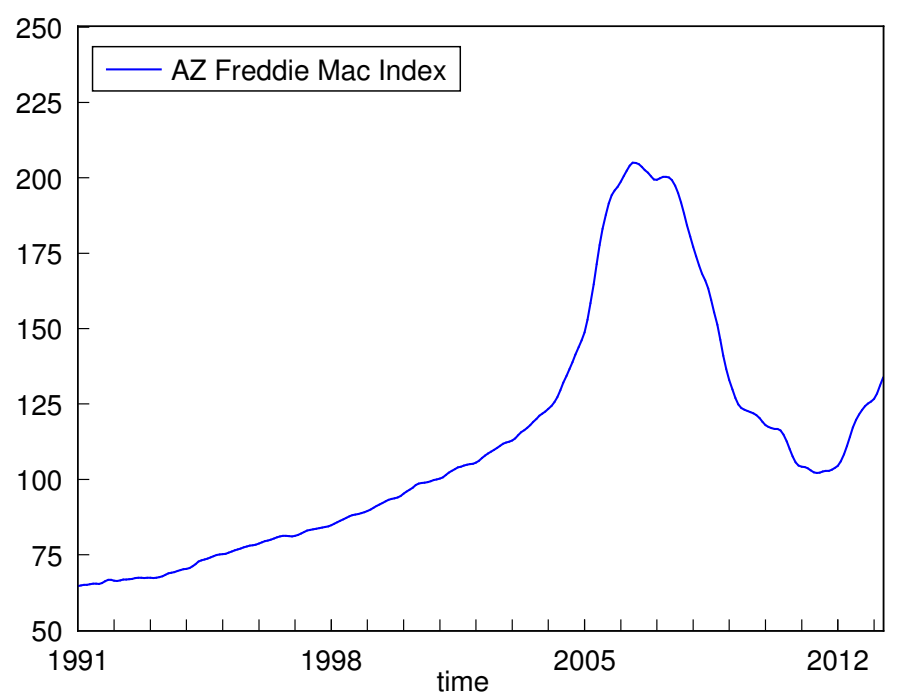

Figure 1.2: Dynamics of housing prices in Arizona

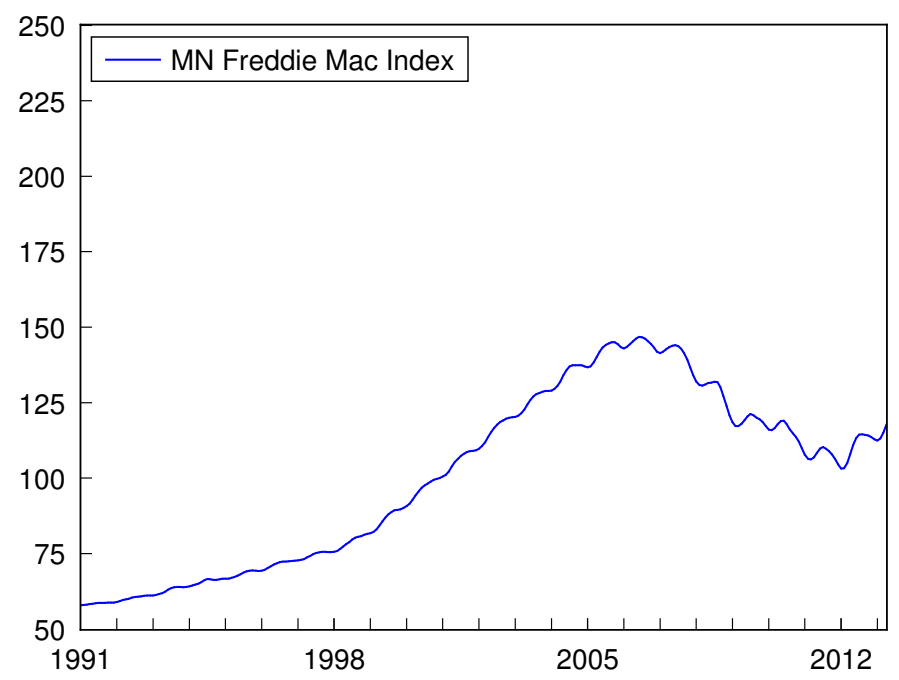

Figure 1.3: Dynamics of housing prices in Minnesota 


\section{Chapter 2}

\section{Literature Review}

\subsection{Introduction}

In this chapter, I provide literature review on studies and issues related to housing price bubbles. These works are expanding rapidly in recent years and most of them have concentrated around few controversial issues which are generating lively debate. One main issue is the detection of a housing price bubble, which usually attracts great interest during the boom of the housing market. For example, prior to 2006, the possibility of a house price bubble in the U.S. real estate market was an active topic of discussion in both the popular press and academic journals. Another main issue is the debate over the causes of housing bubbles. The literature on this topic is popular, especially since the bursting of the recent housing bubble in the U.S. real estate market.

Next, I provide a general literature on heterogeneous agent model (HAM), which has become well developed in recent decades. HAMs provide a recently developed tool, which can be used to study temporary deviations from market equilibria in various asset markets. Then, I devote my focus on the literature of HAMs in real estate market which aim to provide some contributions to. Finally, I review papers on Markov chain regime-switching HAM. 


\subsection{Literature on Housing Bubbles in the U.S.}

There is a general agreement that the bursting of the housing price bubble in the U.S. set off the financial crisis and deep recession of 2007-2009. The literature on the housing price bubble is expanding rapidly in recent years and the main issues in this field include the debate over the causes of housing bubbles as well as how to detect them.

\subsubsection{The Causes of Housing Bubbles}

Different economists have various perspectives on the causes of housing market bubbles. Some of them attribute the increasing trends in the housing prices before 2006 to various exogenous factors, while others focuses on some endogenous origin in the dynamics of housing prices.

There are generally two strands of literature which concentrates on the exogenous causes. The first strand blames the interest rate policy of the Federal Reserve Bank during the critical years of 2001-2004, while the second strand of literature does not place the Fed's interest rate policy at the center of the story. Here is a sampling of the different opinions.

Schwartz et al. (2009) argue that the Fed was too accommodative from 2001 on and was slow to tighten monetary policy. Although other factors are mentioned, the very relax expansionary monetary policy is the first to be blamed. Taylor (2009) explains that the Federal Reserve Bank held the interest rate too low to reach the Taylor Rule from the beginning of 2002 till the end of 2005, an episode that coincides roughly with the most remarkable increase in housing prices. McDonald et al. (2013) use the Granger causality analysis and VAR modeling methods to show that the artificially low interest rate in the critical time period of 2001-2004 is the cause.

Krugman (2009) takes a very different position by placing loose credit standards at the center of the story. His findings suggest that loose credit standards fed the housing bubble and rising home prices fed back into loose credit standards. Hendershott et al. (2010) think the so-called mortgage finance bubble is the main reason, which had two phases, with the first phase was due to the expansion of the Government Sponsored Enterprises and the second one originated from the securitization of "junk" mortgages. Roubini and 
Mihm (2010) do not blame the Federal Reserve Bank, either. Instead, they explain that it was the financial innovation that fueled up the bubble in the real estate market.

Intensive efforts have been devoted to analyze the impact of external causes, monetary policy shocks in particular. Although these studies clearly have virtues and contributes to explaining how the housing price bubble was fueled up, most of them have neglected the potentially important endogenous causes in the housing price dynamics. Shiller (2005 and 2009) offers some different insights. He argues that (1) the artificially low interest rate should not be regarded as an exogenous cause of the housing bubble, and (2) many of the other alleged causes - such as loose lending standards, wildly inaccurate ratings given to mortgage-backed securities, and the failure of regulating agencies to stop risky lending practices - are driven by the increasing housing prices, not the other way around. Instead, it is the irrational exuberance, defined as a heightened state of speculative fervor, that repeatedly leads to an increase in housing prices. Market participants expect that the home prices would continue to increase, leading to the remarkably fast growth of housing prices.

Most studies referred to above concentrate on the empirical analysis. However, they rarely build the theoretical models to shed light upon the causes of housing bubbles. To fill in the gap in the existing literature, this thesis first builds a three-agent heterogeneous agent model (HAM) consisting of fundamentalists, trend followers and naive agents to show that, without any exogenous shocks, housing price bubbles could have some endogenous origin.

\subsubsection{Housing Bubble Detection}

As a house price bubble is a situation when the growth of the price is not supported by changes in its fundamentals (Stiglitz, 1990), the basic idea of how to detect a housing price bubble is to compare the housing price in real market with its fundamental benchmark prices. Generally, there are two streams of papers which consider breaks in the relationship between house price and fundamental house price. The first stream of papers calculate the fundamental housing prices using aggregate data. For instance, McCarthy and Peach (2004) explain that no bubble exists in the U.S. real estate market for that changes 
in house prices reflect movements in personal income and nominal mortgage rates. In contrast, Shiller (2005) uses aggregate data on home prices, personal income, building costs, population, user costs of housing and interest rates to calculate the fundamental benchmark prices. His results show that changes in fundamentals do not explain the rapid growth of U.S. house prices after 2000, suggesting the existence of housing price bubbles.

The second stream of this literature relies on regional or micro data in order to get more insights into the participants' behaviors in real estate market. For example, Smith and Smith (2006) suggest that home prices are below their fundamentals derived from rents where housing prices and rents are taken from a sample of matched single-family homes. Therefore, no bubble exists in the U.S. housing market. However, Case and Shiller (2003) are more in favor of the existence of a speculative bubble in some regional U.S. housing markets by conducting a survey of consumers attitudes toward housing. In addition, Gallin (2006) and Mikhed and Zemck (2007) employ the panel data for the U.S. Metropolitan Statistical Areas (MSA) to analyze house prices. The former study uses personal income and the latter rents as the only fundamental variable. Both studies make use of panel data stationarity tests to find that housing price dynamics could not be explained by either of the two factors.

\section{$2.3 \quad$ Literature on HAMs}

Historical evidence indicates large fluctuations of asset prices, such as stock prices, compared to indicators of its fundamentals. Such large fluctuations compared to economic fundamentals imply that the market is not fully efficient and thus that not all market participants behave rationally according to the Efficient Market Hypothesis (EMH) (see Fama (1970)). This theory assumes a single, representative, fully rational agent in financial markets. If investors were representative and fully rational, they would all have expected the stock price to reflect or return to its fundamental benchmark values.

Now that the EMH is losing popularity, other theories are gaining momentum. Simon (1957) employs a behavioral approach in which traders with boundedly rational expectations on market prices are contained. There is only one way of behaving rationally while 
there is an infinite number of ways of behaving boundedly rational. DeLong et al. (1990) introduce noise traders into financial markets and shed light on a number of anomalies, including the excess volatility puzzle, mean reversion of stock returns, the underpricing of closed end mutual funds, and the Mehra-Prescott equity premium puzzle.

Brock and Hommes (1997 and 1998) make a distinction between naive investors and rational investors and argue that investors switch between different types of forecasting strategies based on the past performance of these heuristics. The models that are designed based on these heterogeneous investor expectations are commonly known as Heterogeneous Agent Models (HAMs) (Hommes (2006) and Chiarella et al. (2009) provide a very thorough review on this class of models).

Within a typical HAM, agents are distinguished into two groups, fundamentalists and chartists. Fundamentalists base their expectations on economic theory, expecting that market prices are mean-reverting towards the assets' economic fundamental. Therefore, they form their expectations according to the deviation of the asset price from the fundamental value. Technical traders, or chartists, on the other hand, base their predictions on past price changes. They extrapolate historical price patterns observed, and use these patterns to forecast the future.

Most of HAM studies focus on applications in the financial market. Battiston et al. (2016) explain that traditional economic theory could not explain, much less predict, the near collapse of the financial system and its long-lasting effects on the global economy. And they emphasize the importance of using ideas from complexity theory to monitor and manage highly interconnected economic and financial systems. It has demonstrated that both deterministic (Day and Huang, 1990; Brock and Hommes, 1998; He and Westerhoff, 2005; Huang et al., 2010) and stochastic (Chiarella et al., 2003; He and Li, 2007) HAM are able to capture extreme movements in stock prices through their interaction and specification of different types of agents, and they do a better job in modelling the dynamics of stock prices than other models based on efficient markets and rational expectations.

HAMs with performance-based endogenous switching have been successfully estimated for various stock markets. Boswijk et al. (2007) estimate the HAM by Brock and Hommes $(1997,1998)$ using annual S\&P 500 stock market data from 1871 to 2003 . They find ev- 
idence of behavioral heterogeneity in stock markets and endogenous switching for a fundamental price based on both price-to-earnings ratio and price-to-dividend ratio. They show that in the late 1990s, the rise of the stock prices were mainly driven by trend followers, while in the 2000s fundamentalists contributed to the mean-reversion of the stock price towards its fundamental values. Using quarterly S\&P 500 data from 1950 to 2013, Hommes and in't Veld (2014) employ a similar approach with both the dynamic Gordon present-discounted-value and the Campbell-Cochrane consumption habit fundamental benchmarks to conclude that financial crises have been amplified by switching between fundamentalists and trend following speculators. Lof (2014) estimates a HAM with different VAR-model specifications using S\&P 500 index and finds temporary switches between fundamentalists and rational and contrarian speculators. Franke and Westerhoff (2011 and 2012), on the other hand, use S\&P 500 index data to estimate HAMs with structural stochastic volatility.

Various HAMs have been developed to document the evidence of behavioral heterogeneity in other markets, such as oil market (Ellen and Zwinkels, 2010), option market (Frijns et al., 2010), real estate market (Bolt et al., 2014; Dieci and Westerhoff, 2012; Sommervoll et al., 2010; Kouwenberg et al., 2014; Eichholtz et al., 2015) and foreign exchange market (Gilli and Winker, 2003; Westerhoff and Reitz, 2005; Menkhoff et al., 2009; De Jong et al., 2010; Chia et al., 2014). More recently HAMs have also been applied to macroeconomics, particularly extending the New Keynesian framework. These include the work of Gali and Gertler (1999), Branch and Evans (2006) and Massaro (2013).

Investment behavoral heterogeneity is also supported by the experimental evidence of Hommes (2011) and the questionnaire survey of Allen and Taylor (1990), Cheung and Chinn (2011) and Gehrig and Menkhoff (2004). A more comprehensive summary of these surveys can be found in Menkhoff and Taylor (2007).

\subsubsection{HAM in Housing Market}

While HAMs have been commonly applied in financial market, its application in real estate market is relatively recent. Sommervoll et al. (2010) differentiates itself from the literature by modeling the interactions of buyers, sellers and mortgagees in the real es- 
tate market, showing that credit constraints imposed by mortgagees can influence market dynamics with periods of mild oscillations interrupted by violent collapses. Dieci and Westerhoff (2012) assume that investors rely on extrapolative and regressive heuristics informing their expectations whose relative importance depends on the magnitude of the deviations of housing prices from long run fundamental steady state. They conduct a HAM which is able to display irregular boom and bust in the housing price cycles as observed in many actual real estate markets. Dieci and Westerhoff (2013) investigate the impact of speculative behavior on house price dynamics using three alternative models which capture in different ways the interplay between fundamental trading rules and extrapolative trading rules, resulting in a $2 \mathrm{D}$, a 3D, and a $4 \mathrm{D}$ nonlinear discrete-time dynamical system, respectively. They find that while the destabilizing effect of speculative behavior on the models steady state is proven in general, the three specific cases illustrate a variety of situations that can bring about endogenous dynamics, with lasting and significant price swings around the fundamental price. Dieci and Westerhoff (2016) combine a standard stock-flow housing market model, incorporating explicit relationships between house prices, the housing stock, and the rent level, with a parsimonious expectation formation scheme of housing market investors, reflecting an evolving mix of extrapolative and regressive expectation rules to generate endogenous boom-bust housing market dynamics with lasting periods of overvaluation and overbuilding. The model can be used to investigate how real forces, in particular supply conditions, interact with expectations-driven housing market fluctuations. Kouwenberg and Zwinkels (2015) build a model in which agents are heterogeneous, adaptive, and boundedly rational. By estimating the multiagent system with historical house prices for the U.S. market, they find that the model fits the data well and a deterministic version of the model can endogenously produce boom-and-bust cycles on the basis of the estimated coefficients.

HAMs in housing market have been estimated and tested empirically using actual data. Bolt et al. (2014) introduce heterogeneous expectations in a standard housing market model and estimate the model parameters for eight countries, U.S., UK, Netherland, Japan, Switzerland, Spain, Sweden and Belgium. For all countries they identify temporary house price bubbles, amplified by trend followers, and crashes reinforced by fundamentalists. Kouwenberg and Zwinkels (2014) develop and estimate a HAM for the U.S. 
housing market to show that the proportions of fundamentalists and chartists are usually equal, except for the period of housing boom from 1992 to 2005 during which the proportion of chartists in the market was substantially above the long-term average. Eichholtz et al. (2015) conduct a long-term time series of prices of houses along the Herengracht in Amsterdam, covering 350 years. Their findings suggest that agents base their expectations more on fundamentals during periods with economic slowdown but tend to focus on recent trends or momentum during periods of economic booms.

\subsubsection{HAM with Markov Regime-dependent Beliefs}

More recently HAMs have also been used to examine the effect of the switches of booms and busts on the behaviors of market participants by modeling the market conditions to follow a Markov chain regime switching process. The Markov regime-switching framework addresses how investors shift their expectations by extrapolating the housing market conditions from price information available and switch their investing behavior accordingly.

Chiarella et al. (2012) propose a HAM of fundamentalists and chartists with two-state Markov regime-dependent expectations for the U.S. stock market. The estimation of the model provides evidence of within-group time-varying behavioural heterogeneity and it matches well with the boom and bust periods in the U.S. stock market. They present that such a set up improves the forecasting accuracy compared to the Boswijk et al. (2007) heterogenous agent model. Huang and Zheng (2012) argue that a simple marketmaker framework with Markov regime-dependent beliefs is capable to model all types of crises, that is, sudden crisis, disturbing crisis and smooth crisis, and to offer economic and dynamic justifications on how these crises appear. Moreover, Chia et al. (2016) estimate a Markov regime switching HAM consisting of the $l$-investors, the $v$-investors and the $s$ investors for the Australia housing market. Their results suggest that the investors adapt their strategies over time based on market state in the Australia housing market. 


\subsection{Conclusion}

We have clearly organized the issues related to housing price bubbles. These issues include the causes and the detection of housing price bubbles, which are generating lively debate in the real estate literature.

Generally, the papers regarding to the causes of housing bubbles can be classified into two categories, with one attributes the exceptionally high appreciation rates of housing prices to various exogenous factors such as low interest rate policy or loose credit standards and the other on the role of irrational exuberance defined as a heightened state of speculative fervor. While the first category clearly has virtues and contributes to explaining the housing price dynamics, most of them have neglected the potentially important endogenous causes of housing bubbles. The second category of studies provide new insights by suggesting that the speculative behavior of the investors could lead to housing price bubbles. However, the studies mentioned above generally concentrate on the empirical analysis, rarely building the theoretical models. In the next chapter we attempt to fill the gap in the literature by constructing a theoretical HAM consisting of fundamentalists, trend followers and naive agents to show that, without any exogenous shocks, various types of housing price bubbles could have been affected by the interaction between agents with different beliefs.

The basic idea of how to detect a housing price bubble is to compare the housing price in real market with its economic fundamental benchmarks. There are two strands of literature which consider breaks in the relationship between house price and fundamentals, with the first strand using aggregate data and the second one relying on regional or micro data.

Second, we provide a general literature on HAM, which has become well developed recently. Various HAMs have been developed to document the evidence of behavioral heterogeneity in different asset markets, such as stock market, option market and foreign exchange market. Although a number of HAMs have been applied to financial market, its application in real estate market is relatively rare. 


\section{Chapter 3}

\section{Endogenous Origin of an Exponential Bubble and a Linear Trend}

\subsection{Introduction}

Using Freddie Mac housing price index in the United States from 1997 to 2006, I classify the dynamics of housing prices on its rising trend into two patterns: an exponential pattern and a linear pattern (see Chapter 1). An exponential bubble is a housing price bubble that grows exponentially before it bursts, while a linear trend is a housing price trend that increases slowly in a linear pattern before it collapses. In order to examine whether housing price bubbles can be formed in the absence of any external shocks, I construct a heterogeneous agent model (HAM) that consists of fundamentalists, chartists and naive agents to explore whether the interaction of agents with different beliefs can affect the dynamics of the housing prices and subsequently the formation of an exponential bubble and a linear trend. The fundamentalists trade on mean-reversion towards the benchmark fundamental price, the chartists are either trend followers or contrarians, and the naive agents adopt naive expectations to predict future prices. Agents switch 
between each other based on relatively recent past performances. Using housing market data from Jan 1975 to Jul $2006^{1}$, I conduct nonlinear least squares (NLLS) to estimate the parameters of the proposed model.

Our nonlinear regression provides some interesting results. First, I see that for the two markets demonstrating the exponential bubble and linear trend, the estimated parameters measuring the heterogeneity and switching behavior are statistically significant. This finding not only confirms the co-existence of the three types of agents in the housing market but also shows that they are interacting between each other. Second, the formation of both the exponential bubble and linear trend could be explained by the evolutionary switching mechanism between agents so the dynamics of housing price could have at least some, if not all, endogenous origin. In particular, I show that while the formation of the exponential bubble is driven mainly by the dominance of trend followers, the linear price trend is attributed to the systematically constant proportions of each type of agents in the housing market. Third, our simulation experiments suggest that the housing price is more likely to rise exponentially when there are more frequent transition between trading strategies, stronger belief in the housing trend and smaller gross return on risk-free asset relative to housing.

The remainder of this chapter is organized as follows. In section 3.2, I describe our HAM model with three types of heterogeneous agents, namely the fundamentalists, the chartists and the naive agents. In section 3.3, I estimate the HAM model on market data of the U.S. from Jan 1975 to Jul 2006 using nonlinear least squares (NLLS). Section 3.4 provides a sensitivity analysis to examine how the housing price trends are affected by different key parameters. Finally, section 3.5 concludes.

\subsection{The Model}

In the development of our model, I see housing markets from an asset-pricing perspective which is commonly used in finance theory to relate the risk premium of a housing asset to its exposure to risk. I extend a standard housing asset pricing model under a temporary

\footnotetext{
${ }^{1}$ I have ended our sample at Jul 2006 because our main focus in this chapter is on the formation of housing price bubbles. The housing price began to crash after the mid-2006.
} 
equilibrium framework developed by Brock and Hommes (1998). Agents are boundedly rational and they have different beliefs in the future values of housing prices. Different from the economy characterized by two types of agents as in Boswijk et al. (2007), I include the third type of participants, namely the naive agents proposed by Brock and Hommes (1997).

Assume that there are only two types of assets, a housing asset and a risk free asset, in the market. Housing is assumed to have a zero net supply with an uncertain rent of $Y_{t}$ in each period. The risk free asset, on the other hand, is paid a constant return of $r$ and is assumed to have a perfectly elastic supply. The discount rate $r$ is the risk free interest rate plus a risk premium.

Following Boswijk et al. (2007), I assume that $\log Y_{t}$ follows a Gaussian random walk with drift, that is,

$$
\log Y_{t+1}=\mu+\log Y_{t}+\nu_{t+1}, \quad \nu_{t+1} \sim \text { i.i.d.N }\left(0,{\sigma_{\nu}}^{2}\right)
$$

which implies that

$$
\frac{Y_{t+1}}{Y_{t}}=(1+g) \epsilon_{t+1},
$$

where $g=e^{\mu+\frac{1}{2} \sigma_{\nu}{ }^{2}}-1$ and $\epsilon_{t+1}=e^{\nu_{t+1}-\frac{1}{2} \sigma_{\nu}{ }^{2}}$, such that $E_{t}\left(\epsilon_{t+1}\right)=1$. Since rent is an exogenous stochastic process, I assume that agents only learn about the correct beliefs in the next period. As a result, the expected rent in period $t+1$ is

$$
E_{t}\left(Y_{t+1}\right)=(1+g) Y_{t}
$$

The housing price in period $t$ and $t+1$ is denoted by $p_{t}$ and $p_{t+1}$, respectively and the excess return of the housing asset at period $t+1$ is defined as

$$
R_{t+1}=Y_{t+1}+p_{t+1}-(1+r) p_{t}
$$

Assuming that investors have heterogeneous beliefs about future payoffs where they choose among $H$ types of beliefs or forecasting rules, the expectation of type- $h$ investors about the conditional mean and variance of the excess return are denoted by $E_{h, t}$ and $V_{h, t}$, for 
$h=1, \ldots, H$. Type- $h$ agents are assumed to have a myopic mean-variance demand function defined by

$$
z_{h, t}=\frac{E_{h, t}\left[R_{t+1}\right]}{a_{h} V_{h, t}\left[R_{t+1}\right]} .
$$

where $a_{h}$ is the risk aversion parameter. For simplicity, I assume that all agents have the same risk aversion parameter so that $a_{h}=a$ and homogeneous expectations about the conditional variance, $V_{h, t}\left[R_{t+1}\right]=V_{t}\left[R_{t+1}\right]$ so that the model is analytically tractable. A key feature of the framework developed in Brock and Hommes (1998) is that they use a temporary equilibrium pricing model. I follow this framework and assume that the net supply of the housing asset is zero, so that the market clearing equation is given by

$$
\sum_{h=1}^{H} n_{h, t} \frac{E_{h, t}\left[Y_{t+1}+p_{t+1}\right]-(1+r) p_{t}}{a V_{t}\left[R_{t+1}\right]}=0
$$

where $n_{h, t}$ is the fraction of agents using forecasting rule $h$ at time $t$.

Solving the market clearing equation for the price $p_{t}$ leads to the price equation ${ }^{2}$

$$
p_{t}=\frac{1}{1+r} \sum_{h=1}^{H} n_{h, t} E_{h, t}\left[Y_{t+1}+p_{t+1}\right] .
$$

In order to estimate the model using monthly housing prices and rents, I reformulate the equilibrium pricing equation in terms of price-to-rents ratio such that

$$
\delta_{t}=\frac{p_{t}}{Y_{t}}=\frac{1}{R^{*}}\left\{1+\sum_{h=1}^{H} n_{h, t} E_{h, t}\left[\delta_{t+1}\right]\right\}, \quad R^{*}=\frac{1+r}{1+g},
$$

where $Y_{t+1} / Y_{t}$ is assumed to be conditionally independent of $\delta_{t+1}$ and $R^{*}$ is the relative gross return of the risk free asset.

I define the fundamental benchmark price as the price under the assumption that all the agents form homogeneous rational expectations $E_{t}\left(R_{t+1}\right)$ about the conditional mean of $R_{t}$. Under rational expectations, the price equation can be simplified to

$$
p_{t}=\frac{1}{1+r} E_{t}\left(Y_{t+1}+p_{t+1}\right) .
$$

\footnotetext{
${ }^{2}$ See Boswijk et al. (2007) for a detailed derivation of the equilibrium price under the assumption of zero external supply.
} 
With rents growing at a constant rate, $g$, the fundamental housing price under rational expectations can be written as

$$
p_{t}^{*}=\frac{1+g}{r-g} Y_{t}, \quad r>g
$$

or equivalently, in terms of fundamental price-to-rents ratio, I have

$$
\delta_{t}^{*}=\frac{p_{t}^{*}}{Y_{t}}=\frac{1+g}{r-g} \equiv m
$$

where $\delta_{t}{ }^{*}$ and $m$ are the fundamental price-to-rent ratio.

This suggests that the fundamental price of housing is directly proportional to the actual rent level. I assume that the fundamental housing price is common knowledge to all the agents. The only difference is that the agents use heterogeneous strategies to forecast the future relative deviation of housing price from its fundamental price, which is defined as $x_{t}=\left(p_{t}-p_{t}^{*}\right) / p_{t}^{*}$. The equilibrium pricing equation can be reformulated in terms of the relative deviation of housing price from its fundamental price, $x_{t}$, such that

$$
x_{t}=\frac{1}{R^{*}} \sum_{h=1}^{H} n_{h, t} E_{h, t}\left[x_{t+1}\right] .
$$

\subsubsection{Evolutionary Selection of Expectations}

There is significant evidence of time variation in the sentiment of investors. This has been documented, for example, by Case and Shiller (2003) using survey data in 1988 and 2003 from a number of home buyers in Los Angeles, San Francisco, Boston and Milwaukee. An important feature of our model is the endogenous, evolutionary selection of beliefs or expectation rules based upon the relative recent performances of varies regimes, as proposed by Brock and Hommes (1997). The recent performance of type $h$ at time $t-1$, $\pi_{h, t-1}$, is defined as,

$$
\pi_{h, t-1}=R_{t-1} z_{h, t-2}=R_{t-1} \frac{E_{h, t-2}\left[R_{t-1}\right]}{a_{h} V_{h, t-2}\left[R_{t-1}\right]}
$$


In other words, $\pi_{h, t-1}$ represents the excess profit realized in the previous period by strategy $h$, in terms of quantities observed at the beginning of period $t$. Two more simplifying assumptions are made in order to have a convenient expression of the excess profit in terms of the relative deviation, $x_{t}$. The first assumption is $Y_{t-1} \approx(1+g) Y_{t-2}$. Under this assumption, the fitness measure is not affected by the stochastic growth rate of the rent, but rather depends on the average growth rate $g$. Brock and Hommes (1998) refer to the model where stochastic rent is replaced by expected rent as the nonlinear deterministic skeleton model. Thus, the realized excess return in eq. (3.4) is approximated as

$$
R_{t-1} \approx \frac{1+g}{r-g} Y_{t-1}\left(x_{t-1}-R^{*} x_{t-2}\right)
$$

A second simplifying assumption is on the beliefs about the conditional variance of excess returns. Following Boswijk et al. (2007), I assume that the rent $Y_{t}$ has a constant growth rate, so that for all types the beliefs, the conditional variance is given by

$$
\begin{aligned}
V_{h, t-2}\left[R_{t-1}\right] & =V_{h, t-2}\left[p_{t-1}+Y_{t-1}-(1+r) p_{t-2}\right] \\
& =V_{t-2}\left[p_{t-1}^{*}+Y_{t-1}-(1+r) p_{t-2}^{*}\right] \\
& =V_{t-2}\left[(1+m)(1+g) Y_{t-2} \epsilon_{t-1}\right] \\
& =Y_{t-2}^{2} \eta^{2},
\end{aligned}
$$

where $\eta^{2}=(1+m)^{2}(1+g)^{2} V_{t-2}\left[\epsilon_{t-1}\right]$. The implied expected return is

$$
E_{h, t-2}\left[R_{t-1}\right]=\frac{(1+g)^{2}}{r-g} Y_{t-2}\left[E_{h, t-2}\left(x_{t-1}\right)-R^{*} x_{t-2}\right]
$$

Investors compare the recent relative performances of the different strategies and switch to better ones. A commonly used assumption in the HAM literature is that the fractions $n_{h, t}$ evolve according to a discrete choice model with multinomial logit probabilities,

$$
n_{h, t}=\frac{\exp \left[\beta \pi_{h, t-1}\right]}{\sum_{k=1}^{H} \exp \left[\beta \pi_{k, t-1}\right]},
$$


where the parameter $\beta>0$ is called the intensity of choice. The multinomial logit model is widely applied to describe the choice probabilities of boundedly rational agents among finitely many alternatives. The key feature of eq. (3.17) is that regimes with higher fitness (performances) in the recent past attract more followers. Agents are boundedly rational so they abandon beliefs that performed poorly in the recent past. The intensity of choice parameter, $\beta$, regulates the speed of transition between different beliefs. A large value of $\beta$ implies a situation in which agents switch rapidly. In this case, they switch rapidly to last periods best performing belief. In contrast, a low value of $\beta$ illustrates the case where agents are reluctant to turn to other beliefs unless they observe large performance gap between the strategies.

\subsubsection{A Three-type Example}

I assume that the economy is characterized by three types of traders so that $H=3$. Assume that all types of agents predict next periods relative deviation by extrapolating past realizations in a linear fashion, I have

$$
E_{h, t}\left[x_{t+1}\right]=\phi_{h} x_{t-1},
$$

where $\phi_{h}$ denotes the parameter characterizing the strategy of type $h$ agents. The dynamic asset pricing model can then be written as

$$
R^{*} x_{t}=\sum_{h=1}^{3} \phi_{h} n_{h, t} x_{t-1},
$$

where $\phi_{1}, \phi_{2}$ and $\phi_{3}$ represent the coefficients of the three types of beliefs and $n_{1, t}, n_{2, t}$ and $n_{3, t}$ are the fractions of investors that belong to the three types of agents. Agents forecast the future relative deviation, $x_{t+1}$, using heterogeneous strategies. For example, following Brock and Hommes (1997), Type-1 agents use naive expectations. Their expectation is just the last observations they have seen:

$$
E_{1, t}\left[x_{t+1}\right]=x_{t-1}
$$


It implies that their beliefs parameter $\phi_{1}=1$. This type of agents are just like naive agents. Type-2 agents expect the price to mean-revert towards the fundamental value, which implies that their beliefs parameter $0<\phi_{2}<1$. Following Brock and Hommes (1998), this type of agents are like fundamentalists. The beliefs parameter $\phi_{2}$ indicates how strongly the fundamentalists believe in mean-reversion. The closer the value of $\phi_{2}$ to 1 the more persistent are the expected relative deviations. Furthermore, Type-3 agents are chartists and their beliefs parameter is smaller than 0 or larger than 1 . When $\phi_{3}$ is larger than 1, they are trend followers who expect the relative deviation between the housing price and the fundamental housing price to enlarge. When $\phi_{3}$ is smaller than 0 , they are contrarians. And they expect the price trend to reverse in the next period. I dont know whether trend followers or contrarians exist in my sample. I make the model general enough to accommodate all the possible scenarios and let the data tell us the answer.

In the case with three-types of linear beliefs, the fraction of type $h$ investors is

$$
n_{h, t}=\left\{1+\sum_{k \neq h} \exp \left[\beta^{*}\left(\phi_{k}-\phi_{h}\right) x_{t-3}\left(x_{t-1}-R^{*} x_{t-2}\right)\right]\right\}^{-1},
$$

where $\beta^{*}=\frac{\beta(1+g)^{4}}{a \eta^{2}(r-g)^{2}}$. The fraction $n_{h, t}$ depends on the difference in (1) extrapolation rates of the three groups, (2) the relative deviation from the fundamental prices and (3) the last period change in relative deviations. Notice that in periods when the relative deviations are large and upgrading, that is, $x_{t-1}>x_{t-2}>x_{t-3} \gg 0$, the fraction of chartists, $n_{3, t}$, tends to 1 while the fractions of naive agents and fundamentalists drop to 0. The dominance of trend following regime may reinforce an extraordinary deviation. On the contrary, in periods when the relative deviation is approximately constant, that is, $x_{t-1} \approx x_{t-2} \approx x_{t-3} \approx \bar{x}$, the fraction $n_{h, t}$ depends on the squared value of the relative deviation. If the relative deviation is small, the fractions of all the three types of agents, $n_{1, t}, n_{2, t}$ and $n_{3, t}$, are approximately $\frac{1}{3}$. The dynamics of real estate prices may vary relatively slowly. On the contrary, if the relative deviation, $\bar{x}$, is large, the fractions of fundamentalists, $n_{2, t}$, approaches 1 . The dominance of fundamentalists may be the catalyst for the mean-reverting of the housing prices towards the fundamental benchmarks. 
The three-heterogeneous agent model is given by

$$
\begin{aligned}
R^{*} x_{t} & =\sum_{h=1}^{3} \phi_{h} n_{h, t} x_{t-1} \\
n_{h, t} & =\left\{1+\sum_{k \neq h} \exp \left[\beta^{*}\left(\phi_{k}-\phi_{h}\right) x_{t-3}\left(x_{t-1}-R^{*} x_{t-2}\right)\right]\right\}^{-1}
\end{aligned}
$$

\subsection{Results and Discussions}

I estimate the three-heterogeneous agent model using monthly Freddie Mac house price index and the rent component of consumer price index from Jan 1975 to Jul 2006. As the focus of the paper is on the formation of the housing price bubbles, I end our sample on July 2006, that is, before the housing price collapsed in the United States. From the Federal Home Loan Mortgage corporation I obtain the Freddie Mac house price index which contains the nominal housing prices for 50 states in the country and also the District of Columbia. Year 2000 is used as the base year for the nominal housing price. I then derive the real housing price by dividing the nominal house price by the urban consumer price index. The urban consumer price index is obtained from Bureau of Labor statistics. The rent component of the consumer price index is obtained from CEIC database. The annual average user cost of housing is retrieved from Himmelberg et al. (2005). I divide the annual rate by 12 to get the monthly average user cost of housing. All nominal rates are converted into real rates using the urban consumer price index.

\subsubsection{Calculating the Fundamental Model Parameter}

Before estimating the behavioral model, I calibrate the fundamental benchmark price $p_{t}^{*}$ and the fundamental model parameter, $R^{*}$.

One of the convenient features of the model is that its price variable has been formulated as relative deviations from a benchmark fundamental price so that the model can be estimated after I choose the fundamental price. As discussed in the previous section, an asset fundamental price is directly proportional to its actual rent level. As a result, 
I derive the asset fundamental price using the rent, $Y_{t}$, times a constant fundamental price-to-rents $(\mathrm{PR})$ ratio, $m$, such that

$$
p_{t}^{*}=m Y_{t}
$$

To calibrate the fundamental price-to-rents ratio, $m$, I make a presumption that the average housing price would be converging towards the fundamental benchmark in the long run. Equivalently, the PR ratio would also be converging to the fundamental PR ratio in the long term. So I use the long-term average PR ratio as an estimation for the fundamental PR ratio.

Next, I calibrate the parameter $R^{*}$. Recall from the previous section that the gross return on risk free asset relative to housing, $R^{*}$, is given by

$$
R^{*}=\frac{1+r}{1+g}
$$

where $g$ is the constant growth rate of the rent and $r$ is the discount rate which is defined as the sum of the risk free interest rate and a risk premium. As the risk premium is difficult to calibrate directly, I use the cost of home ownership, which is known as the "imputed rent" in the literature (Himmelberg et al. 2005) to calculate the discount rate $r$. Following Himmelberg et al. $(2005)^{3}$, I let the discount rate $r$ to be equal to

$$
r=q+u,
$$

where $q$ represents the average rate of capital gain and $u$ denotes the monthly average user cost of housing. I calculate the gross return on risk free asset relative to housing, $R^{*}$, in three steps. First, the average rates of capital gain, $q$, in Arizona and Minnesota are calculated using the monthly data of the Freddie Mac house price index in the two states. I find that the average rate of capital gain is 0.0157 in Arizona and 0.0050 in Minnesota. Second, I retrieve the monthly average user cost of housing from Himmelberg et al. (2005). The annual average user cost is 0.033 for Arizona and 0.058 for Minnesota.

\footnotetext{
${ }^{3}$ The average user cost available in Himmelberg et al. (2005) is the user cost in 2004. So I use $q$ and $g$ in the same period to calculate $R^{*}$ in $2004 . R^{*}$ in 2004 may be an under-estimation of the actual level of $R^{*}$ for the whole period. However, robustness check shows that the exact choice of the period to calibrate $R^{*}$ has relatively small effects on the estimated behavioural parameters.
} 
After dividing the annual user cost by 12, I obtain the monthly average user cost of housing to be 0.0028 for Arizona and 0.0048 for Minnesota. As a result, the discount rate for Arizona and Minnesota is 0.0185 and 0.0097, respectively. Finally, the rent growth rate, $g$, is obtained from the monthly rent component of consumer price index which is $0.0024^{4}$ for the two states. Substituting these values into eq. (3.24) gives $R^{*}$ of 1.0160 for Arizona and 1.0072 for Minnesota.

Table 3.1 summarizes the values I use in our estimation for the two states. All the nominal variables are deflated using the consumer price index.

Table 3.1: Values used for the fundamental process

\begin{tabular}{lccccccccc}
\hline & $\pi$ & $h$ & $r p$ & $m$ & $g$ & $q$ & $u$ & $r$ & $R^{*}$ \\
\hline Arizona & 1.2884 & 75.98 & 136.74 & 0.5492 & 0.0024 & 0.0157 & 0.0028 & 0.0185 & 1.0160 \\
Minnesota & 1.2884 & 67.94 & 136.74 & 0.4867 & 0.0024 & 0.0050 & 0.0048 & 0.0097 & 1.0072 \\
\hline
\end{tabular}

Notes: $\pi$ is the average CPI, $h$ is the average Freddie Mac Index and $r p$ is the average rent level.

\subsubsection{Estimating the HAM using Nonlinear Regression}

The deviation between the beliefs parameters of type $h$ agents, $\phi_{h}$, and Type-1 agents, 1 , is defined as

$$
\Delta \phi_{h}=\phi_{h}-1
$$

The three-heterogeneous agent model can be reformulated in terms of $\Delta \phi_{h}$ such that

$$
x_{t}=\frac{1}{R^{*}} \sum_{h=1}^{3}\left(\Delta \phi_{h}+1\right) n_{h, t} x_{t-1}+\varepsilon_{t}
$$

and

$$
n_{h, t}=\left\{1+\sum_{k \neq h} \exp \left[\beta^{*}\left(\Delta \phi_{k}-\Delta \phi_{h}\right) x_{t-3}\left(x_{t-1}-R^{*} x_{t-2}\right)\right]\right\}^{-1} .
$$

Using the monthly data of the Freddie Mac house price index and rents for the period of Jan 1975 to Jul 2006, I estimate the parameters $\left(\Delta \phi_{2}, \Delta \phi_{3}, \beta^{*}\right)$ for Arizona and

\footnotetext{
${ }^{4}$ As the monthly rent component of the consumer price index for each individual state is not available to collect, I use the monthly rent component of the consumer price index in the United States in the estimation. So the constant rates of the rent, $g$, are the same for both states.
} 
Minnesota using eqs. (3.27) and (3.28) by nonlinear least squares (NLLS). $\Delta \phi_{2}$ and $\Delta \phi_{3}$ are parameter vectors of the deviations between the beliefs parameters of Type-2 from Type-1 agents, $\Delta \phi_{2}=\phi_{2}-1$, and the deviations between the beliefs parameters of Type-3 from Type-1 agents, $\Delta \phi_{3}=\phi_{3}-1$.

I estimate the model using nonlinear regression. Substituting eq. (3.28) into eq. (3.27) yields

$$
x_{t}=\frac{1}{R^{*}} \sum_{h=1}^{3} \frac{\left(\Delta \phi_{h}+1\right) x_{t-1}}{1+\sum_{k \neq h} \exp \left[\beta^{*}\left(\Delta \phi_{k}-\Delta \phi_{h}\right) x_{t-3}\left(x_{t-1}-R^{*} x_{t-2}\right)\right]}+\varepsilon_{t} .
$$

Suppose $f\left(x_{t-1}, x_{t-2}, x_{t-3} ; \Delta \phi_{2}, \Delta \phi_{3}, \beta^{*}\right)=\frac{1}{R^{*}} \sum_{h=1}^{3} \frac{\left(\Delta \phi_{h}+1\right) x_{t-1}}{1+\sum_{k \neq h} \exp \left[\beta^{*}\left(\Delta \phi_{k}-\Delta \phi_{h}\right) x_{t-3}\left(x_{t-1}-R^{*} x_{t-2}\right)\right]}$, the regression equation becomes

$$
x_{t}=f\left(x_{t-1}, x_{t-2}, x_{t-3} ; \Delta \phi_{2}, \Delta \phi_{3}, \beta^{*}\right)+\varepsilon_{t} .
$$

Least squares estimation chooses the parameter values that minimize the sum of squared residuals:

$$
S\left(\Delta \phi_{2}, \Delta \phi_{3}, \beta^{*}\right)=\sum_{t}\left(x_{t}-f\left(x_{t-1}, x_{t-2}, x_{t-3} ; \Delta \phi_{2}, \Delta \phi_{3}, \beta^{*}\right)\right)^{2} .
$$

There is no way to rearrange the terms in this model so that ordinary least squares can be used to minimize the sum-of-squared residuals. I must use nonlinear least squares techniques to estimate the parameters of the model. Nonlinear least squares minimizes the sum-of-squared residuals with respect to the choice of parameters $\left(\Delta \phi_{2}, \Delta \phi_{3}, \beta^{*}\right)$. While there is no closed form solution for the parameters, estimates may be obtained from iterative methods (see Takeshi, 1983). The method is presented in Appendix A. 


\subsubsection{Estimation Results}

Table $3.2^{5}$ reports the estimated parameters $\left(\Delta \phi_{2}, \Delta \phi_{3}, \beta^{*}\right)$ and hence the implied beliefs parameters $\phi_{2}$ and $\phi_{3}$. All the estimated parameters are found to be statistically significant. Since both $\Delta \phi_{2}$ and $\Delta \phi_{3}$ are found to be statistically significant, these suggest that there is significant difference between the belief parameter of Type-2 agents from Type- 1 agents, and the belief parameter between the belief parameter of Type- 3 agents from Type-1 agents.

Table 3.2 not only provides evidence of behavioral heterogeneity in the U.S. real estate market, but also supports the co-existence of fundamentalists and trend followers. The implied beliefs, $\phi_{2}$, is $0.9848^{6}$ for the exponential bubble and 0.9666 for the linear trend, lies between 0 and 1 . This suggests that fundamentalists believe in mean-reversion and hence will expect the asset price to return back towards its fundamental values. In contrast, I find the implied beliefs parameter, $\phi_{3}$, is 1.0892 for the exponential bubble and 1.0699 for the linear trend. Since both of these parameters are statistically significant and exceed 1, this suggests that investors who are trend followers will expect the deviation of housing prices from its fundamental values to enlarge. The scaled intensity of choice, $\beta^{*}$, provides evidence that different types of participants in the market are interacting between each other.

Figure 3.1 shows the time series of the relative deviations between the actual housing prices from its fundamental prices, $x_{t}$, and estimated fractions of Type- 1 agents $\left(n_{1, t}\right)$, Type-2 agents $\left(n_{2, t}\right)$, and Type-3 agents $\left(n_{3, t}\right)$, for the exponential bubble. If the fraction of type $h$ agents is 0 , i.e. $n_{h, t}=0$, this means that type $h$ agents do not exist in the market. On the contrary, if $n_{h, t}=1$, type $h$ agents dominate the entire market at time t. From Figure 3.1, it is noted that all the three fractions are found to be positive and vary considerably over time, confirming that the three types of agents co-exist in the

\footnotetext{
${ }^{5}$ I emphasize that this value is an invalid goodness-of-fit statistic for my nonlinear HAM because it is not possible to calculate a valid $R^{2}$ for nonlinear regression. $R^{2}$ is based on the underlying assumption that one is fitting a linear model. In nonlinear regression, $R^{2}$ no longer has to be between 0 and $100 \%$. Spiess and Neumeyer (2010) performed thousands of simulations for their study that show how using $R^{2}$ to evaluate the fit of nonlinear models leads one to incorrect conclusions.

${ }^{6}$ The implied beliefs parameters $\phi_{2}$ and $\phi_{3}$ are close to 1 because I use monthly data to estimate the model. Market participants expect that the change in the relative deviations between the housing prices and the fundamental housing prices within a month is small. This should not be worrying as long as the estimated $\Delta \phi_{2}$ and $\Delta \phi_{3}$ are significantly different from 0 , implying that there is significant difference between the beliefs parameter of fundamentalists from naive agents, and the belief parameter between the belief parameter of trend followers from naive agents.
} 
Table 3.2: Estimation results for the three-agent HAM, 1975:1-2006:7

\begin{tabular}{lcccc}
\hline & \multicolumn{2}{c}{ Exponential (Arizona) } & \multicolumn{2}{c}{ Linear (Minnesota) } \\
\cline { 2 - 5 } & Estimate & $p$-value & Estimate & $p$-value \\
\hline Deviation of beliefs, $\Delta \phi_{2}$ & $-0.0152^{* * *}$ & 0.0000 & $-0.0334^{* * *}$ & 0.0000 \\
Deviation of beliefs, $\Delta \phi_{3}$ & $0.0892^{* * *}$ & 0.0000 & $0.0699^{* * *}$ & 0.0000 \\
Scaled intensity of choice, $\beta^{*}$ & $3679.34^{* * *}$ & 0.0000 & $10475.24^{* * *}$ & 0.0081 \\
Implied beliefs parameter, $\phi_{2}$ & 0.9848 & & 0.9666 & \\
Implied beliefs parameter, $\phi_{3}$ & 1.0892 & & 1.0699 & \\
$R^{2}$ & 0.9986 & & 0.9990 & \\
$A I C$ & -7.2941 & & -7.9300 & \\
\hline
\end{tabular}

Arizona housing market and they are interacting with each other. Interestingly, these plots also offer an explanation for the formation of an exponential housing bubble in Arizona. The shaded area in Figure 3.1 represents the period when the most recent bubble was formed. As our focus of the paper is only on the formation of the housing price bubble, we concentrate our discussion on the shaded area. During the period when the bubble was formed, both $n_{1, t}$ and $n_{2, t}$ fell towards 0 . This suggests that naive agents and fundamentalists were not present in the market. In contrast, the fraction of Type-3 agents, $n_{3, t}$, is found to approach 1 during the period of bubble formation, suggesting that the majority of the agents in the market were switching towards the trend following strategy. The dominance of the trend followers reinforced an extraordinary deviation of housing prices from its fundamental benchmarks, resulting in an accelerating growth of the housing price bubble in Arizona. This finding suggests that the formation of the exponential bubble is driven mainly by the dominance of the trend followers. Figure 3.2 plots the time series of $x_{t}$, and estimated fractions of Type- 1 agents, $n_{1, t}$, Type- 2 agents, $n_{2, t}$, and Type- 3 agents, $n_{3, t}$, for the linear trend. Similar to the previous finding from Figure 3.1, Figure 3.2 supports the co-existence of the three types of agents in the market. However, these plots show a constant proportion of all types of agents in the market. I see no agent was dominating. The fractions of Type-1, Type-2 and Type-3 agents stay systematically constant in shaded area. In sum, the formation of a linear trend in Minnesota could be explained by approximately constant proportions of each type of agents. Combining the findings from both Figures 3.1 and 3.2, I can then conclude that the endogenous interacting between different types of agents could lead to the formation of both types of housing price trends, that is, the dynamics of the housing prices could 
have some endogenous origin.
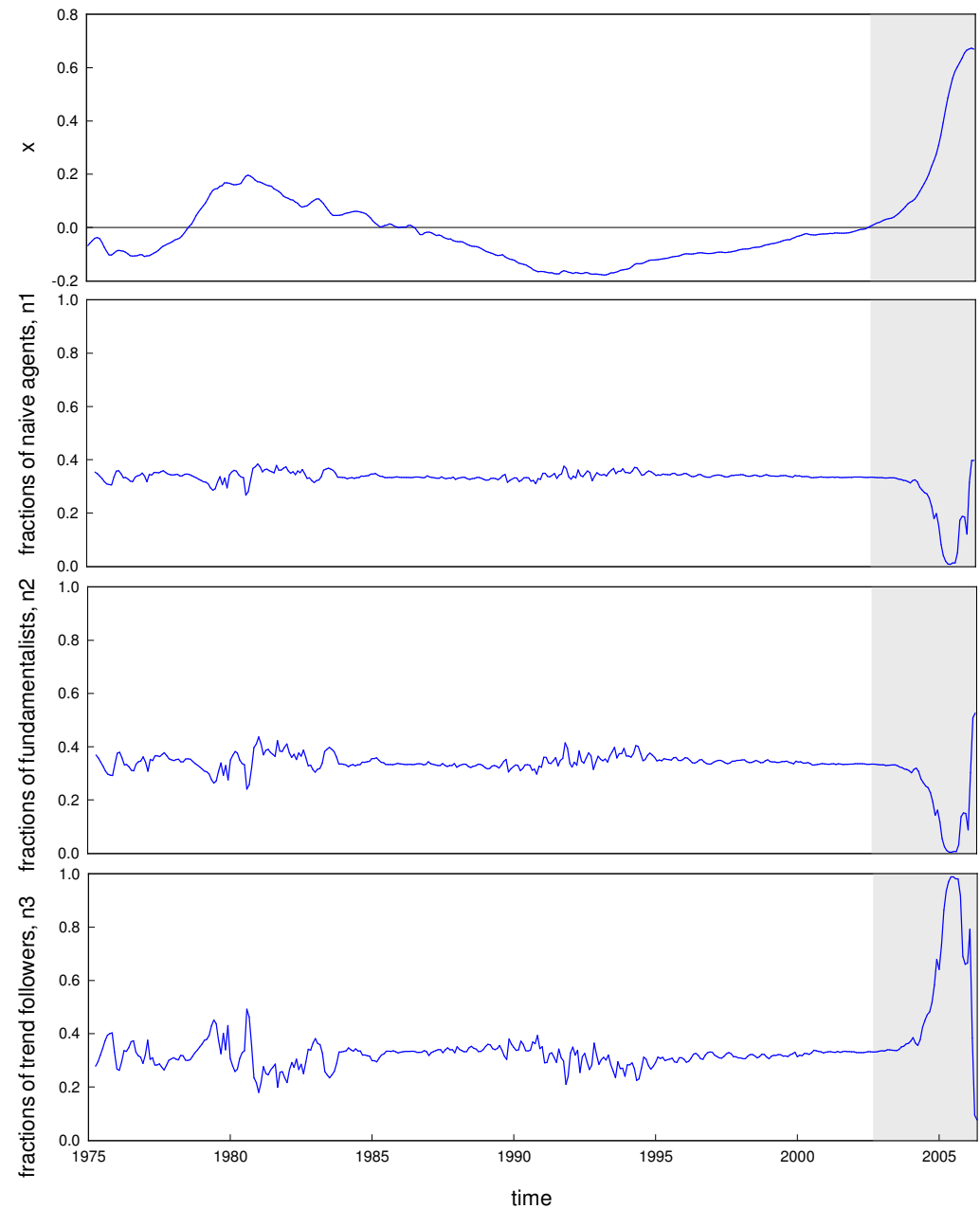

Figure 3.1: Relative deviations and estimated fractions of agents in the formation of an exponential bubble

\subsection{Factors Affecting the Formations of an Exponen- tial Bubble}

In this section, I conduct some simulation experiments to identify key factors that determine the formations of exponential bubbles.

In the identification process, I simulate the dynamics of $x_{t}$ to gauge the impact of each of 

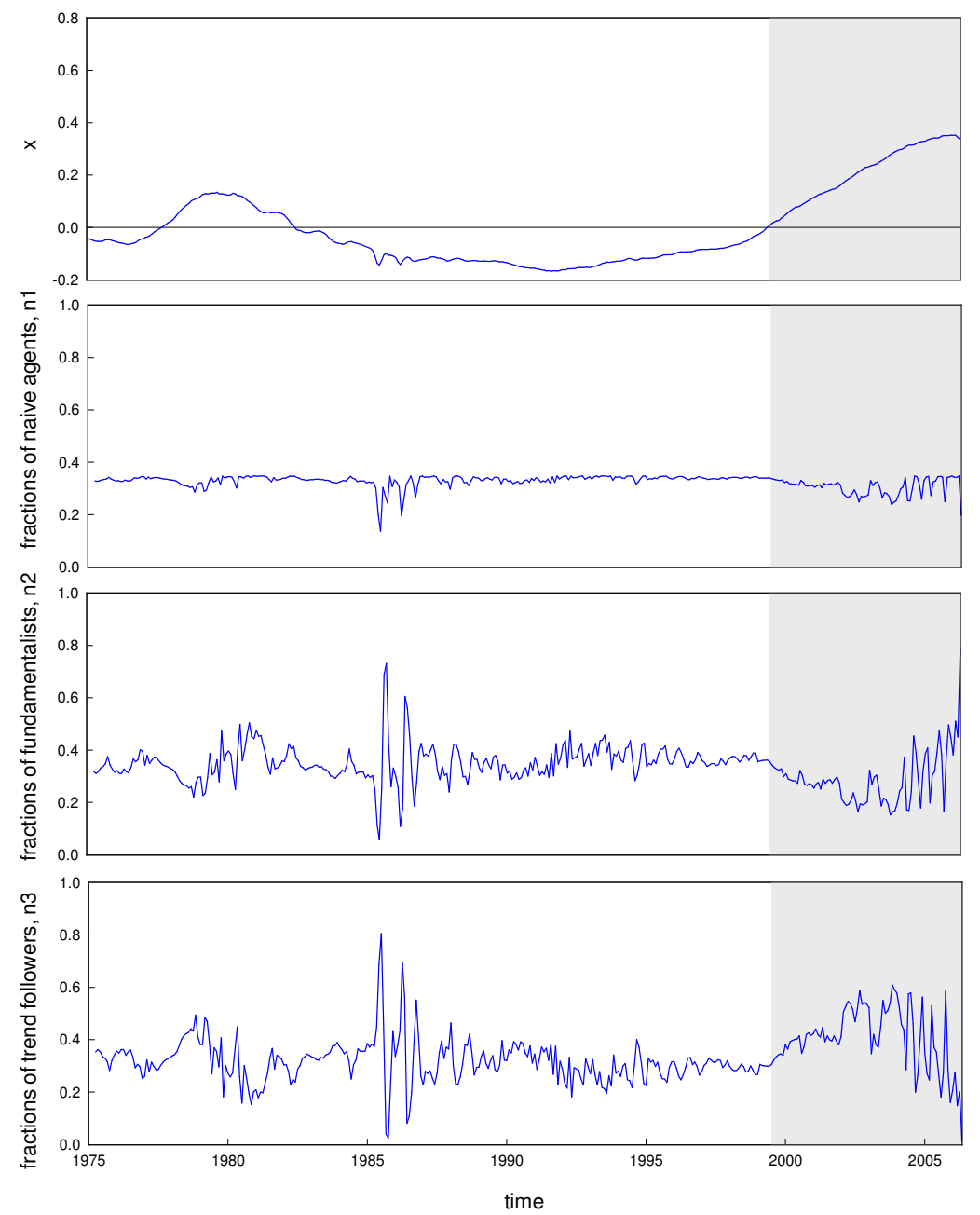

Figure 3.2: Relative deviations and estimated fractions of agents in the formation of a linear trend

these key parameters in the model independently. I deem the factors to be the intensity of choice $\left(\beta^{*}\right)$, the beliefs parameter of trend followers, $\left(\phi_{3}\right)$, and the relative gross return of the risk free asset $\left(R^{*}\right)$.

I simulate the dynamics of relative deviations, $x_{t}$, with the parameters set to be the same as those estimated from Arizona's real estate market ${ }^{7}$.

Figure 3.3 throws light on the effect of transition speed between different strategies, $\beta^{*}$,

\footnotetext{
${ }^{7}$ The set of parameters are $\beta^{*}=3679.344, \phi_{2}=0.9848, \phi_{3}=1.0892$, and the initial relative deviations are $x_{1}=0.1018431, x_{2}=0.1097697, x_{3}=0.1209042, n_{1,1}=0.25, n_{1,2}=0.25, n_{1,3}=0.19, n_{2,1}=0.22$,
} $n_{2,2}=0.21, n_{2,3}=0.14, n_{3,1}=0.53, n_{3,2}=0.55$ and $n_{3,3}=0.67$. 
on the formations of exponential bubbles. When $\beta^{*}$ is 3587.51 , the bubble is a linear trend. A $5 \%$ increase in $\beta^{*}$ immediately offers the formation of an exponential bubble. When $\beta^{*}$ is increased by $10 \%$, the housing price is found to increase even more drastically, revealing an obvious exponential trend. This finding is indeed intuitive. When agents are allowed to change their expectation fast and act upon it, it becomes easier for them to cluster to the trend following strategy, and hence the bubble presents a more exponentially ascending trend.

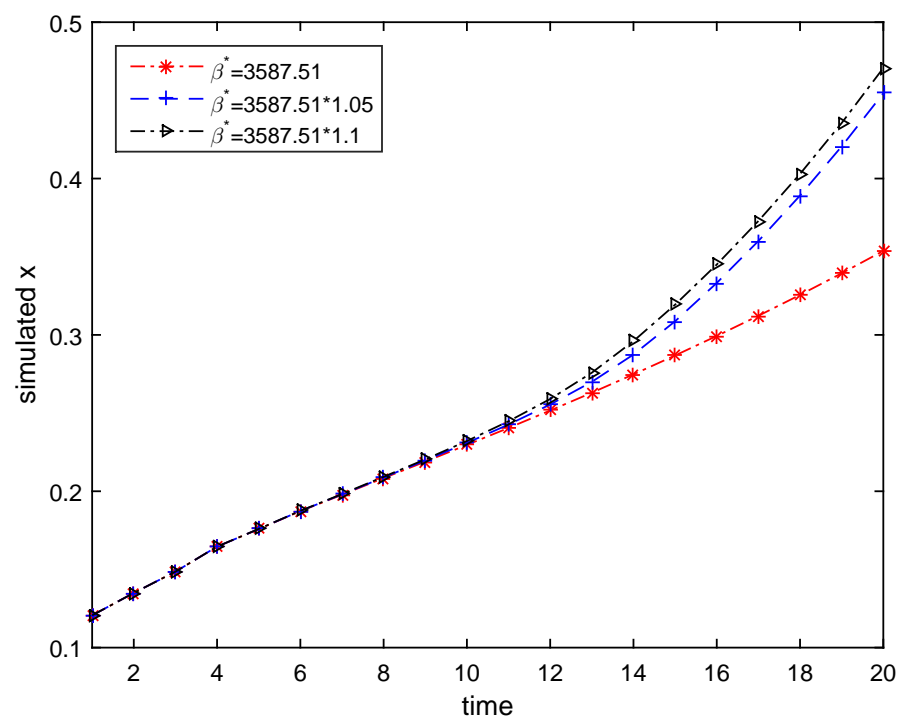

Figure 3.3: Sensitivity of $x_{t}$ to the transition speed between different strategies, $\beta^{*}$

Figure 3.4 shows the sensitivity of relative deviations between housing prices and fundamental prices, $x_{t}$, to the beliefs parameter of trend followers, $\phi_{3}$. When $\phi_{3}$ is 1.089247 , the bubble is a linear trend. A $1 \%$ increase in $\phi_{3}$ will immediately make the price trend to exhibit an exponential trend. A $2 \%$ increase in $\phi_{3}$ results in an even more sharper increase in price trend. The simulation results implies that the housing price ascends more drastically when the trend followers hold a stronger belief in trend. In other words, the stronger the beliefs parameter of the trend followers, the steeper the increase in the housing price.

Figure 3.5 examines how the gross return of risk free asset relative to houses, $R^{*}$, affect the formations of an exponential bubble. The housing price movement is a linear trend when $R^{*}$ equals 1.0181427. The trend turns to an exponential rising pattern when we reduce 


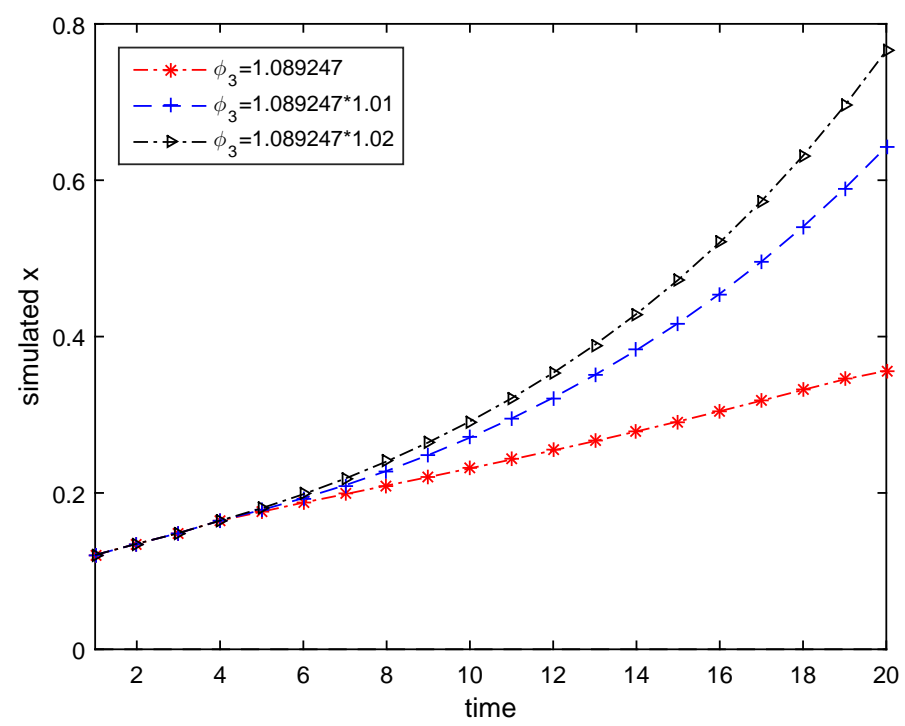

Figure 3.4: Sensitivity of $x_{t}$ to the beliefs parameter of trend followers, $\phi_{3}$

$R^{*}$ by $1 \%$. It exhibits a steeper ascending trend when $R^{*}$ is reduced by $2 \%$. In other words, the smaller the $R^{*}$, the more profound is the rise in the asset price. Intuitively, this means that when the gross return of risk free asset relative to houses reduces, it becomes more attractive for agents to turn to housing and hence making the housing price rises exponentially.

\subsection{Conclusion}

In this paper I develop a nonlinear evolutionary switching model with heterogeneous beliefs to explain how the interaction between agents with different beliefs can affect the dynamics of the housing prices. I classify the dynamics of the housing prices on its rising trend into an exponential bubble and a linear rising trend. I show that three types of investors, namely naive agents who use naive expectations to predict prices, fundamentalists who believe that prices will converge towards the fundamental prices and trend followers who expect the deviation between actual prices and the fundamental benchmarks to enlarge, to co-exist in the U.S. housing market and they are interacting between each other. 


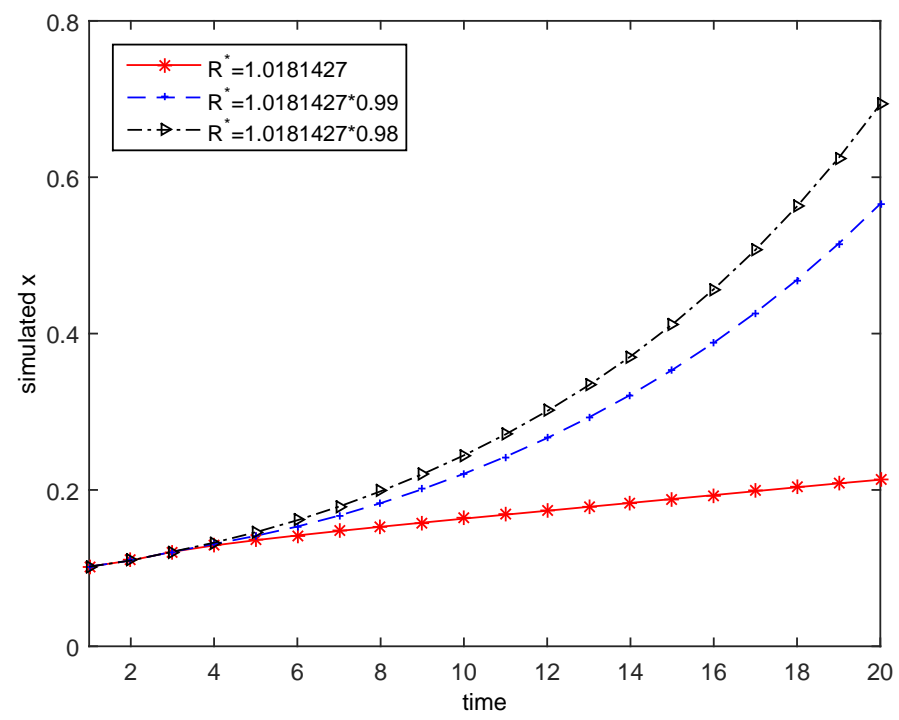

Figure 3.5: Sensitivity of $x_{t}$ to the gross return of risk free asset relative to houses, $R^{*}$

The estimated parameters measuring the heterogeneity and switching behaviour turn out to be statistically significant for markets with both exponential bubbles and linear trends. I find that while the formation of an exponential bubble is driven mainly by the dominance of the trend followers, a linear trend could be explained by the constant proportions of each type of participants. In summary, the formation of both exponential bubbles and linear trends could be attributed to the evolutionary switching mechanism, so the dynamics of housing prices could have at least some endogenous origin. I also proceed with some simulation experiments to identify key factors that could be used to explain the formation of bubble of the exponential type. These simulation experiments cast light upon some crucial factors including the speed of transition between heterogeneous strategies, the beliefs parameter of the trend followers and the gross return of risk free asset relative to houses. 


\section{Chapter 4}

\section{Housing Bubbles: Causes and Corrections under}

\section{Heterogeneous Expectations}

\subsection{Introduction}

Existing studies, including my Chapter 3, only analyze how an exponential bubble and a linear trend are formed or how they crash in isolation. They rarely look into the formation and the collapse of the two price patterns jointly within the same setup. Meanwhile, the model in Chapter 3 (BHM-type model) cannot predict the timing of market switches (Bolt et al., 2014).

Figure 4.1 shows the forecasted relative deviation, $x_{t}$, by BHM-type model. The actual relative deviation in Arizona increased exponentially and peaked at around Apr 2006. I use BHM-type model to forecast the relative deviations. I divide the data sample into two segments. The first one is for the estimation, and the second one is for the out-ofsample comparison. The dividing point is Sep 2005. The red line is the forecasted relative deviation and it is upward sloping. So it doesnt match the actual housing price trend. I use the dividing points from Sep 2005 to Apr 2006, and I find that BHM-type model 


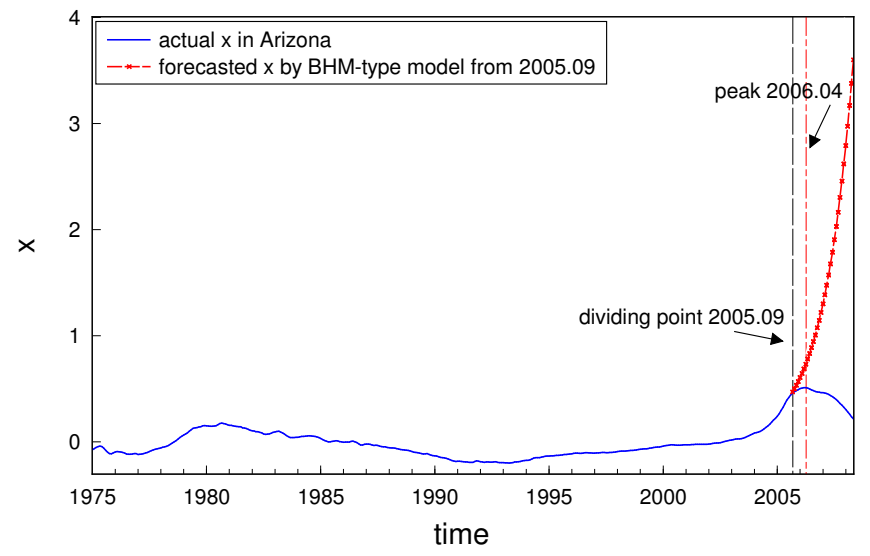

Figure 4.1: Forecasted relative deviation, $x_{t}$, by BHM-type model from Sep 2005

cannot to forecast the timing of market switches when the dividing point is from Sep 2005 to Feb 2006. It predicts that the relative deviation $x_{t}$ is going to decline when the dividing point is Mar 2006 or Apr 2006 (not reported here).

In this chapter, I aim to provide an explanation not only on how a bubble is formed endogenously but also on the subsequent collapse of an exponential bubble and a linear trend using a three-type heterogeneous agent model (HAM) consisting of fundamentalists, chartists and naive agents under a market-correction-adjusted fitness measure framework. The market-correction-adjusted fitness measure suggests that investors consider two aspects when choosing their forecasting rules. On one hand, they will cluster to the strategies that performed better in the recent past. On the other hand, market participants believe that the further the price deviates from its fundamental price, the more likely the market corrections will occur.

I estimate the model using empirical housing market data from two representative states, Arizona and Minnesota, from Jan 1975 to Mar 2015. My Result 1 is that the HAM is capable to explain not only the booms but also the busts of the two price patterns jointly. In particular, consistent with my earlier findings in Chapter 3, I show that while the formation of an exponential bubble is originated from the activations of chartists, a linear trend is due to a constant proportion of each type of agents. More importantly, my findings suggest that the subsequent collapse of both an exponential bubble and a 
linear trend could be primarily explained by the dominance of fundamentalists in the housing market. Result 2 suggests that my nonlinear HAM is able to predict the timing of market corrections. Compared to the HAMs in the existing literature, such as BHMtype (Boswijk et. al., 2007) heterogeneous agent models, my nonlinear HAM performs better forecasting accuracy when the dividing point is from Nov 2005 to Feb 2006. When the dividing point is Mar 2006 or Apr 2006, both models predict that the market is going to reverse. Result 3 suggests that policy makers can stabilize housing price through an increase in risk-free interest rate and/or a property tax rate.

This chapter is organized as follows. In section 4.2, I describe a nonlinear HAM under a market-correction-adjusted fitness measure framework. In section 4.3, I estimate the HAM on market data of the U.S. from Jan 1975 to Mar 2015 using nonlinear least squares (NLLS). Section 4.4 shows the ability of the HAM to predict the timing of market switches. Section 4.5 offers some policy implications. The last section concludes.

\subsection{HAM under Market-correction-adjusted Fitness Measure Framework}

In this section, I develop a simple housing asset pricing model with heterogeneous beliefs by introducing an evolutionary selection mechanism based on market-correction-adjusted fitness measure into a standard temporary equilibrium framework developed by Brock and Hommes (1998). Agents are bounded rational and have different beliefs in the future values of housing prices. At the same time, agents are allowed to switch from one period to the next between a number of available strategies, based on how well they have performed after market-correction adjusted.

Assume that there are only two types of assets, a housing asset and a risk free asset, in the market. Housing is assumed to have a zero net supply with an uncertain rent of $Y_{t}$ in each period.

In equilibrium the cost of home ownership, in the literature known as the "imputed rent" (e.g. Himmelberg et al. (2005)), must equal the housing rent. The total cost of housing 
ownership, $C_{t}$, is decided by

$$
C_{t+1}=p_{t} r_{t}^{r f}+p_{t} \omega_{t}-p_{t} q_{t+1}+p_{t} \iota_{t}
$$

where $p_{t}$ denotes the price for one unit of housing at time $t . r_{t}^{r f}$ is the risk-free interest rate. And $p_{t} r_{t}^{r f}$ is the cost of foregone interest that the homeowner could have earned by investing in something other than a house. $\omega_{t}$ represents the property taxes rate minus tax deductibility, and the maintenance costs expressed by a fraction of home value. $q_{t+1}=\frac{p_{t+1}-p_{t}}{p_{t}}$ is the capital gain (or loss) rate, and $\iota_{t}$ represents an additional risk premium to compensate homeowners for the higher risk of owning versus renting.

In the real estate literature, the fraction $u_{t}$ is known as the user-cost of housing, defined as

$$
u_{t}=r_{t}^{r f}+\omega_{t}-q_{t+1}+\iota_{t} .
$$

The user-cost $u_{t}$ is just a restatement of the total cost of ownership defined in eq. (4.1), but expressed in terms of the cost per dollar of house value.

I define the discount rate $r_{t}$ as

$$
r_{t}=r_{t}^{r f}+\omega_{t}+\iota_{t}
$$

The discount rate $r_{t}$ is the sum of the risk free interest rate, the mortgage/maintenance costs rate and a risk premium. Substituting eq. (4.2) into (4.3), the discount rate $r_{t}$ can be expressed as

$$
r_{t}=u_{t}+q_{t+1} .
$$

According to Brock and Hommes (1998), the excess return of the housing asset during the period between time $t$ and $t+1, R_{t+1}$, is given by

$$
R_{t+1}=Y_{t+1}+p_{t+1}-\left(1+r_{t}\right) p_{t}
$$


where $Y_{t+1}$ is the rent at time $t+1$ and $p_{t+1}$ is the housing price at time $t+1$. Eq (4.5) implies that the excess return $R_{t+1}$ is the sum of the rental income, the capital gain minus taxes (maintenance) costs and the risk premium for the higher risk of owning housing.

For simplicity, I assume that the discount rate $r_{t}$ is constant in each period so that $r_{t}=r$. The excess return of the housing asset can be rewritten as

$$
R_{t+1}=Y_{t+1}+p_{t+1}-(1+r) p_{t}
$$

Assume investors have heterogeneous beliefs about future payoffs where they choose among $H$ types of beliefs or forecasting rules and the fraction of agents using forecasting rule $h$ at time $t$ is $n_{h, t}$. Following Brock and Hommes (1998), the equilibrium price under the assumption of zero external supply satisfies.

$$
p_{t}=\frac{1}{1+r} \sum_{h=1}^{H} n_{h, t} E_{h, t}\left[Y_{t+1}+p_{t+1}\right]
$$

This price equation implies that the current price at time $t, p_{t}$, is the weighted average of investors' expected price plus dividend (rent).

Assume that $\log Y_{t}$ follows a Gaussian random walk with drift, that is,

$$
\log Y_{t+1}=\mu+\log Y_{t}+\nu_{t+1}, \quad \nu_{t+1} \sim i . i . d . N\left(0, \sigma_{\nu}^{2}\right)
$$

which implies that

$$
\frac{Y_{t+1}}{Y_{t}}=(1+g) \epsilon_{t+1}
$$

where $g=e^{\mu+\frac{1}{2}{\sigma_{\nu}}^{2}}-1$ and $\epsilon_{t+1}=e^{\nu_{t+1}-\frac{1}{2}{\sigma_{\nu}}^{2}}$, such that $E_{t}\left(\epsilon_{t+1}\right)=1$. Since rent is an exogenous stochastic process, I assume that agents only learn about the correct beliefs in the next period. As a result, the expected rent in period $t+1$ is

$$
E_{t}\left(Y_{t+1}\right)=(1+g) Y_{t}
$$

The fundamental benchmark price is defined as the price under the assumption that all the agents form homogeneous rational expectations. Under rational expectations, the 
price equation can be simplified to

$$
p_{t}=\frac{1}{1+r} E_{t}\left(Y_{t+1}+p_{t+1}\right)
$$

With rents growing at a constant rate, $g$, the fundamental housing price, $p_{t}^{*}$, under rational expectations can be written as

$$
p_{t}^{*}=\frac{1+g}{r-g} Y_{t}, \quad r>g
$$

This suggests that the fundamental price of housing is directly proportional to the actual rent level. I assume that the fundamental housing price is common knowledge to all the agents. The only difference is that the agents use heterogeneous strategies to forecast the future relative deviation of housing price from its fundamental price, which is defined as $x_{t}=\frac{p_{t}-p_{t}{ }^{*}}{p_{t}^{*}}$. The price equation can be reformulated in terms of the relative deviation of housing price from its fundamental price, $x_{t}$, such that

$$
x_{t}=\frac{1}{R^{*}} \sum_{h=1}^{H} n_{h, t} E_{h, t}\left[x_{t+1}\right] .
$$

where $R^{*}=\frac{1+r}{1+g}$ is the gross return on risk-free asset relative to housing. A large $R^{*}$ implies that it is more attractive for investors to hold risk-free asset than houses. This equation implies that the current relative deviation between housing price and its fundamental housing price, $x_{t}$, is the weighted sum of investors' expected relative deviations, $E_{h, t}\left[x_{t+1}\right]$.

\subsubsection{Market-correction-adjusted Fitness Measure}

There is significant evidence of time variation in the sentiment of investors. This has been documented, for example, by Case and Shiller (2003) using survey data in 1988 and 2003 from a number of home buyers. Piazzesi and Schneider (2009) also show that heterogeneity in price expectations changes over time in surveys among home owners. A commonly used assumption in the HAM literature is that the fractions $n_{h, t}$ evolve 
according to a discrete choice model with multinomial logit probabilities,

$$
n_{h, t}=\frac{\exp \left[\beta A_{h, t-1}\right]}{\sum_{k=1}^{H} \exp \left[\beta A_{k, t-1}\right]},
$$

where the parameter $\beta>0$ is called the intensity of choice and $A_{h, t}$ is the fitness measure of type- $h$ agents. A strategy could attract more agents if its fitness measure is better than other strategies. The intensity of choice parameter, $\beta$, regulates the speed of transition between different forecasting rules. A large value of $\beta$ implies a situation in which participants switch rapidly to strategy with better fitness measure, while at the same time, a low value of $\beta$ demonstrates the case where agents are reluctant to change their beliefs.

The fitness measure of type- $h$ at time $t, A_{h, t}$, is made up of two components, given by,

$$
A_{h, t}=B_{h, t}+S_{h, t},
$$

where $B_{h, t}$ is the past relative performance of type- $h$ agents and $S_{h, t}$ is the marketcorrection factors that varies across different investor groups. A key feature of this fitness measure is that it implies investors consider two aspects when choosing their forecasting rules. On one hand, they will cluster to the strategies that performed better in the recent past. On the other hand, they believe the further the price deviates from its fundamental price, the more likely the market corrections will occur. I call $A_{h, t}$ the market-correctionadjusted fitness measure. This fitness measure is more realistic compared to the frequently applied fitness measure, the realized-profit fitness measure, in the HAM literature. In the realized-profit fitness measure, investors usually consider only a single factor, that is, the relative performance of each heuristics, when choosing their forecasting rules.

I assume that $B_{h, t}$ is the average of the recent relative performance of type- $h$ agents for the last $L$ periods such that

$$
B_{h, t}=\frac{1}{L} \sum_{l=1}^{L} \pi_{h, t-l+1},
$$

where $\pi_{h, t-l+1}$ is the recent relative performance of type- $h$ agents at time $t-l+1$. For $L=1$ there is no memory and the past relative performance of type- $h$ agents at time $t$ equals their relative performance at time $t-1$.

According to Boswijk et al. (2007), the recent performance of type- $h$ agents at time $t-1$, 
$\pi_{h, t-1}$, is given by ${ }^{1}$

$$
\pi_{h, t-1}=R_{t-1} \frac{E_{h, t-2}\left[R_{t-1}\right]}{a_{h} V_{h, t-2}\left[R_{t-1}\right]},
$$

where $E_{h, t-2}\left[R_{t-1}\right]$ and $V_{h, t-2}\left[R_{t-1}\right]$ are the expectation of type- $h$ investors about the conditional mean and variance of the excess return of the housing asset, $R_{t-1}$, at time $t-2$. $a_{h}$ is the risk aversion parameter. For simplicity, I assume that all agents have the same risk aversion parameter so that $a_{h}=a$ and homogeneous expectations about the conditional variance, $V_{h, t}\left[R_{t+1}\right]=V_{t}\left[R_{t+1}\right]$ so that the model is analytically tractable. Two more simplifying assumptions are made in order to have a convenient expression of the excess profit in terms of the relative deviation, $x_{t}$. The first assumption is $Y_{t-1} \approx$ $(1+g) Y_{t-2}$. Under this assumption, the fitness measure is not affected by the stochastic growth rate of the rent, but rather depends on the average growth rate $g$. Brock and Hommes (1998) refer to the model where stochastic rent is replaced by expected rent as the nonlinear deterministic skeleton model. Thus, the realized excess return in eq. (4.6) is approximated as

$$
R_{t-1} \approx \frac{1+g}{r-g} Y_{t-1}\left(x_{t-1}-R^{*} x_{t-2}\right)
$$

A second simplifying assumption is on the beliefs about the conditional variance of excess returns. I assume that the rent, $Y_{t}$, has a constant growth rate, so that for all types of beliefs, the conditional variance is given by

$$
\begin{aligned}
V_{h, t-2}\left[R_{t-1}\right] & =V_{h, t-2}\left[P_{t-1}+Y_{t-1}-(1+r) P_{t-2}\right] \\
& =V_{t-2}\left[P_{t-1}^{*}+Y_{t-1}-(1+r) P_{t-2}^{*}\right] \\
& =V_{t-2}\left[(m+1)(1+g) Y_{t-2} \epsilon_{t-1}\right] \\
& =Y_{t-2}^{2} \eta^{2}
\end{aligned}
$$

where $\eta^{2}=(1+m)^{2}(1+g)^{2} V_{t-2}\left[\epsilon_{t-1}\right]$. The implied expected return is

\footnotetext{
${ }^{1}$ See Boswijk et al. (2007) for a detailed derivation of recent performance of type- $h$ agents, $\pi_{h, t-1}$.
} 


$$
E_{h, t-2}\left[R_{t-1}\right]=\frac{(1+g)^{2}}{r-g} Y_{t-2}\left[E_{h, t-2}\left(x_{t-1}\right)-R^{*} x_{t-2}\right] .
$$

Eq. (4.17) can be further rewritten as

$$
\pi_{h, t-1}=\frac{(1+g)^{4}}{a \eta^{2}(r-g)^{2}}\left[x_{t-1}-R^{*} x_{t-2}\right]\left[E_{h, t-2}\left(x_{t-1}\right)-R^{*} x_{t-2}\right] .
$$

Therefore, the past relative performance of type- $h$ agents, $B_{h, t}$, can be rewritten as

$$
B_{h, t}=\frac{1}{L} \sum_{l=1}^{L} \frac{(1+g)^{4}}{a \eta^{2}(r-g)^{2}}\left[x_{t-l+1}-R^{*} x_{t-l}\right]\left[E_{h, t-l}\left(x_{t-l+1}\right)-R^{*} x_{t-l}\right] .
$$

Since my goal is to estimate a simple heterogeneous expectations model, I restrict my attention to the types of agents $h \in\{1,2,3\}$, but the case with $H$ types is straightforward. Assume that all types of agents predict next periods relative deviation by extrapolating past realizations in a linear fashion, I have

$$
E_{h, t}\left[x_{t+1}\right]=\phi_{h} x_{t-1},
$$

where $\phi_{h}$ denotes the parameter characterizing the strategy of type- $h$ agents. The dynamic asset pricing model in eq. (4.13) can then be written as

$$
R^{*} x_{t}=\sum_{h=1}^{3} \phi_{h} n_{h, t} x_{t-1}
$$

where $\phi_{1}, \phi_{2}$ and $\phi_{3}$ represent the coefficients of the three types of beliefs and $n_{1, t}, n_{2, t}$ and $n_{3, t}$ are the fractions of agents that belong to the three groups. Participants form their expectations using various strategies. For instance, following Brock and Hommes (1997), Type-1 agents use naive expectations. Their expectation is just the last observations they have seen:

$$
E_{1, t}\left[x_{t+1}\right]=x_{t-1},
$$

It implies that their beliefs parameter $\phi_{1}=1$. This type of agents are just like naive agents. Type-2 agents expect the home price to mean-revert towards the benchmark 
fundamental price so that their beliefs parameter $0<\phi_{2}<1$. This type of agents behave like fundamentalists. The beliefs parameter $\phi_{2}$ indicates how strongly the fundamentalists believe in mean-reversion. The closer the value of $\phi_{2}$ to 1 the more persistent are the expected relative deviations. Furthermore, Type-3 agents are chartists and their beliefs parameter is smaller than 0 or larger than 1 . When $\phi_{3}$ is larger than 1 , they are trend followers who expect the relative deviation between the housing price and the fundamental housing price to enlarge. When $\phi_{3}$ is smaller than 0 , they are contrarians. And they expect the price trend to reverse in the next period. I dont know whether trend followers or contrarians exist in my sample. I make the model general enough to accommodate all the possible scenarios and let the data tell us the answer.

In the case with three-types of linear beliefs, the past relative performance of type $h$ agents, $B_{h, t}$, can be rewritten as

$$
B_{h, t}=\frac{1}{L} \sum_{l=1}^{L} \frac{(1+g)^{4}}{a \eta^{2}(r-g)^{2}}\left[x_{t-l+1}-R^{*} x_{t-l}\right]\left[\phi_{h} x_{t-l-1}-R^{*} x_{t-l}\right] .
$$

Next, I define the market-correction factors for type $h$ agents, $S_{h, t}$. Investors believe the further the price deviates from its fundamental price, the more likely the market corrections will occur and they will feel more inclined to switch to fundamental strategy. As such, the market-correction factor for fundamentalists (Type-2 agents) is a function of contemporaneous relative deviation between current price and the fundamental price. Assume $S_{2, t}\left(x_{t}\right)=2 x_{t}{ }^{2}$. And the market-correction factors for naive agents and chartists, $S_{1, t}$ and $S_{3, t}$, are assumed to be zero.

The market-correction-adjusted relative past performance, $A_{h, t}$, can therefore be rewritten as

$$
\begin{array}{r}
A_{1, t}=\frac{1}{L} \sum_{l=1}^{L} \frac{(1+g)^{4}}{a \eta^{2}(r-g)^{2}}\left[x_{t-l+1}-R^{*} x_{t-l}\right]\left[x_{t-l-1}-R^{*} x_{t-l}\right] \\
A_{2, t}=2 x_{t}^{2}+\frac{1}{L} \sum_{l=1}^{L} \frac{(1+g)^{4}}{a \eta^{2}(r-g)^{2}}\left[x_{t-l+1}-R^{*} x_{t-l}\right]\left[\phi_{2} x_{t-l-1}-R^{*} x_{t-l}\right]
\end{array}
$$

and 


$$
A_{3, t}=\frac{1}{L} \sum_{l=1}^{L} \frac{(1+g)^{4}}{a \eta^{2}(r-g)^{2}}\left[x_{t-l+1}-R^{*} x_{t-l}\right]\left[\phi_{3} x_{t-l-1}-R^{*} x_{t-l}\right] .
$$

Eqs. (4.14) and (4.27) - (4.29) indicates that investors not only cluster to the heuristics which performed better in the recent past, but also act based on the expectations that the market is more inclined to reverse when the current price deviates further from its fundamentals.

Substituting eqs. (4.27) and (4.28) into (4.14) yields

$$
\begin{aligned}
n_{1, t}= & \left\{1+\exp \left[\frac{\beta^{*}}{L} \sum_{l=1}^{L}\left(\phi_{2}-1\right) x_{t-l-2}\left(x_{t-l}-R^{*} x_{t-l-1}\right)+2 \gamma \beta^{*} x_{t}^{2}\right]\right. \\
& \left.+\exp \left[\frac{\beta^{*}}{L} \sum_{l=1}^{L}\left(\phi_{3}-1\right) x_{t-l-2}\left(x_{t-l}-R^{*} x_{t-l-1}\right)\right]\right\}^{-1}
\end{aligned}
$$

and

$$
\begin{aligned}
n_{2, t}= & \left\{1+\exp \left[\frac{\beta^{*}}{L} \sum_{l=1}^{L}\left(1-\phi_{2}\right) x_{t-l-2}\left(x_{t-l}-R^{*} x_{t-l-1}\right)-2 \gamma \beta^{*} x_{t}^{2}\right]\right. \\
& \left.+\exp \left[\frac{\beta^{*}}{L} \sum_{l=1}^{L}\left(\phi_{3}-\phi_{2}\right) x_{t-l-2}\left(x_{t-l}-R^{*} x_{t-l-1}\right)-2 \gamma \beta^{*} x_{t}^{2}\right]\right\}^{-1},
\end{aligned}
$$

where $\gamma=\frac{a \eta^{2}(r-g)^{2}}{(1+g)^{4}}$ and $\beta^{*}=\frac{\beta}{\gamma}$ is the scaled intensity of choice. Recall that $\sum_{h=1}^{3} n_{h, t}=1$, so $n_{3, t}$ can be expressed by $n_{1, t}$ and $n_{2, t}$ as

$$
n_{3,1}=1-n_{1, t}-n_{2, t}
$$

The full dynamic system for the housing market model with heterogeneous beliefs is given by

$$
\begin{aligned}
x_{t} & =\frac{1}{R^{*}}\left[n_{1, t}+\phi_{2} n_{2, t}+\phi_{3}\left(1-n_{1, t}-n_{2, t}\right)\right] x_{t-1} \\
n_{1, t} & =\left\{1+\exp \left[\frac{\beta^{*}}{L} \sum_{l=1}^{L}\left(\phi_{2}-1\right) x_{t-l-2}\left(x_{t-l}-R^{*} x_{t-l-1}\right)+2 \gamma \beta^{*} x_{t}^{2}\right]\right.
\end{aligned}
$$




$$
\begin{aligned}
& \left.+\exp \left[\frac{\beta^{*}}{L} \sum_{l=1}^{L}\left(\phi_{3}-1\right) x_{t-l-2}\left(x_{t-l}-R^{*} x_{t-l-1}\right)\right]\right\}^{-1} \\
n_{2, t}= & \left\{1+\exp \left[\frac{\beta^{*}}{L} \sum_{l=1}^{L}\left(1-\phi_{2}\right) x_{t-l-2}\left(x_{t-l}-R^{*} x_{t-l-1}\right)-2 \gamma \beta^{*} x_{t}^{2}\right]\right. \\
& \left.+\exp \left[\frac{\beta^{*}}{L} \sum_{l=1}^{L}\left(\phi_{3}-\phi_{2}\right) x_{t-l-2}\left(x_{t-l}-R^{*} x_{t-l-1}\right)-2 \gamma \beta^{*} x_{t}^{2}\right]\right\}^{-1} .
\end{aligned}
$$

At the fundamental equilibrium, $n_{1, t}=n_{2, t}=\frac{1}{3}$. By linearizing the dynamics around this equilibrium one finds that the fundamental equilibrium is locally stable if

$$
\left|\frac{1+\phi_{2}+\phi_{3}}{3 R^{*}}\right|=\left|\frac{(1+g)\left(1+\phi_{2}+\phi_{3}\right)}{3(1+r)}\right|<1
$$

\subsection{Results and Discussions}

I estimate the three-heterogeneous agent model using monthly Freddie Mac house price index and the rent component of consumer price index in two representative states, Arizona and Minnesota, from Jan 1975 to Mar 2015. I obtain the Freddie Mac house price index which contains the nominal housing prices from the Federal Home Loan Mortgage corporation. Year 2000 is used as the base year for the nominal housing price. I then derive the real housing price by dividing the nominal house price by the urban consumer price index which is obtained from Bureau of Labor statistics. I gain the rent component of the consumer price index is from CEIC database. I retrieve the annual average user cost of housing from Himmelberg et al. (2005) and divide the rate by 12 to get the monthly average user cost of housing. All nominal rates are converted into real rates using the urban consumer price index.

\subsubsection{Fundamental Price and Fundamental Model Parameters}

Before estimating the behavioral model, I calibrate the fundamental benchmark price, $p_{t}^{*}$, and the fundamental model parameter, $R^{*}$. The relation between an asset fundamental price and the actual rent level in eq. (4.12) can be rewritten as 


$$
p_{t}^{*}=m Y_{t}
$$

where $m$ is a constant which presents the fundamental price-to-rents (PR) ratio. This equation implies that the fundamental housing price is directly proportional to the rent.

To calibrate the fundamental price-to-rents ratio, $m$, I make a presumption that the average housing price would be converging towards the fundamental benchmark in the long run. Equivalently, the PR ratio would also be converging to the fundamental PR ratio in the long term. So I use the long-term average PR ratio as an estimation for the fundamental PR ratio.

Next, I calculate the fundamental model parameter $R^{*}$. Recall that the gross return on risk free asset relative to housing, $R^{*}$, is given by

$$
R^{*}=\frac{1+r}{1+g}
$$

where $g$ is the constant growth rate of the rent and $r$ is the discount rate. $q$ represents the average rate of capital gain and $u$ denotes the monthly average user cost of housing so that eq. (4.4) can be rewritten as

$$
r=q+u
$$

I retrieve the monthly average user cost of housing from Himmelberg et al. $(2005)^{2}$. The annual average user cost is 0.033 for Arizona and 0.058 for Minnesota. After dividing the annual user cost by 12 , I obtain the monthly average user cost of housing to be 0.0028 for Arizona and 0.0048 for Minnesota. I then calculate the average rates of capital gain, $q$, in Arizona and Minnesota using the monthly data of the Freddie Mac house price index in the two states. I find that the average rate of capital gain is 0.0157 in Arizona and 0.0050 in Minnesota. As a result, the discount rate for Arizona and Minnesota is 0.0185 and 0.0097 , respectively. Finally, the rent growth rate, $g$, is obtained from the monthly

\footnotetext{
${ }^{2}$ The average user cost available in Himmelberg et al. (2005) is the user cost in 2004. So we use $q$ and $g$ in the same period to calculate in 2004. $R^{*}$ in 2004 may be an under-estimation of the actual level of $R^{*}$ for the whole period. However, robustness check shows that the exact choice of the period to calibrate $R^{*}$ has relatively small effects on the estimated behavioural parameters.
} 
rent component of consumer price index which is $0.0024^{3}$ for the two states. Substituting these values into eq. (4.35) gives $R^{*}$ of 1.0160 for Arizona and 1.0072 for Minnesota.

Table 4.1 summarizes the values we use in our estimation for the two states. All the nominal variables are deflated using the consumer price index.

Table 4.1: Summary of the values used in the estimation

\begin{tabular}{lccccccccl}
\hline & $\pi$ & $h$ & $r p$ & $m$ & $g$ & $q$ & $u$ & $r$ & $R^{*}$ \\
\hline Arizona & 1.4886 & 59.25 & 107.44 & 0.5513 & 0.0024 & 0.0157 & 0.0028 & 0.0185 & 1.0160 \\
Minnesota & 1.4886 & 52.37 & 107.44 & 0.4867 & 0.0024 & 0.0050 & 0.0048 & 0.0097 & 1.0072 \\
\hline
\end{tabular}

Notes: $\pi$ is the average CPI, $h$ is the average Freddie Mac Index and $r p$ is the average rent level.

\subsubsection{Estimating the HAM using Nonlinear Regression}

The deviation between the beliefs parameters of type $h$ agents, $\phi_{h}$, and type 1 agents, 1 , is defined as

$$
\Delta \phi_{h}=\phi_{h}-1
$$

Since my goal is to estimate a simple heterogeneous expectations model, I assume that $L=2$. The three-heterogeneous agent model can be reformulated in terms of $\Delta \phi_{h}$ such that

$$
\begin{aligned}
x_{t}= & \frac{1}{R^{*}}\left[n_{1, t}+\left(\Delta \phi_{2}+1\right) n_{2, t}+\left(\Delta \phi_{3}+1\right)\left(1-n_{1, t}-n_{2, t}\right)\right] x_{t-1} \\
n_{1, t}= & \left\{1+\exp \left[\frac{\beta^{*}}{2} \sum_{l=1}^{2} \Delta \phi_{2} x_{t-l-2}\left(x_{t-l}-R^{*} x_{t-l-1}\right)+2 \beta^{*} \gamma x_{t}^{2}\right]\right. \\
& \left.+\exp \left[\frac{\beta^{*}}{2} \sum_{l=1}^{2} \Delta \phi_{3} x_{t-l-2}\left(x_{t-l}-R^{*} x_{t-l-1}\right)\right]\right\}^{-1} \\
n_{2, t}= & \left\{1+\exp \left[\frac{\beta^{*}}{2} \sum_{l=1}^{2}(-1) \Delta \phi_{2} x_{t-l-2}\left(x_{t-l}-R^{*} x_{t-l-1}\right)-2 \gamma \beta^{*} x_{t}^{2}\right]\right. \\
& \left.+\exp \left[\frac{\beta^{*}}{2} \sum_{l=1}^{2}\left(\Delta \phi_{3}-\Delta \phi_{2}\right) x_{t-l-2}\left(x_{t-l}-R^{*} x_{t-l-1}\right)-2 \gamma \beta^{*} x_{t}^{2}\right]\right\}^{-1} .
\end{aligned}
$$

Using the monthly data of the Freddie Mac house price index and rents for the period

\footnotetext{
${ }^{3}$ As the monthly rent component of the consumer price index for each individual state is not available to collect, I use the monthly rent component of the consumer price index in the United States in the estimation. So the constant rates of the rent, $g$, are the same for both states.
} 
of Jan 1975 to Mar 2015, we estimate the parameters $\left(\Delta \phi_{2}, \Delta \phi_{3}, \beta^{*}\right)$ for Arizona and Minnesota by nonlinear least squares (NLLS). $\Delta \phi_{2}$ and $\Delta \phi_{3}$ are parameter vectors of the deviations between the beliefs parameters of Type-2 from Type- 1 agents, $\Delta \phi_{2}=\phi_{2}-1$, and the deviations between the beliefs parameters of Type- 3 from Type- 1 agents, $\Delta \phi_{3}=$ $\phi_{3}-1$

Table 4.1 reports the estimates of gross return of the risk free asset relative to houses, $R^{*}$.

The value is 1.0160 for Arizona and 1.0072 for Minnesota. In addition, $\gamma=\frac{a \eta^{2}(r-g)^{2}}{(1+g)^{4}}$ is calculated before estimating the heterogeneous agent model. Here I assume that the risk aversion parameter, $a$, equals 1 and calculate that $\gamma$ is 0.001057 for Arizona and 0.000197 for Minnesota.

The estimated parameters $\left(\Delta \phi_{2}, \Delta \phi_{3}, \beta^{*}\right)$ and hence the implied beliefs parameters $\phi_{2}$ and $\phi_{3}$ are reported in Table $4.2^{4}$.

Table 4.2: Estimates for the booms and busts of the two patterns, 1975:1-2015:3.

\begin{tabular}{lcccc}
\hline & \multicolumn{2}{c}{ Exponential bubble } & \multicolumn{2}{c}{ Linear trend } \\
\cline { 2 - 5 } & Estimate & $p$-value & Estimate & $p$-value \\
\hline Deviation of beliefs, $\Delta \phi_{2}$ & $-0.0050^{* *}$ & 0.0492 & $-0.0368^{* * *}$ & 0.0000 \\
Deviation of beliefs, $\Delta \phi_{3}$ & $0.0981^{* * *}$ & 0.0000 & $0.0800^{* * *}$ & 0.0000 \\
Scaled intensity of choice, $\beta^{*}$ & $22864.36^{* * *}$ & 0.0000 & $13900.38^{* * *}$ & 0.0065 \\
Implied beliefs parameter, $\phi_{2}$ & 0.9950 & & 0.9632 & \\
Implied beliefs parameter, $\phi_{3}$ & 1.0981 & & 1.0800 & \\
$R^{2}$ & 0.9982 & & 0.9988 & \\
$A I C$ & -7.0190 & & -7.7409 & \\
\hline
\end{tabular}

All the estimated parameters are found to be statistically significant. The significance of $\Delta \phi_{2}$ and $\Delta \phi_{3}$ suggests that there is significant difference between the belief parameter of Type-2 agents from Type-1 agents, and the belief parameter between the belief parameter of Type-3 agents from Type-1 agents.

Table 4.2 not only provides evidence of behavioral heterogeneity in the U.S. real estate market, but also supports the coexistence of fundamentalists and trend followers. The implied beliefs, $\phi_{2}$, is $0.9950^{5}$ for the exponential bubble and 0.9632 for the linear trend,

\footnotetext{
${ }^{4}$ It is not possible to calculate a valid $R^{2}$ for nonlinear regression so this value is an invalid goodnessof-fit statistic for my nonlinear HAM. $R^{2}$ is based on the underlying assumption that we are fitting a linear model. In nonlinear regression, $R^{2}$ is no longer between 0 and $100 \%$ and using $R^{2}$ to evaluate the fit of nonlinear models leads to incorrect conclusions.

${ }^{5}$ As discussed in Chapter 3, the implied beliefs parameters $\phi_{2}$ and $\phi_{3}$ are close to 1 because I use
} 
lies between 0 and 1 . This indicates that Type- 2 agents are fundamentalists who believe in mean-reversion and hence will expect the asset price to return back towards its fundamental values. In contrast, the implied beliefs parameter, $\phi_{3}$, is 1.0981 for the exponential bubble and 1.0800 for the linear trend. Since both of these parameters exceed 1, Type-3 agents are trend following investors who expect the deviation of housing prices from its fundamental values to enlarge. The significance of the scaled intensity of choice, $\beta^{*}$, provides evidence that different types of investors are interacting between each other.

Figure 4.2 shows the time series of the relative deviations between the actual housing prices from its fundamental prices, $x_{t}$, and estimated fractions of Type- 1 agents $\left(n_{1, t}\right)$, Type-2 agents $\left(n_{2, t}\right)$, and Type-3 agents $\left(n_{3, t}\right)$, for the exponential bubble. If the fraction of type- $h$ agents is 0 , i.e. $n_{h, t}=0$, this means that type- $h$ agents do not exist in the market. On the contrary, if $n_{h, t}=1$, all the participants in the market are type- $h$ agents. In Figure 4.2, all the three fractions are found to be positive and vary considerably over time, providing evidence that the three types of agents coexist in the Arizona's real estate market and they are interacting with each other.

More importantly, these plots offer an explanation for the formation and the subsequent collapse of an exponential housing bubble in Arizona. The shaded area in Figure 4.2 represents the period when the most recent bubble was formed and crashed. During the period when the bubble was fueled up, trend followers dominated the market. The dominance of the trend followers reinforced an extraordinary deviation of housing prices from its fundamental benchmarks, resulting in an accelerating growth of the housing price bubble in Arizona, which is in line with the results in Chapter 3.

However, during the period when the housing prices declined, $n_{1, t}$ remains at 0 and $n_{3, t}$ fell towards 0 . This suggests that naive agents and trend followers were not in the market. On the contrary, the fraction of Type- 2 agents, $n_{2, t}$, is found to approach 1 during the period of bubble collapse, showing that the majority of the agents were switching towards the fundamental regime. The activation of fundamentalists pushed the housing prices back towards its fundamental prices. This finding shows that the dominance of fundamentalists contributes to the burst of the exponential bubble in Arizona.

monthly data to estimate the model. Market participants expect that the relative deviations between the housing prices and the fundamental housing prices would exhibit only small changes within one month. 

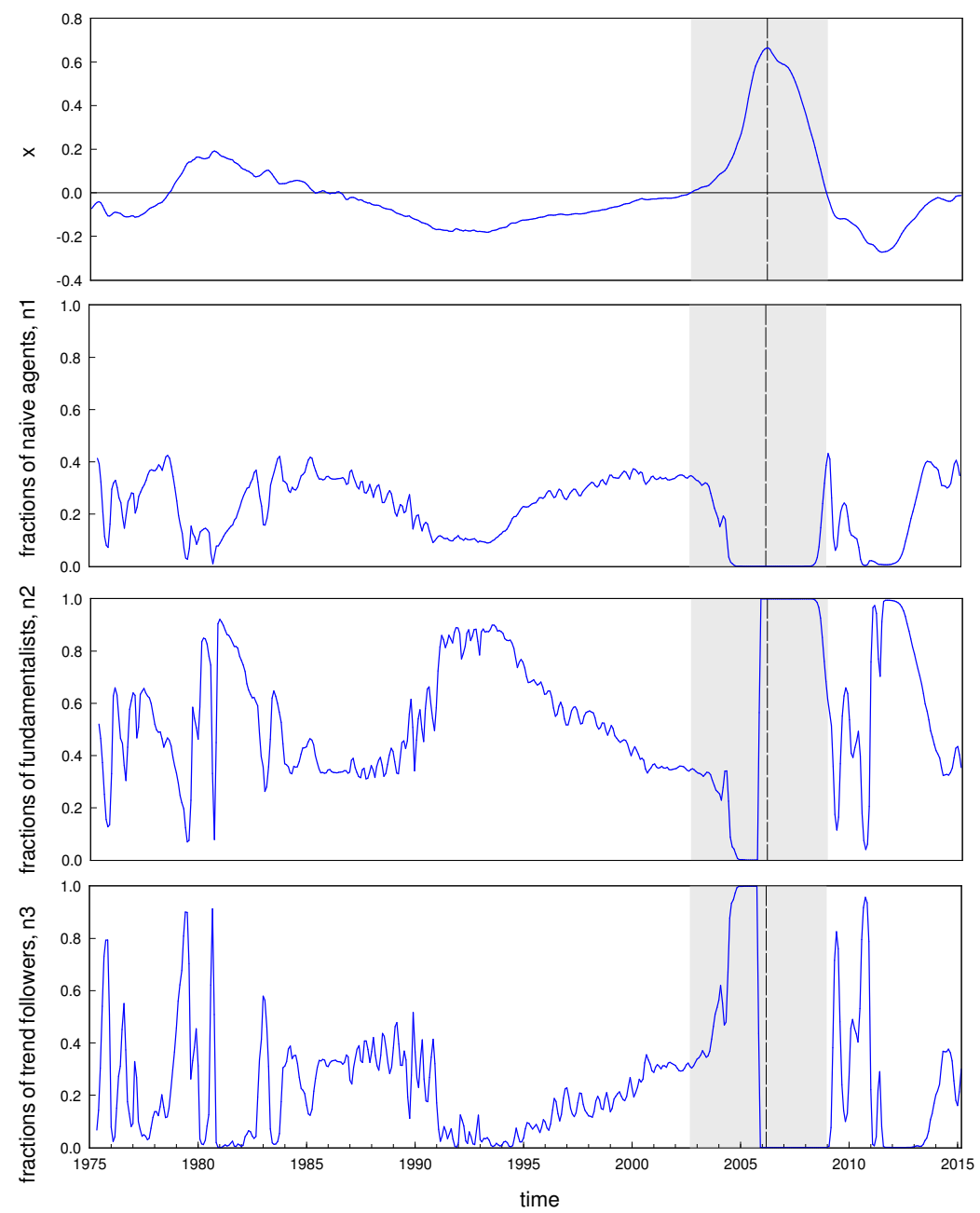

Figure 4.2: Relative deviations and fractions of three types of agents in Arizona housing market

Since the formation of the exponential bubble is driven mostly by the dominance of the trend followers, while the burst of the exponential bubble could be due to the dominance of fundamentalists, the boom-bust housing price dynamics could be explained by the interactions between difference types of agents. In other words, the dynamics of housing prices could have some endogenous origin.

Why initially the trend followers dominate the market, but all of a sudden most of them switch to the fundamental strategy? It can be explained by our market-correctionadjusted fitness measure framework. When the housing price move further and further 
away from its fundamental value, observers expect that the market is more likely to reverse, and the market-correction factor for the fundamentalists is increasing as it is positively related to the relative deviation between current housing price and the fundamental housing price. When the gap between current price and its fundamentals enlarges, the market-correction-adjusted fitness measure of fundamentalists outperforms that of trend followers, participants will cluster to the mean-reversion strategy.

Figure 4.3 plots the time series of $x_{t}$, and estimated fractions of Type- 1 agents, $n_{1, t}$, Type-2 agents, $n_{2, t}$, and Type-3 agents, $n_{3, t}$, for the linear trend in Minnesota. Similar to the previous findings from Figure 4.2, it supports the coexistence of the three types of agents in the market. These plots offer a possible explanation for the formation and collapse of a linear trend. The shaded area in Figure 4.3 shows the period when the linear trend was formed and collapsed. These plots show a constant proportion of all types of agents in the market when the linear trend was formed. It suggests that the formation of a linear trend in Minnesota could be explained by approximately constant proportions of each type of agents.

The collapse of a linear trend could also be explained by Figure 4.3. It is noted that during the period when the linear trend collapsed in the shaded area, $n_{3, t}$ fell towards 0 . This implies that trend followers were not present in the market. The fractions of Type-1 agents, $n_{1, t}$, fell towards about 0.2 , suggesting that naive agents were the minority in the market. However, the fraction of Type- 2 agents, $n_{2, t}$, is found to increase towards about 0.8 , which indicates that fundamentalists are the majority of the agents in the market during the collapse of the linear trend. The activation of fundamentalists could push the housing prices back to fundamental prices, contributing to the collapse of the linear trend. So the collapse of the linear trend could be due to the dominance of fundamentalists.

Combining the findings from both Figure 4.2 and Figure 4.3, I can then conclude that I could offer an endogenous explanation for the formation and the subsequent collapse of the two patterns simultaneously within the same framework. 


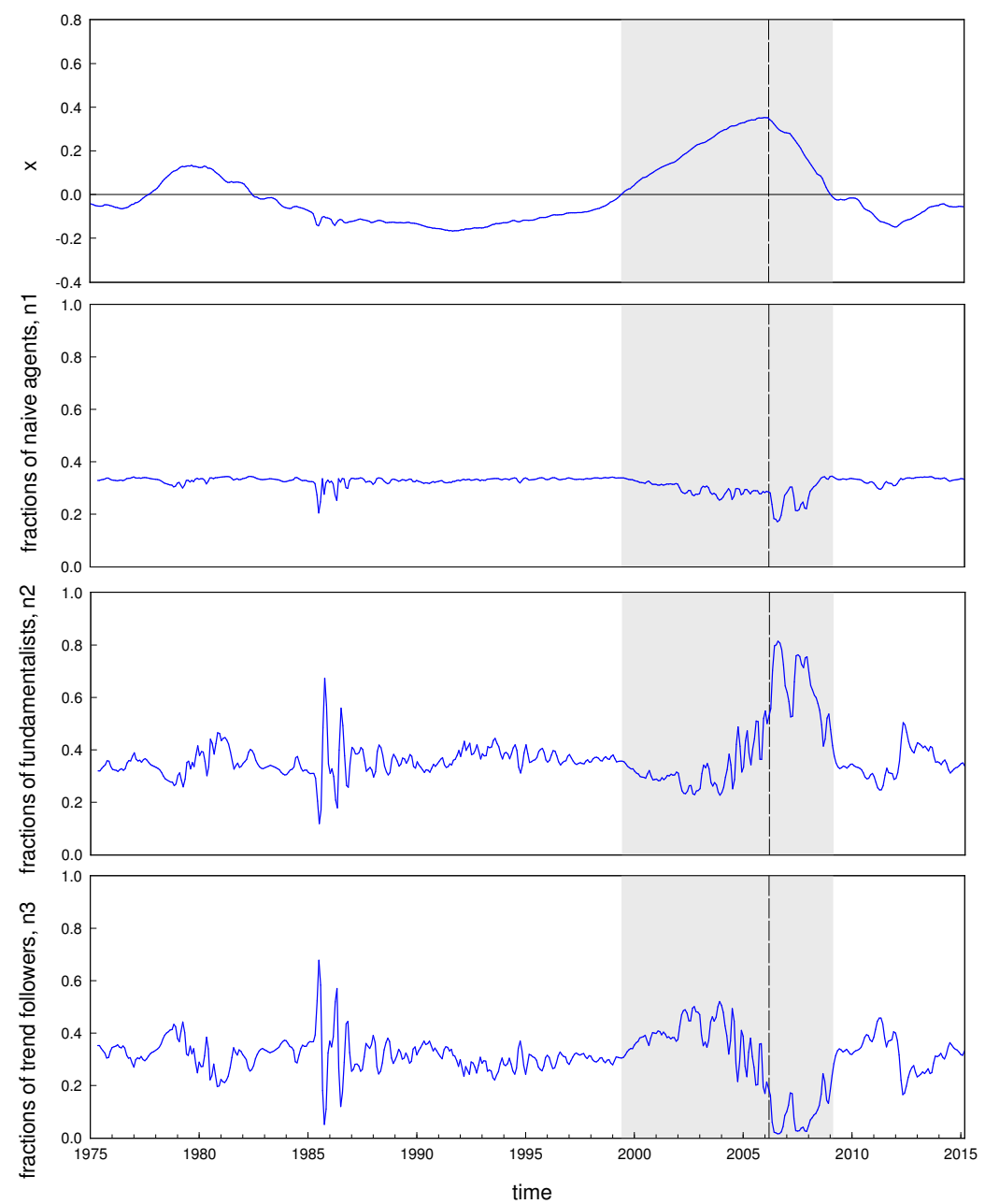

Figure 4.3: Relative deviations and fractions of three types of agents in Minnesota housing market

\subsection{Predict the Timing of Market Switches}

I want to explore whether the timing of the market switches could be predictable using the heterogeneous agent model. While many academic studies predict the price trend in financial market or housing market using HAMs, such as Boswijk et al. (2007) and Chiarella et al. (2012), most of them have not forecast the timing of market corrections. Since the booms and the busts of an exponential bubble could be quite harmful for the economy, my main purpose is to forecast when the recent exponential bubble will burst using the proposed nonlinear HAM. In order to evaluate the predictability, I compare 


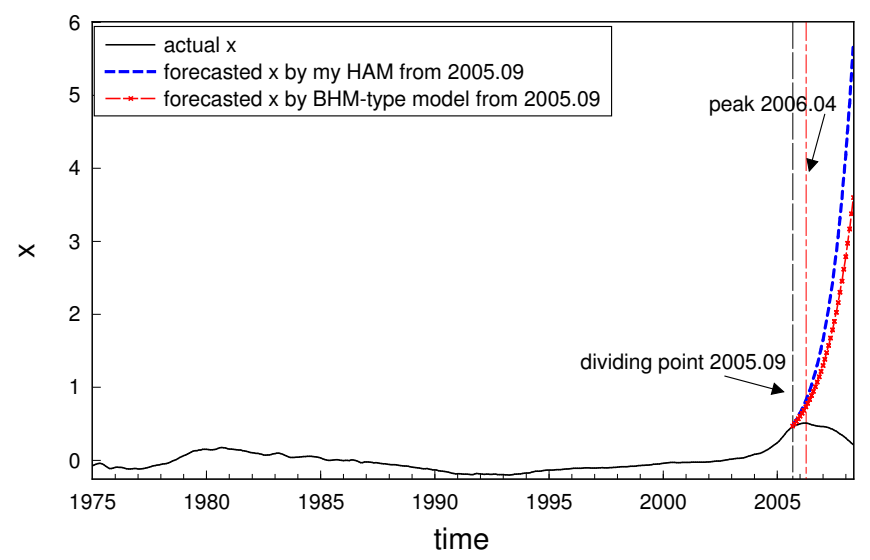

Figure 4.4: Forecast relative deviation, $x_{t}$, by my HAM and BHM-type model when the dividing point is Sep 2005

the prediction of our model with the HAM in Chapter 3 (BHM-type heterogeneous agent model).

The relative deviation between housing prices and fundamental housing prices, $x_{t}$, in the exponential bubble climbed remarkably fast in the early 2000s and reached the peak around Apr 2006 before it collapsed quickly in the same year. I divide the data sample into two segments; one for the in-sample estimation, the other for the out-of-sample comparison. If a model predict that the housing price will continue to increase when the dividing point is far away from the sample peak, and it predicts that the housing price is going to decline when the dividing point is near the sample peak, I can say that this model can roughly predict the timing of market switches.

Figure 4.4 shows the forecast relative deviation, $x_{t}$, by my HAM and BHM-type model from Sep 2005. The red line is the prediction using BHM-type model and the blue line is the prediction using my model. Both models predict that the housing price will increase.

Figure 4.5 shows the forecast relative deviation, $x_{t}$, by my HAM and BHM-type model when the dividing point is Oct 2005. Similarly, both models predict that the housing price is going to increase.

Figure 4.6 shows the prediction when the dividing point is Nov 2005. The red is upward sloping, so BHM-type model predict that the housing price will increase. However, the 


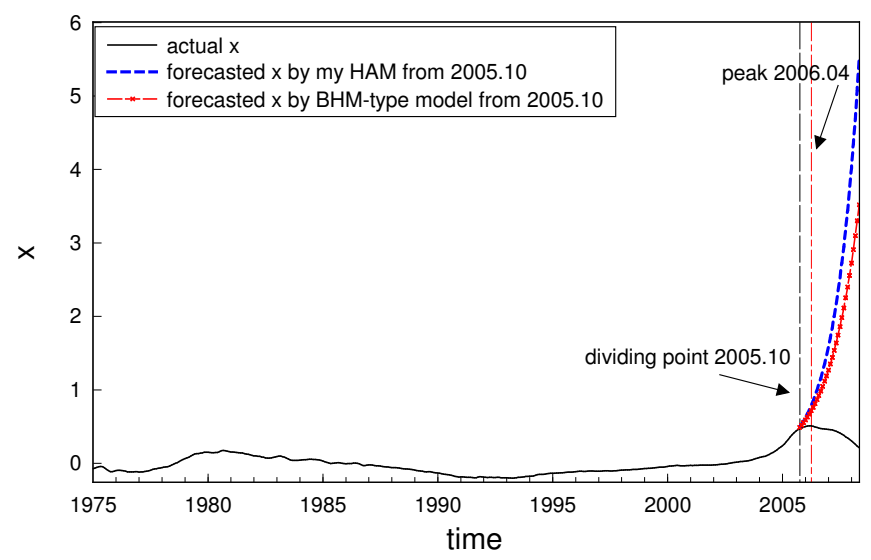

Figure 4.5: Forecast relative deviation, $x_{t}$, by my HAM and BHM-type model when the dividing point is Oct 2005

blue line is downward sloping, so my model predicts that the housing price is going to decline. It matches well with the actual housing price trend, and my HAM can roughly predict the timing of market switches. This is probably because, my model is more realistic. In my HAM, investors believe that the further the price deviates from its fundamental price, the more likely it is going to reverse. The deviations between the housing price and the fundamental housing price are so large that most participants expect the market is going to reverse. So they cluster to fundamental strategy. The dominance of fundamentalists will contribute to the mean-reversion towards the fundamental prices.

As a robust check, I also forecast the relative deviations using both models when the dividing point is Dec 2005. In Figure 4.7, the forecast $x_{t}$ using my HAM drops significantly after the dividing point, warning that the system is going to reverse. In contrast, the forecast $x_{t}$ using BHM-type model remains on a rapidly increasing trend.

I further use Jan 2006, Feb 2006, March 2006 and Apr 2006 as the dividing point, respectively (not reported here). When the dividing point is Jan 2006 or Feb 2006, the forecast $x_{t}$ using BHM-type model remains on a rapidly increasing trend, while my HAM forecasts that the market is going to reverse. When the dividing point is March 2006 or Apr 2006, both my HAM and the BHM-type model predict that $x_{t}$ is going to decline. In conclusion, my HAM can roughly predict the timing of market switches. And my model exhibits a better accuracy in predicting the timing of market switches compared to the 


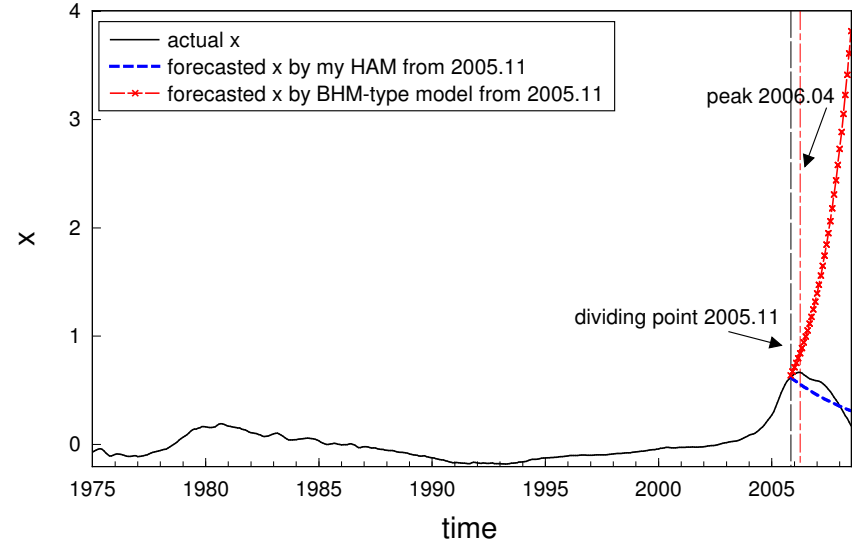

Figure 4.6: Forecast relative deviation, $x_{t}$, by my HAM and BHM-type model when the dividing point is Nov 2005

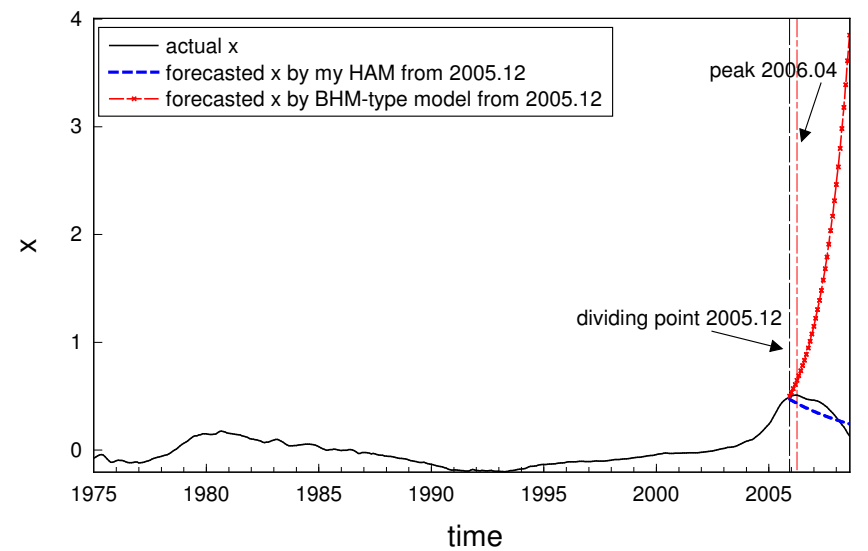

Figure 4.7: Forecast relative deviation, $x_{t}$, by my HAM and BHM-type model when the dividing point is Dec 2005 
model in Chapter 3 (BHM-type model) when the dividing point is from Nov 2006 to Feb 2006. Both my model and the BHM-type model predict that $x_{t}$ is going to drop when the dividing point is from Mar 2006 to Apr 2006.

\subsection{Dynamics and Policy Implications}

What are the policy implications from my HAM? In order to identify useful policy implications, it is necessary to analyze how changes in different parameter values could affect the price dynamics. In order to address this, I therefore first investigate the housing price dynamics of the nonlinear HAM for a range of parameter values containing the estimated coefficients for both exponential bubbles and linear trends. In particular, I discuss multiple steady state equilibria and global instability of the system and then draw some policy conclusions that could help stabilize the real estate market. I focus on the role of $R^{*}$ as the policy parameter, since it contains parameter(s) that can be affected by policy makers.

The first step is to study the local stability and bifurcations of the fundamental steady state. Recall from the stability condition (4.33) that the fundamental equilibrium $X_{t}=0$ is locally stable when

$$
\frac{1+\phi_{2}+\phi_{3}}{3 R^{*}}=\frac{(1+g)\left(1+\phi_{2}+\phi_{3}\right)}{3(1+r)}<1,
$$

where I have removed the notation for absolute value as all parameters are positive.

I define the implied critical value of $R^{*}, R_{c r i t}^{*}$, as a policy parameter such that

$$
\frac{1+\phi_{2}+\phi_{3}}{3 R^{*}}=1 .
$$

From the above equation, $R_{c r i t}^{*}$ can be rewritten as

$$
R_{c r i t}^{*}=\frac{1+\phi_{2}+\phi_{3}}{3} .
$$


The bifurcation diagram from Figure 4.8 shows the equilibrium and stability for the exponential bubble as $R^{*}$ decreases, with all other parameters held constant. The bifurcation diagram is constructed by plotting for each parameter value $R^{*} 1000$ subsequent states visited by the model after a transient of 100 iterations. A small amount of dynamic noise is added, $\operatorname{NID}\left(0, \sigma^{2}\right)$ with $\sigma=10^{-4}$, to enable the system to move away from the equilibrium once it becomes unstable. The solid vertical line indicates the estimated value of $R^{*}$ and the dashed vertical line the implied critical value $R_{c r i t}^{*}$.

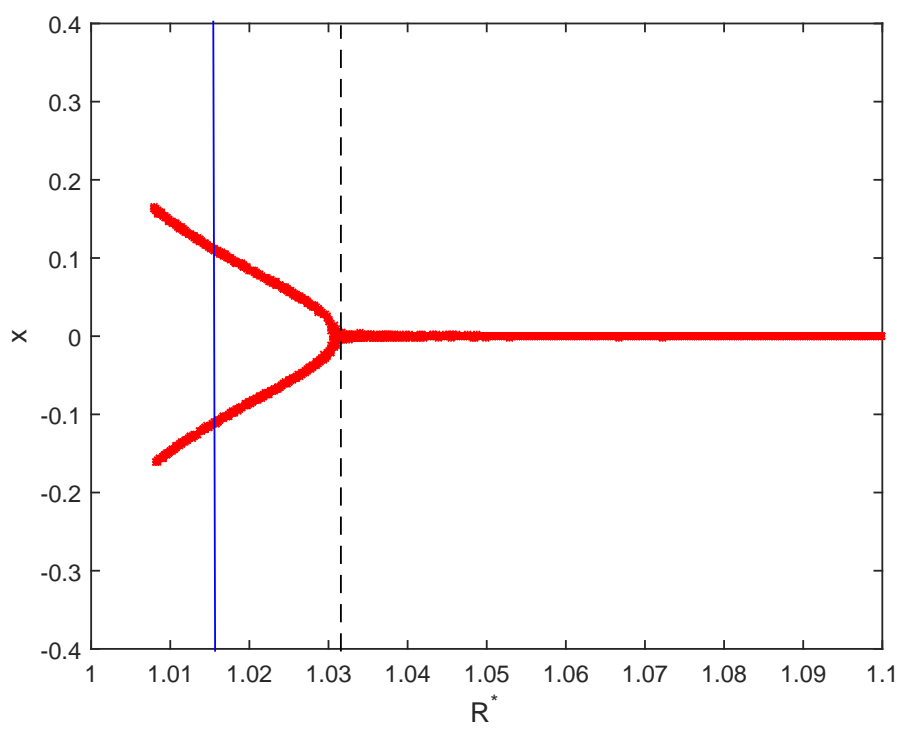

Figure 4.8: Bifurcation diagrams showing the long run behaviour for Arizona as a function of the bifurcation parameter $R^{*}$

Figure 4.8 illustrates that, firstly, the fundamental steady state destabilizes when $R^{*}$ decreases and hits the critical value $R_{c r i t}^{*}$. In other words, the system transits from local stability to (local) instability of the fundamental steady state when $R^{*}$ declines to the critical value, $R_{c r i t}^{*}$. Secondly, for value of $R^{*}$ below $R_{c r i t}^{*}$, two coexisting stable non-fundamental steady states arise, one above and one below the unstable fundamental steady state. Hence, for the Arizona real estate market the nonlinear heterogeneous agent model exhibits multiple stable steady state equilibria for relatively low values of $R^{*}$. Finally, when $R^{*}$ decreases further, the nonlinear HAM system becomes globally unstable with exploding house prices.

What can policymakers do to stabilize house price bubbles and prevent market instability? 
Based on the bifurcation diagrams in Figures 4.8, I suggest that the policymakers should keep the parameter $R^{*}$ sufficiently large, so that the system stays away from the globally unstable fundamental steady state. Recall that $R^{*}=\frac{1+r}{1+g}$, where $g$ is the growth rate of housing rents and $r$ is the discount rate. Recall from eq. (4.3) that the discount rate $r$ can be rewritten as

$$
r=r^{r f}+\omega+\iota
$$

where $r^{r f}$ is the risk-free interest rate, $\omega$ is the mortgage/maintenance costs rate and $\iota$ is a risk premium. Hence, stabilizing policies include an increase of the risk-free interest rate and a rise of property tax rate to increase the costs of mortgage and maintenance. This is in line with Taylor (2010) who explains that a higher interest rate would have avoided much of the housing boom.

\subsection{Conclusion}

I construct a three-type heterogeneous agent model (HAM) that consists of fundamentalists, chartists and naive agents to explain the formation and the subsequent collapse of the two housing price patterns jointly within the same setup. Fundamentalists believe in mean-reversion of house price towards the benchmark fundamental price, chartists are either trend followers or contrarians, and the naive agents adopt naive expectations to forecast future prices. I introduce a market-correction-adjusted fitness measure which governs the interactions between different types of agents. Under this framework, investors not only cluster to heuristics which performs better in the recent past, but also act based on the expectations that the market is more inclined to reverse when the current price deviates further from its fundamentals.

I estimate the HAM on Freddie Mac housing price index from Jan 1975 to Mar 2015 using nonlinear least squares (NLLS). The empirical results confirm the coexistence of fundamentalists, trend followers and naive agents and that they are interacting with each other. Result 1, I show that the formation and the collapse of different housing price patterns, namely an exponential bubble and a linear trend, could be explained by the 
endogenous evolutionary switching mechanism. Besides, the findings also suggest that while the formation of an exponential bubble is driven mainly by the activations of trend followers, the linear trend could be due to stable proportions of each type of investors. The collapse of both an exponential bubble and a linear trend, on the other hand, could be the result of the dominance of fundamentalists. Result 2 , my model is able to predict the timing of market switches and it can provide an early warning signal for market corrections. Result 3, my findings have important policy implications, which suggest that policymakers should prevent the system to enter the globally unstable fundamental steady state by increasing risk-free interest rate or property tax rate. 


\section{Chapter 5}

\section{Boom-Bust Housing Price Dynamics under Markov Regime Switching}

\subsection{Introduction}

Most heterogeneous agent models (HAMs) in the literature assume that heterogeneous market participants expect the prices to evolve as a linear or linearly auto-regressive process, although the price is modeled as a non-linear dynamic system. This assumption, as a result, ignores the potential influence of regime switching on investors' expectations. Recent studies in the real estate literature suggest that the behavior of investors could be affected by market conditions. For instance, Nneji et al. (2013) argue that the U.S. housing market switches from a bubble state, a steady state and a crash state, and that market participants behave differently under different states.

To examine how the market conditions could affect the expectations of market participants, I build a HAM with Markov chain regime-dependent beliefs for the U.S. real estate market. The housing market consists of three different types of agents, namely fundamentalists, chartists and noise traders whose demand can be divided into a real component 
and a speculative component. While fundamentalists trade on mean-reversion, chartists use either the trend following strategy or the contrarians strategy and noise traders' demand follows a normal distribution. Following the standard literature (De Grauwe, 2008; Uhlig, 2010; Chiarella et al., 2012), I assume two states, namely a boom state and a bust state, in the U.S. housing market and that their switches follow a two-state Markov regime switching process. The beliefs of chartists and noise traders are modeled to be regime-dependent.

I estimate the Markov switching HAM using quarterly FHFA housing price index from 1975Q1 to 2015Q1 in the U.S. real estate market. The estimation results show that while the real demand and supply for housing keep each other in balance, the speculative fundamentalists, chartists, and noise traders do show highly significant coefficients of the hypothesized signs. Moreover, I not only confirm the co-existence of the three types of investors, but also find evidence of time-varying behavioural heterogeneity within-group. To be more specific, I find that chartists form trend following expectation in the boom periods while take contrarian strategy in the bust periods, and noise traders are much more sensitive to external news in the bust regime than in the boom regime.

In addition, my simulation experiments suggest that the housing price increases (decreases) more drastically with a larger probability of staying in the boom (bust) regime and a stronger bandwagon (contrarian) expectation of chartists. Finally, I carry out a simple out-of-sample prediction exercise and show that the regime switching model exhibits strong predictive power.

The remaining of the chapter is organized as follows. Section 5.2 describes the model. Section 5.3 presents the data and discusses the estimation results. Section 5.4 conducts the simulation experiments. Section 5.5 provides some conclusion remarks.

\subsection{Model Description}

This section develops a simple and stylized heterogeneous agent model with Markov chain regime-dependent beliefs for the U.S. real estate market. The model is based on, among others, the models of Day and Huang (1990), Brock and Hommes (1997, 1998), Chiarella 
et al. (2012) and Huang et al. (2012). Most of the work on HAMs focus on financial markets. However, as housing is also traded as an asset by speculators, as well as being a pure commodity, these models can also be applied to housing markets. The demand for housing is divided into two components, a real component and a speculative component, from three types of speculators, namely fundamentalists, chartists and noise traders. Within the Markov-switching framework, chartists and noise traders are assumed to update their investing behavior based on market conditions.

\subsubsection{Speculators}

Fundamentalists, chartists and noise traders make up the speculative component. Fundamentalists trade on mean-reversion. Following Huang et al. (2012), fundamentalists expect the asset price to converge towards its fundamental price, $p_{t}^{*}$, with a time-varying convergence speed $v_{t}$. They buy in house when the price is below $p_{t}^{*}$ and sell it out when the price is above. Given the housing price $p_{t}$, fundamentalists' demand at period $t, D_{f, t}$ is given by:

$$
D_{f, t}=\alpha_{f} v_{t}\left(p_{t}^{*}-p_{t}\right)
$$

where $\alpha_{f}>0$ is the beliefs parameter of fundamentalists which indicates how strongly the fundamentalists believe in mean-reversion. The larger the value of $\alpha_{f}$, the stronger the belief of mean-reversion the fundamentalists incline to. The convergence speed $v_{t}$ is a nonlinear function of $p_{t}$. Following Day and Huang (1990), $v_{t}$ is given by

$$
v_{t}= \begin{cases}\frac{\left(p_{t}^{*}-p_{t}\right)^{2}}{p_{t}^{* 2}}, & \underline{m} \leq \frac{p_{t}}{p_{t}^{*}} \leq \bar{m} \\ 0, & \frac{p_{t}}{p_{t}^{*}}>\bar{m}, \frac{p_{t}}{p_{t}^{*}}<\underline{m} .\end{cases}
$$

$\frac{p_{t}}{p_{t}^{*}}$ is the price-to-fundamental ratio. $\bar{m}$ is the topping price-to-fundamental ratio and $\underline{m}$ is the bottoming price-to-fundamental ratio. Eq. (5.2) indicates that the more the price deviates from its fundamental price $p_{t}^{*}$, the more quickly it is going to reverse. However, if the price deviates too much from the fundamental price so that the price-to-fundamental ratio is above $\bar{m}$ or below $\underline{m}$, the fundamentalists expect that the probability of meanreversion to be 0 . 
Chartists do not expect the price to converge to $p_{t}^{*}$. Instead, they try to extrapolate observed historical patterns in past housing prices and exploit these patterns in their expectations about future housing prices. Following Huang et al. (2012), they update their price expectations according to the latest price information and estimation bias between the current price and the fundamental price, that is,

$$
E_{c, t}\left(p_{t+1}\right)=p_{t}+\tau_{c, t}\left(p_{t}-p_{t}^{*}\right),
$$

where the parameter $\tau_{c, t} \in(-\infty, 0) \cup(0,+\infty)$. When $\tau_{c, t}>0$, the chartists expect the price trend to persist and hence form the so-called bandwagon expectation. They are like trend followers in HAM literature. On the other hand, when $\tau_{c, t}<0$, the chartists expect the recent past price trend to reverse in the next period and thus demonstrate contrarian expectation. They behave like contrarians (see Chiarella and He, 2002 and Chiarella et al., 2012 for both trend followers and contrarians).

Following the standard literature (De Grauwe, 2008; Uhlig, 2010; Chiarella et al., 2012), I assume two aggregate states, a boom state and a bust state, for the real estate market. The boom state is characterized by a prosperous housing market with increasing price and low volatility, while in the bust state, market is depressed with decreasing price and high volatility. Investors' trading behavior is likely to vary in different regimes. To capture these characteristics, I assume the housing market conditions to follow a two-state Markov regime switching process. $s_{t}$ is the housing market regime and it takes a discrete value of 1 or 2 where $s_{t} \in \varphi=\{1,2\}$. The dynamics of the state is assumed to be a Markov chain on $\varphi$ with transition probabilities given by

$$
P\left(s_{t}=j \mid s_{t-1}=i, s_{t-2}=k, \ldots\right)=P\left(s_{t}=j \mid s_{t-1}=i\right)=P_{j, i}
$$

for $i, j, k \in \varphi$, where $P_{j, i}$ denotes the probability that regime $i$ switches to regime $j$ for $i, j \in\{1,2\}$. The transition probabilities $P_{j, i}$ are constants which satisfy the conditions of $\sum_{j=1}^{2} P_{j, i}=1$ and $0 \leq P_{j, i} \leq 1$ for $i=1,2$. Although the housing market state $s_{t}$ is a random variable that is not directly observable, a filter estimate can be computed from the past price information available. Some filters, for instance sequential filter, are able to perform accurate inferences of $s_{t}$. As a result, it is reasonable to assume that investment 
professionals can estimate the market state with high precision.

Instead of assuming the parameter $\tau_{c, t}$ to be constants as in most HAM literature, I model it to be regime-dependent and allow it to switch between two different states, that is,

$$
\tau_{c, t}=\left\{\begin{array}{cc}
\tau_{c, 1}, & s_{t}=1, \\
\tau_{c, 2}, & s_{t}=2,
\end{array}\right.
$$

where $\tau_{c, 1} \neq \tau_{c, 2}$.

The chartists' excess demand, $D_{c, t}$, is proportional to the expected price change ${ }^{1}$ :

$$
\begin{aligned}
D_{c, t} & =\eta_{c}\left[E_{c, t}\left(p_{t+1}\right)-p_{t}\right] \\
& =\alpha_{c, t}\left(p_{t}-p_{t}^{*}\right)
\end{aligned}
$$

in which parameter $\eta_{c}>0$ measures the extent to which chartists act on their belief and $\alpha_{c, t}=\eta_{c} \tau_{c, t}$ is the beliefs parameter of chartists. As $\alpha_{c, t}$ is proportional to the parameter $\tau_{c, t}$, when chartists expect the price trend to persist and form bandwagon expectation, $\tau_{c, t}>0$, making the belief parameter of chartists $\alpha_{c, t}>0$. On the contrary, when chartists believe in trend reversal and form contrarian expectation, $\tau_{c, t}<0$ and hence the beliefs parameter $\alpha_{c, t}<0 . \alpha_{c, t}$ is a regime-dependent parameter given by

$$
\alpha_{c, t}= \begin{cases}\alpha_{c, 1}, & s_{t}=1, \\ \alpha_{c, 2}, & s_{t}=2,\end{cases}
$$

where $\alpha_{c, 1}=\eta_{c} \tau_{c, 1}$ and $\alpha_{c, 2}=\eta_{c} \tau_{c, 2}$.

The noise traders ${ }^{2}$ do not trade on mean-reversion nor extrapolate the price trend. However, they develop a general understanding of the market condition, for example, from the market report generated by technical analysts, stockbrokers, or economic consultants. The demand of noise traders in period $t, D_{n, t}$, is an independent and identically distributed normal random variable which follows $N\left(0, \sigma_{n, t}^{2}\right)$ distribution. The variance

\footnotetext{
${ }^{1}$ See for example Huang et al. (2012) and Chiarella et al. (2012) among many others.

${ }^{2}$ We include the noise traders because we do not know whether they exist in our sample or not. Moreover, if we do not add noise traders, the model would become a deterministic dynamic model which is less suitable for empirical regression.
} 
$\sigma_{n, t}^{2}$ is regime-dependent. As such, the demand of noise traders $D_{n, t}$ is given by

$$
D_{n, t} \sim \begin{cases}N\left(0, \sigma_{n, 1}^{2}\right), & s_{t}=1, \\ N\left(0, \sigma_{n, 2}^{2}\right), & s_{t}=2,\end{cases}
$$

where $\sigma_{n, 1}^{2} \neq \sigma_{n, 2}^{2}$.

\subsubsection{Consumers and Suppliers}

When using the HAM model to evaluate financial assets, it is sufficient to only include investors. But real estate market is distinguished from financial market in several aspects. First, apart from demanding houses for investment, people also buy houses for living purposes. As a result, it is more appropriate to distinguish the investment component from the consumption component. In addition, the supply side of the market can influence the price formation process. Therefore, I add both a real demand and a supply components to the model.

The real demand for housing is made up of an exogenous component, which is not related to the home price, and an endogenous part which is a negative function of the price of housing. Real demand, $D_{r, t}$, can therefore be given by the simple linear demand function of $p_{t}$, that is,

$$
D_{r, t}=a^{D}-b^{D} p_{t},
$$

where $a^{D}$ represents the exogenous demand for housing and $b^{D}>0$ is a reaction parameter of real demanders.

Similarly, the supply of housing, $S_{r, t}$, is assumed to be a linear function of the housing price:

$$
S_{r, t}=a^{S}+b^{S} p_{t}
$$

where $a^{S}$ denotes the exogenous supply for housing and $b^{S}>0$ represents the price sensitivity of supply. 


\subsubsection{Market Structure}

Total market demand for housing, $D_{m, t}$, consists of the real demand, $D_{r, t}$, plus the speculative demand, $D_{s, t}$.

$$
D_{m, t}=D_{s, t}+D_{r, t}
$$

The demand of speculators, $D_{s, t}$, is the weighted average of the demand of fundamentalists, chartists, and noise traders. $D_{s, t}$ is given by

$$
D_{s, t}=\omega_{f} D_{f, t}+\omega_{c} D_{c, t}+\omega_{n} D_{n, t},
$$

where $\omega_{f}, \omega_{c}$ and $\omega_{n}$ are the fractions (or the market weights) of fundamentalists, chartists and noise traders.

Price change, finally, is a function of excess demand:

$$
p_{t+1}-p_{t}=\gamma\left[D_{m, t}-S_{r, t}\right]
$$

in which $\gamma>0$ is a price adjustment parameter governing the price adjustment speed in the market.

Substitute eqs. (5.1), (5.7) and (5.9) - (5.13) into eq. (5.14), the price impact function can be rewritten as

$$
\begin{aligned}
p_{t+1}-p_{t}= & \gamma\left[\omega_{f} D_{f, t}+\omega_{c} D_{c, t}+\omega_{n} D_{n, t}+D_{r, t}-S_{r, t}\right] \\
= & \gamma \omega_{f} \alpha_{f} v_{t}\left(p_{t}^{*}-p_{t}\right)+\gamma \omega_{c} \alpha_{c, t}\left(p_{t}-p_{t}^{*}\right)+\gamma\left(a^{D}-a^{S}\right) \\
& -\gamma\left(b^{D}+b^{S}\right) p_{t}+\gamma \omega_{n} D_{n, t} \\
= & \beta_{f} v_{t}\left(p_{t}^{*}-p_{t}\right)+\beta_{c, t}\left(p_{t}-p_{t}^{*}\right)+a+b p_{t}+\varepsilon_{t},
\end{aligned}
$$

where $\beta_{f}=\gamma \omega_{f} \alpha_{f}, \beta_{c, t}=\gamma \omega_{c} \alpha_{c, t}, a=\gamma\left(a^{D}-a^{S}\right), b=-\gamma\left(b^{D}+b^{S}\right)$ and $\varepsilon_{t}=\gamma \omega_{n} D_{n, t}$. $\beta_{c, t}$ is proportional to the beliefs parameter of chartists, $\alpha_{c, t}$. So $\beta_{c, t}>0$ when the chartists form bandwagon expectation and $\beta_{c, t}<0$ when the chartists believe in trend 
reversal. The scaled beliefs parameter of chartists, $\beta_{c, t}$, is regime-dependent given by

$$
\beta_{c, t}= \begin{cases}\beta_{c, 1}, & s_{t}=1, \\ \beta_{c, 2}, & s_{t}=2\end{cases}
$$

in which $\beta_{c, 1}=\gamma \omega_{c} \alpha_{c, 1}$ and $\beta_{c, 2}=\gamma \omega_{c} \alpha_{c, 2}$.

In addition, the distribution of $\varepsilon_{t}$ follows directly from eq. (5.9), namely

$$
\varepsilon_{t} \sim \begin{cases}N\left(0, \sigma_{1}^{2}\right), & s_{t}=1, \\ N\left(0, \sigma_{2}^{2}\right), & s_{t}=2,\end{cases}
$$

where $\sigma_{1}^{2}=\gamma \omega_{n} \sigma_{n, 1}^{2}$ and $\sigma_{2}^{2}=\gamma \omega_{n} \sigma_{n, 2}^{2}$.

\subsection{Estimation}

\subsubsection{Data}

I estimate the two-state Markov regime switching HAM using quarterly FHFA house price index ${ }^{3}$ from 1975Q1 to 2015Q1. I obtain this series from Federal Housing Finance Agency, which reports the home price index in the United States every quarter since Mar 1975. Year 1980 is used as the base year for the nominal housing price index. I then derive the real housing price by dividing the nominal house price by the urban consumer price index which is obtained from International Monetary Fund (IMF). The data used in the estimation is seasonally adjusted to remove fluctuations that normally occur at about the same time and the same magnitude each year. Figure 5.1 plots the time series of the real housing price index, $p_{t}$, in the United States from 1975Q1 to 2015Q1.

The true fundamental price of housing is inherently unknown. The fundamental price used in the model is actually the fundamental price regarded by the participants in the market. In contrast to the past literature where $p_{t}^{*}$ is assumed to be constant over time or proportional to personal income or rent, I allow the fundamental housing price $p_{t}^{*}$ in

\footnotetext{
${ }^{3}$ The estimation results are qualitively robust if we use other housing price index, for instance, the $\mathrm{S} \& \mathrm{P} /$ Case-Shiller 20-City composite home price index.
} 


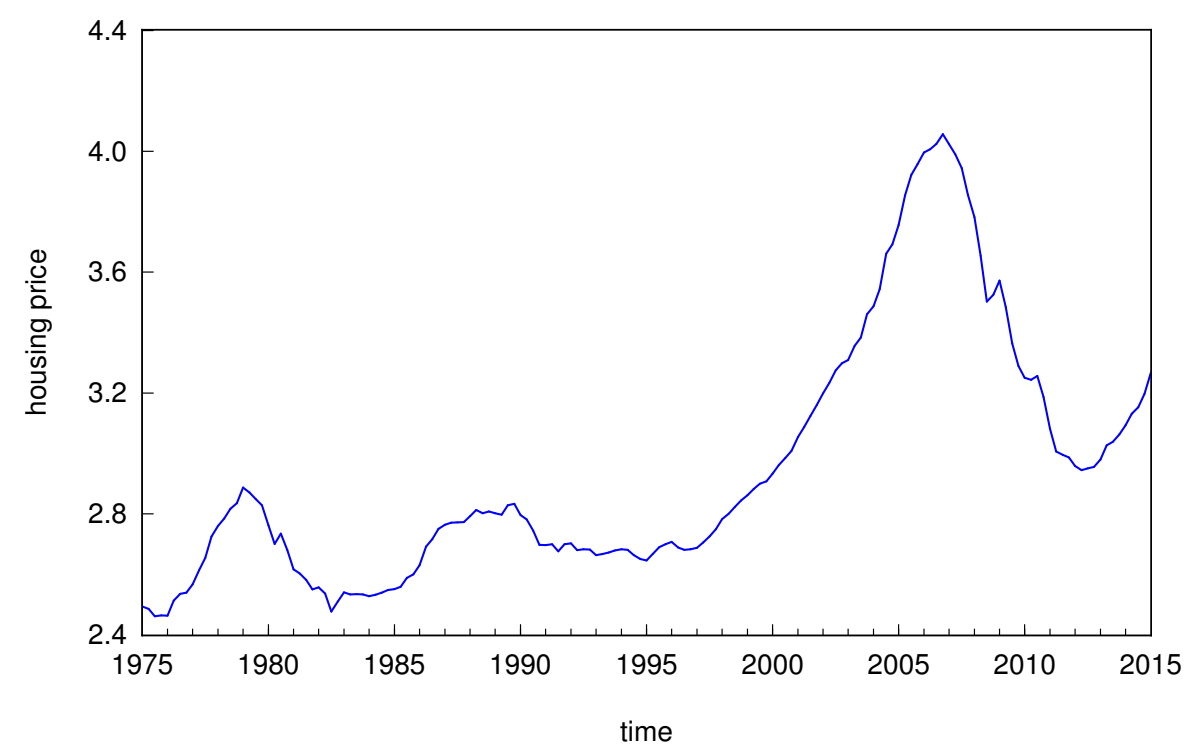

Figure 5.1: Housing price index in the US from 1975Q1 to 2015Q1

the model to fluctuate with a deterministic business cycle and the long term average to increase over time, which is given by

$$
p_{t}^{*}=A \sin (\omega t)+c+\zeta t .
$$

where $A$ and $\omega$ are parameters that guarantee the shape of the business cycle, $c$ is the fundamental price at period 0 , and $\zeta$ determines the increasing speed of the average fundamental price. This is essentially a generalized version of the business cycle fundamental price function in Huang and Zheng (2012).

During Mar 1975 to Mar 2015, the housing market experiences about three boom-bust business cycles, so the average period of cycles $T=\frac{161}{3}$. As $\omega$ is the parameter determining the period, $\omega=\frac{2 \pi}{T} \approx 0.1164$. To calibrate the parameter $c$ and $\zeta$, I make two assumptions. First, the average housing price would be converging towards the average fundamental price in the long run. The recent recovery since 2012 makes the housing price to approach the fundamental benchmark at the end of the sample period, Mar 2015. Then, I can calculate the parameter $c=2.6078$ and $\zeta=0.0042$. For analytical tractability, I assume $A=0.1$, and the estimation results are qualitively robust if I choose a different value of 
A.

Table 5.1 reports the summary statistics of the real housing price index, $p_{t}$, and the fundamental housing price, $p_{t}^{*}$.

Table 5.1: Summary statistics

\begin{tabular}{lrrrr}
\hline Variable & Mean & Std. dev. & Min & Max \\
\hline FHFA housing price index & 207.9823 & 96.2720 & 60.0508 & 378.2334 \\
CPI & 68.2693 & 24.7434 & 24.0420 & 109.1700 \\
Real housing price index, $p_{t}$ & 2.9437 & 0.4091 & 2.4615 & 4.0565 \\
Fundamental housing price, $p_{t}^{*}$ & 2.9458 & 0.1888 & 2.6236 & 3.2680 \\
\hline
\end{tabular}

Notes: Sample period is from 1975Q1 to 2015Q. $N=161$.

Finally, I calculate the topping price-to-fundamental ratio $\bar{m}$ and bottoming price-tofundamental ratio $\underline{m}$ in eq. (5.2). It is reasonable to assume $\bar{m}$ to be the maximum of the price-to-fundamental ratio, and $\underline{m}$ to be the minimum of the price-to-fundamental ratio. So I can calibrate $\bar{m}=1.2619$ and $\underline{m}=0.8898$, and the converging speed $v_{t}$ in eq. (5.2) is given by

$$
v_{t}= \begin{cases}\frac{\left(p_{t}^{*}-p_{t}\right)^{2}}{p_{t}^{* 2}}, & 0.8898 \leq \frac{p_{t}}{p_{t}^{*}} \leq 1.2619 \\ 0, & \frac{p_{t}}{p_{t}^{*}}>1.2619, \frac{p_{t}}{p_{t}^{*}}<0.8898\end{cases}
$$

\subsubsection{Maximum Likelihood}

I estimate the Markov regime switching HAM defined by eqs. (5.17) - (5.19) using maximum likelihood (Hamilton, 1994, Chap. 22). I assume that $y_{t}=p_{t+1}-p_{t}, X_{t}=p_{t}-p_{t}^{*}$, $Z_{t}^{\prime}=\left[\begin{array}{lll}v_{t}\left(p_{t}^{*}-p_{t}\right) & 1 & p_{t}\end{array}\right]$ and $\gamma^{\prime}=\left[\begin{array}{lll}\beta_{f} & a & b\end{array}\right]$. Suppose that we are said to be in state or regime $\varrho$ in period $t$ when $s_{t}=\varrho$, for $\varrho=1$ and 2 , and $\beta_{c, \varrho}=\beta_{c, t}$. The conditional mean of $y_{t}$ in regime $\varrho$ is assumed to be the linear specification

$$
\mu_{t}(\varrho)=X_{t}^{\prime} \beta_{c, \varrho}+Z_{t}^{\prime} \gamma
$$

Lastly, I assume that $\sigma_{\varrho} \epsilon_{t}=\gamma \omega_{n} D_{n, t}$, where $\epsilon_{t}$ is $i . i . d$. standard normally distributed. Note that the standard deviation $\sigma$ may be regime dependent, $\sigma(\varrho)=\sigma \varrho$.Then I have the model: 


$$
y_{t}=\mu_{t}(\varrho)+\sigma(\varrho) \epsilon_{t}
$$

The likelihood contribution for a given observation may be formed by weighting the density function in each of the regimes by the one-step ahead probability of being in that regime:

$$
L_{t}\left(\beta_{c}, \gamma, \sigma, \delta\right)=\sum_{\varrho=1}^{2} \frac{1}{\sigma_{\varrho}} \phi\left(\frac{y_{t}-\mu_{t}(\varrho)}{\sigma_{\varrho}}\right) \cdot P\left(s_{t}=\varrho \mid \Im_{t-1}, \delta\right)
$$

$\beta_{c}=\left(\beta_{c, 1}, \beta_{c, 2}\right), \sigma=\left(\sigma_{1}, \sigma_{2}\right), \delta$ are parameters that determine the regime probabilities, $\phi(\cdot)$ is the standard normal density function, and $\Im_{t-1}$ is the information set in period $t-1$. In the simplest case, the $\delta$ represent the regime probabilities themselves. The full log-likelihood is a normal mixture

$$
l\left(\beta_{c}, \gamma, \sigma, \delta\right)=\sum_{t=1}^{T} \log \left\{\sum_{\varrho=1}^{2} \frac{1}{\sigma_{\varrho}} \phi\left(\frac{y_{t}-\mu_{t}(\varrho)}{\sigma_{\varrho}}\right) \cdot P\left(s_{t}=\varrho \mid \Im_{t-1}, \delta\right)\right\}
$$

which may be maximized with respect to $\left(\beta_{c}, \gamma, \sigma, \delta\right)$.

\section{Markov Switching}

To this point, I have treated the regime probabilities $P\left(s_{t}=\varrho \mid \Im_{t-1}, \delta\right)$ in an abstract fashion. Next I consider a Markov regime switching model by specifying a first-order Markov process for the regime probabilities ${ }^{4}$.

The first-order Markov assumption requires that the probability of being in a regime depends on the previous state, so that

$$
P\left(s_{t}=j \mid s_{t-1}=i\right)=P_{j, i}(t)
$$

In my model, these probabilities are assumed to be time-invariant so that $P_{j, i}(t)=P_{j, i}$ for all $t$, but this restriction is not required in general.

\footnotetext{
${ }^{4}$ It should be emphasized that the following discussion is valid only for speci cations with uncorrelated errors.
} 
I may write these probabilities in a transition matrix

$$
P(t)=\left[\begin{array}{ll}
P_{1,1}(t) & P_{2,1}(t) \\
P_{1,2}(t) & P_{2,2}(t)
\end{array}\right]
$$

where the $i j$-th element represents the probability of transitioning from regime $i$ in period $t-1$ to regime $j$ in period $t$.

Assume $G_{t-1}$ is a vector of exogenous observables. Following Hamilton (1994, Chap. $22), P_{j, i}(t)$ is assumed to be a function of vectors of exogenous observables, $G_{t-1}$, and coefficients $\delta$ using a multinomial logit specification:

$$
P\left(s_{t}=j \mid s_{t-1}=i\right)=p_{i j}\left(G_{t-1}, \delta_{i}\right)=\frac{\exp \left(G_{t-1}^{\prime} \delta_{i j}\right)}{\sum_{s=1}^{2} \exp \left(G_{t-1}^{\prime} \delta_{i s}\right)}
$$

for $j=1$ and 2 and $i=1$ and 2 with the normalizations $\delta_{i 2}=0$. As mentioned previously, my Markov switching model is specified with constant probabilities so that $G_{t-1}$ contains only a constant.

Next, I evaluate the expressions on the right-hand side of eq. (5.25) recursively. Briefly, given filtered probabilities, $P\left(s_{t-1}=\varrho \mid \Im_{t-1}\right)$, the recursion may broken down into three steps:

1. Firstly, form the one-step ahead predictions of the regime probabilities using basic rules of probability and the Markov transition matrix:

$$
\begin{aligned}
P\left(s_{t}=\varrho \mid \Im_{t-1}\right) & =\sum_{j=1}^{2} P\left(s_{t}=\varrho \mid s_{t-1}=j\right) \cdot P\left(s_{t-1}=\varrho \mid \Im_{t-1}\right) \\
& =\sum_{j=1}^{2} p_{j \varrho}\left(G_{t-1}, \delta_{j}\right) \cdot P\left(s_{t-1}=\varrho \mid \Im_{t-1}\right)
\end{aligned}
$$

2. Then, use these one-step ahead probabilities to form the one-step ahead joint densities of the data and regimes in period $t$ :

$$
f\left(y_{t}, s_{t}=\varrho \mid \Im_{t-1}\right)=\frac{1}{\sigma_{\varrho}} \phi\left(\frac{y_{t}-\mu_{t}(\varrho)}{\sigma_{\varrho}}\right) \cdot P\left(s_{t}=\varrho \mid \Im_{t-1}\right)
$$


3. The likelihood contribution for period $t$ is obtained by summing the joint probabilities across unobserved states to obtain the marginal distribution of the observed data

$$
L_{t}\left(\beta_{c}, \gamma, \sigma, \delta\right)=f\left(y_{t} \mid \Im_{t-1}\right)=\sum_{j=1}^{2} f\left(y_{t}, s_{t}=j \mid \Im_{t-1}\right)
$$

4. The final step is to filter the probabilities by using the results in eq. (5.30) to update one-step ahead predictions of the probabilities:

$$
P\left(s_{t}=\varrho \mid \Im_{t}\right)=\frac{f\left(y_{t}, s_{t}=\varrho \mid \Im_{t-1}\right)}{\sum_{j=1}^{2} f\left(y_{t}, s_{t}=j \mid \Im_{t-1}\right)}
$$

These steps are repeated successively for each period, $t=1, \ldots, T$. All that required for implementation are the initial filtered probabilities, $P\left(s_{0}=\varrho \mid \Im_{0}\right)$, or alternately, the initial one-step ahead regime probabilities $P\left(s_{1}=\varrho \mid \Im_{0}\right)$.

The likelihood obtained by summing the terms in eq. (5.31) may be maximized with respect to the parameters $\left(\beta_{c}, \gamma, \sigma, \delta\right)$ using iterative methods. Coefficient covariances may be estimated using standard approaches.

\subsubsection{Estimation Results}

The estimation results are summarized in Table 5.2. Regime 1 denotes the boom state and Regime 2 is the bust state. As mentioned previously, while the housing price during Regime 1 (boom state) is increasing with relatively low volatility, the housing price during regime 2 (bust state) is decreasing with relatively high volatility.

Generally, it can be seen that the real demand and supply for housing keep each other in balance. $a$ and $b$ are not significant. The real demand and supply cancel each other out in the regression equation.

The speculative fundamentalists, chartists, and noise traders, on the other hand, do show highly significant coefficients of the hypothesized signs, suggesting the co-existence of the three types of investors with different beliefs in the housing market. Furthermore, these results provide evidence of within-group heterogeneity over time. To be more specific, the 
Table 5.2: Estimates for the regime switching HAM, 1975Q1-2015Q1

\begin{tabular}{lcc}
\hline Coefficient & Regime 1 (boom state) & Regime 2 (bust state) \\
\hline Chartists' beliefs param., $\beta_{c, \varrho}$ & $0.0825(0.0015)^{* * *}$ & $-0.1279(0.0212)^{* *}$ \\
Std. dev., $\sigma_{\varrho}$ & $0.0215(0.0000)^{* * *}$ & $0.0652(0.0000)^{* * *}$ \\
Fundamentalists' beliefs param., $\beta_{f}$ & $2.1557(0.0000)^{* * *}$ \\
Real excess demand param., $a$ & $-0.0428(0.3800)$ \\
Real excess demand param., $b$ & $0.0225(0.1637)$ \\
Probability, $P_{1,1}$ & $0.9811(0.0000)^{* * *}$ \\
Probability, $P_{1,2}$ & $0.0863(0.0018)^{* * *}$ \\
\hline
\end{tabular}

Notes:

(1) $* * *$ and $* * *$ denote significance at $10 \%, 5 \%$ and $1 \%$, respectively.

(2) Numbers in the parentheses are $p$-values.

scaled beliefs parameter of chartists, $\beta_{c, 1}>0$, in the boom state and the scaled beliefs parameter $\beta_{c, 2}<0$ in the bust state. This means that during the boom regime, most of the chartists are trend followers, believing that the housing price is likely to deviate further from the fundamental housing price. On the other hand, when the housing market is at its bust regime, majority of them become contrarians who expect the past price trend to reverse. The agents behave more like trend followers during the boom, because the price change is proportional to the excess demand. In the boom state, the excess demand is positive, however, fundamentalists demand is negative. So chartists demand is more likely to be positive. So chartists behave more like trend followers. On the other hand, when the housing market is at its bust regime, contrarian expectations tend to dominate. It implies that, in the bust period when the housing price is declining, if the current housing price is above the fundamental housing price, most chartists believe that the market price will be below the fundamental housing price. These results are consistent with Chia et al. (2016) which nd that contrarian expectations tend to dominate in the bust state while the trend following expectations are more overwhelmed in the boom state. These results show the existence of behavioural heterogeneity within the chartist group.

In addition, the standard deviation of noise traders is found to be $\sigma_{1}=0.0215$ in the boom regime and $\sigma_{2}=0.0652$ in the bust regime, respectively. Note that the variance in the boom state $\sigma_{1}^{2}$ is much smaller than that in the bust state $\sigma_{2}^{2}$, suggesting that noise traders are less sensitive to external news in the boom state than in the bust state. These results are in line with our assumption that the price is increasing with low volatility in 
the boom state, while market is depressed with declining price and high volatility in the bust state. Like the chartists, the different behaviour of the noise traders in different states provides evidence of time-varying behavioural heterogeneity within-group.

Moreover, the scaled beliefs parameter of fundamentalists $\beta_{f}>0$. It is in line with our model assumption that fundamentalists buy in house when the price is below the fundamental price and sell it out when price is above.

Finally, the results in Table 5.2 show that the probability of remaining in the boom regime (state 1$)$ is $0.9811\left(P_{1,1}\right)$. Given the two states identified, this also means that the probability for the market to switch from state 1 to 2 is $0.0189\left(P_{2,1}\right)$. Similarly, the probability to switch from the bust to the boom state is $0.0863\left(P_{1,2}\right)$, indicating that the probability of remaining in the bust regime (state 2$)$ is $0.9137\left(P_{2,2}\right)$.

Overall, I find statistically significant results on the regime-dependence of $\beta_{c, \varrho}$ and $\sigma \varrho$, which indicate the existence of time-varying within-group heterogeneity. Chartists switch between the bandwagon expectations and the contrarian expectations according to the market conditions and noise traders adjust their degree of reaction with a time-varying probability.

\section{Classified Boom and Bust Regimes}

With the estimates of the transition probabilities $P_{1,1}$ and $P_{1,2}$, I can further calculate the smoothed probability for the housing market state $s_{t}$ to fall into the two states, $P\left(s_{t}=j \mid p_{1}, \ldots, p_{N}\right)$, for each period, conditioning on the whole price series $\left\{p_{1}, \ldots, p_{N}\right\}$ (for details of the algorithm, see Kim and Nelson, 1999). Then, I can classify the sample periods into the boom and the bust states according to the regime switching probability. The results in this section suggest that the classified regimes match well with the market booms and busts in the actual episodes.

Figure 5.2 shows the smoothed probability for the housing market state $s_{t}$ to fall into the boom regime (upper panel) and the bust regime (lower panel) over the sample period of 1975Q1 to 2015Q1. I can classify the sample periods according to the regime switching probability. To be more specific, the boom periods corresponding to Regime 1 cover the 
1975Q1-1979Q1, the 1983Q3-2007Q2 and the recent recovery since the end of 2011. The bust periods corresponding to Regime 2 include the time from 1979Q2 to 1983Q2 and 2007Q3 to 2011Q3.
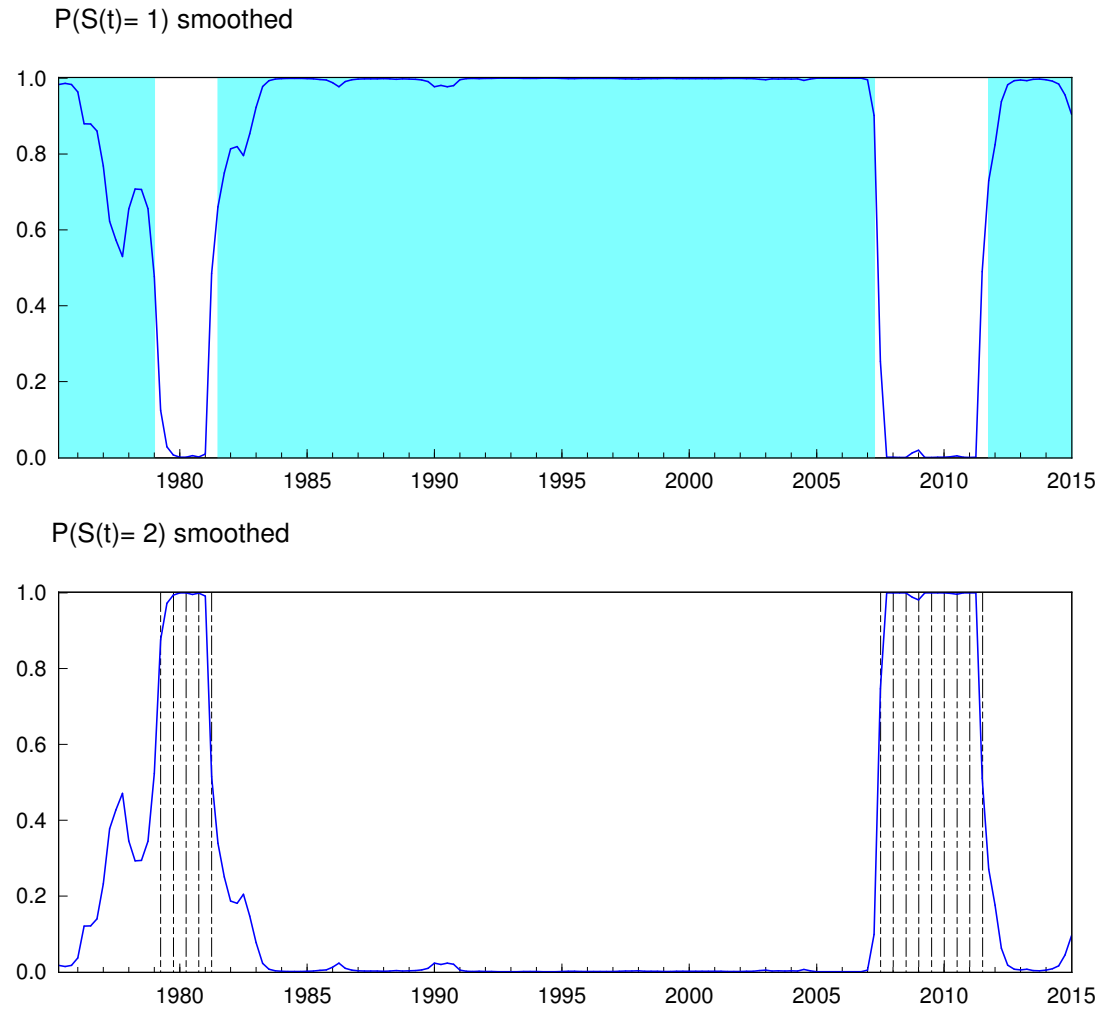

Figure 5.2: Smoothed transition probability

Although the dates of domestic economic instabilities and housing crises are not used in any way to estimate the parameters or the transition probabilities, the classified regimes match well with the market booms and busts in the actual episodes. Figure 5.3 shows the time series of the real housing prices in the U.S. from 1975Q1 to 2015Q1. The shaded areas are the periods classified as Regime 1 (boom state) by the smoothed regime switching probability. The boom periods include the time from the 1980s to early 2007, when the real estate market was prospering. The bust periods corresponding cover the latest episode of housing crisis and the subprime mortgage and credit crisis in 2007. Recently, after the housing market hits the bottom around 2012, investors became optimistic with the housing market recovery and switched their estimates from Regime 2 to Regime 1. 


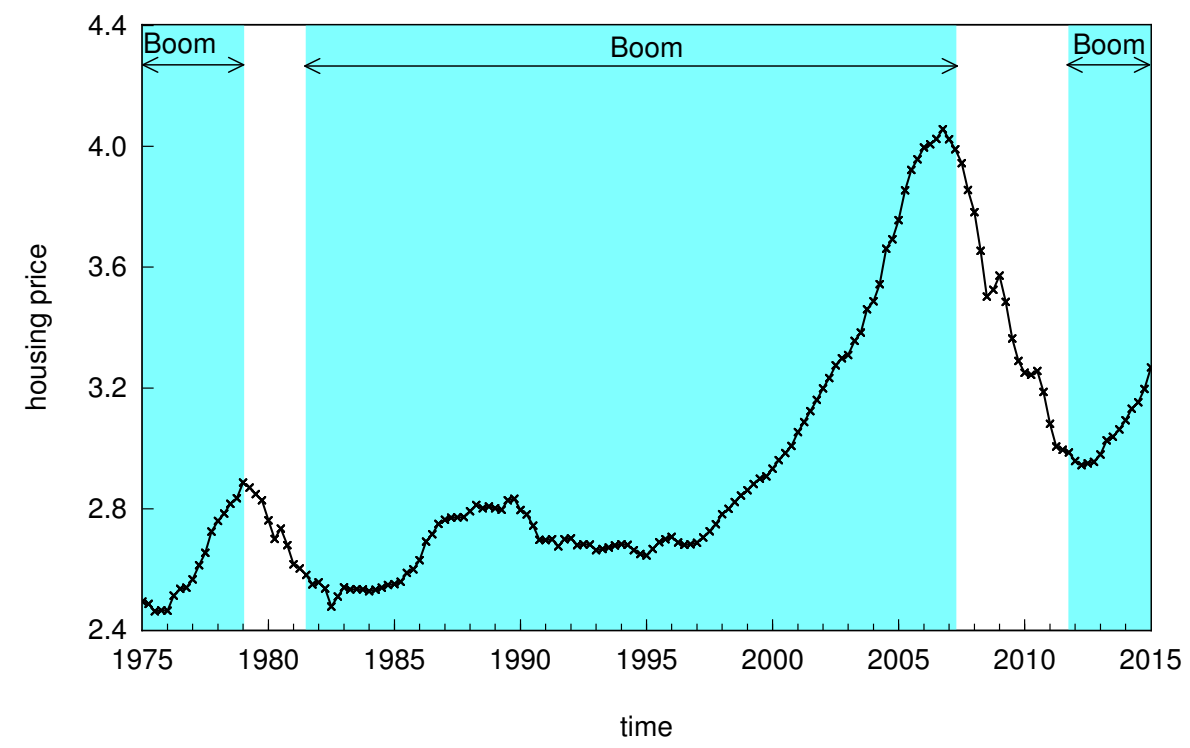

Figure 5.3: Housing price index and classified boom regimes

Figure 5.3 shows that, during the sample period of 1975Q1-2015Q1, the average duration to remain in the bust regime is much shorter than the average duration to stay in the boom regime. However, given the incomplete episodes at the beginning and at the end of the sample, it does not necessarily mean that tranquil episodes are always more persistent than turbulent episodes in the U.S. housing market.

\subsection{Empirical Implications}

I discuss empirical implications of the estimation of our Markov regime switching model with heterogeneous beliefs. Firstly, I conduct some simulation experiments to identify key factors that determine the increasing (decreasing) speed of housing prices. Secondly, I address the question concerning the out-of-sample predictive power of the regime switching model. These simulation experiments are related and both show the importance of considering regime switching in the real estate market. 


\subsubsection{Factors Affecting the Average Increasing (Decreasing) Speed}

In this section, I investigate how some of these key factors affecting the average increasing (decreasing) speed of housing prices using simulation experiments. I deem the key factors to be the probability of remaining in the boom regime (bust regime), $P_{1,1}\left(P_{2,2}\right)$, the beliefs parameter of chartists in the boom regime, $\beta_{c, 1}$, and the beliefs parameter of chartists in the bust regime, $\beta_{c, 2}{ }^{5}$. In the identification process, I simulate the dynamics of the housing prices, $p_{t}$, in a general Markov switching model to gauge the impact of each of these key parameters in the model independently, with the parameters set to be the same as the estimation results shown in Table 5.2 ${ }^{6}$. I use the MS_Regress package written for simulation of a general MS model in Perlin $(2015)^{7}$.

Figure 5.4 indicates the simulated housing prices as the probability of remaining in the boom regime, $P_{1,1}$, remains the original value, drops by $2 \%$ and $4 \%$. When $P_{1,1}$ equals the original value, 0.9811 , the simulated housing price is indicated by the dash-dot line. When $P_{1,1}$ is declined by $2 \%$, the housing price movement exhibits a slower ascending trends (the dash line). The asset price trend demonstrates even flatter slope when the probability of remaining in the boom regime $P_{1,1}$ downgrades to $96 \%$ of the original value (the solid line). This finding is indeed intuitive. When the probability of remaining in the boom state is larger, the average duration to remain in the boom regime will become longer, hence the housing price dynamics will exhibit a more drastic rising trend. Similarly, a larger probability of staying in the bust regime, $P_{2,2}$, results in a longer average duration to remain in the bust periods and a sharper drop in the housing prices. Because their influence on the price movement is qualitively symmetrical, I do not show the effects of $P_{2,2}$ on the housing price dynamics.

Figure 5.5 shows the effects of the beliefs parameter of the chartists in the boom regime, $\beta_{c, 1}$, on the housing price dynamics. Recall from the estimation results that the beliefs parameter of chartists in the boom regime is positive, suggesting that they take trend

\footnotetext{
${ }^{5}$ I do not include $\sigma_{1}^{2}$ and $\sigma_{2}^{2}$ because our simulation experiments show that the variance of noise traders alone cannot affect the average increasing (decreasing) speed of the housing prices.

${ }^{6}$ The set of parameters are $\beta_{c, 1}=0.0825, \beta_{c, 2}=-0.1279, \sigma_{c, 1}=0.0215, \sigma_{c, 2}=0.0652, \beta_{f}=2.1557$, $P_{1,1}=0.9811, P_{1,2}=0.0863, p_{0}=0$.

${ }^{7}$ The independent variables used in the simulation in the MS_Regress package in Perlin (2015) are always random normal, with user defined mean. Without loss of generality, I set the mean of the independent variables to be 0 and 1, respectively. Simulation results are qualitatively robust to the choice of the mean of independent variables.
} 


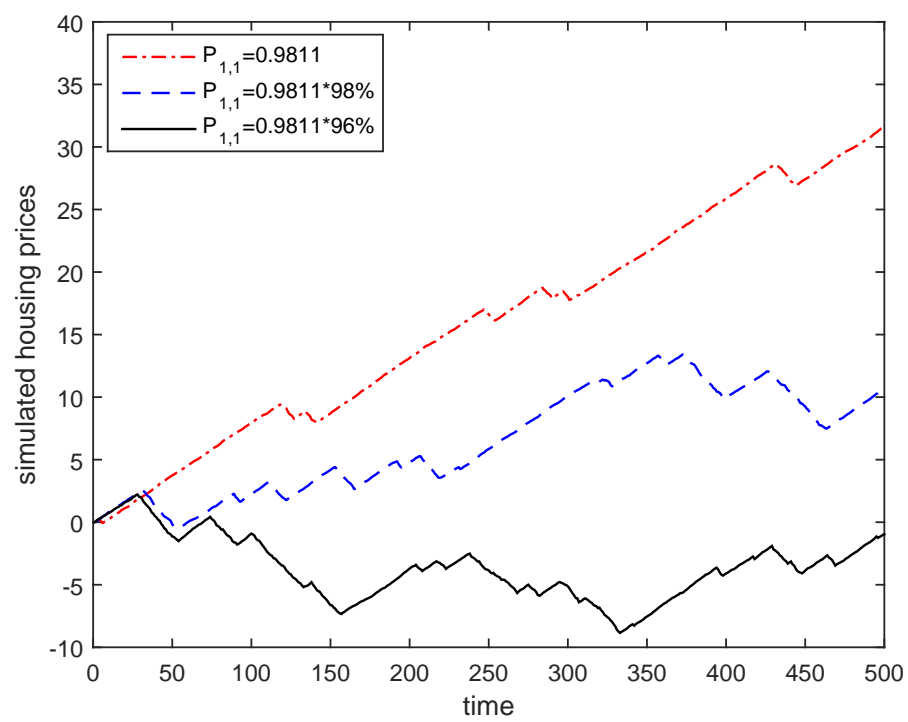

Figure 5.4: The effects of the transition probability, $P_{1,1}$, on the housing price dynamics

following strategy. The dash-dot line shows the simulated time series of the housing prices when the beliefs parameter $\beta_{c, 1}$ is 0.0825 . A 2 -time increase in $\beta_{c, 1}$ will immediately make the price trend to exhibit a more sharper increasing trend (the dash line). Furthermore, a 3 -time increase in $\beta_{c, 1}$ results in an even more sharper increase in price trend (the solid line). The simulation results imply that the housing price increases more quickly if the chartists in the boom regime hold a stronger belief in trend. In other words, the stronger the beliefs parameter of the chartists in the boom regime, the steeper the increase in the housing price.

Figure 5.6 plots the effects of the beliefs parameter of the chartists in the bust regime, $\beta_{c, 2}$, on the housing price movement. The estimation results show that the beliefs parameter of chartists in the bust regime is negative and they hold the contrarian expectations. The dash-dot line plots the simulated housing price dynamics when the beliefs parameter, $\beta_{c, 2}$, is -0.1279. A 2 times increase in $\beta_{c, 2}$ immediately offers a decreasing price trend indicated by the dash line. When $\beta_{c, 2}$ is increased by 3 times, the housing price is found to decline more drastically. The simulation experiments suggest that the housing price exhibits a steeper decreasing trend when the chartists in the bust regime hold a stronger expectation that the past price trend is to reverse. 


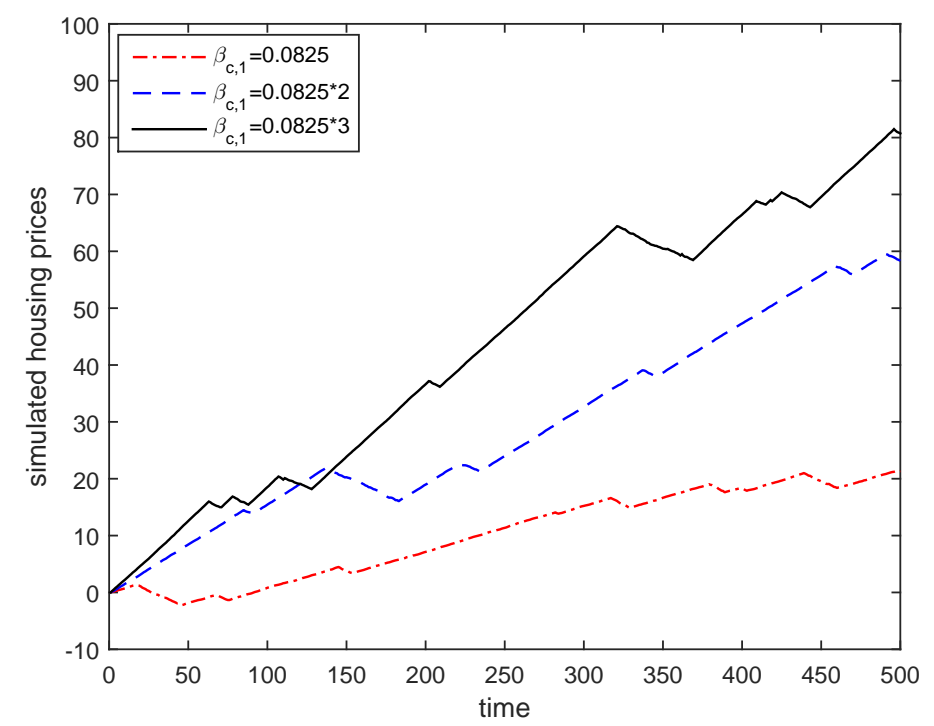

Figure 5.5: The effects of the chartists' beliefs parameter in the boom regime, $\beta_{c, 1}$, on the housing price dynamics

Overall, the housing price increases (decreases) more drastically with a larger probability of staying in the boom (bust) regime and a stronger bandwagon (contrarian) expectation of chartists.

\subsection{Conclusion}

I build a heterogeneous agent model (HAM) with Markov chain regime-dependent beliefs for the U.S. real estate market. In the case of real estate market, apart from demanding houses for investment, people also buy houses for living purposes. As such, I divide the demand for housing in a speculative component and a real component, with the real component contains real demand and supply, and the speculative component consists of three heterogeneous groups: fundamentalists, chartists and noise traders. Fundamentalists believe in mean-reversion, chartists use either the trend following strategy or the contrarians strategy and noise traders' demand follows a normal distribution. Within the Markov-switching framework, the beliefs of chartists and noise traders are modeled to be regime-dependent.

I then estimate the model using quarterly FHFA housing price index from 1975Q1 to 


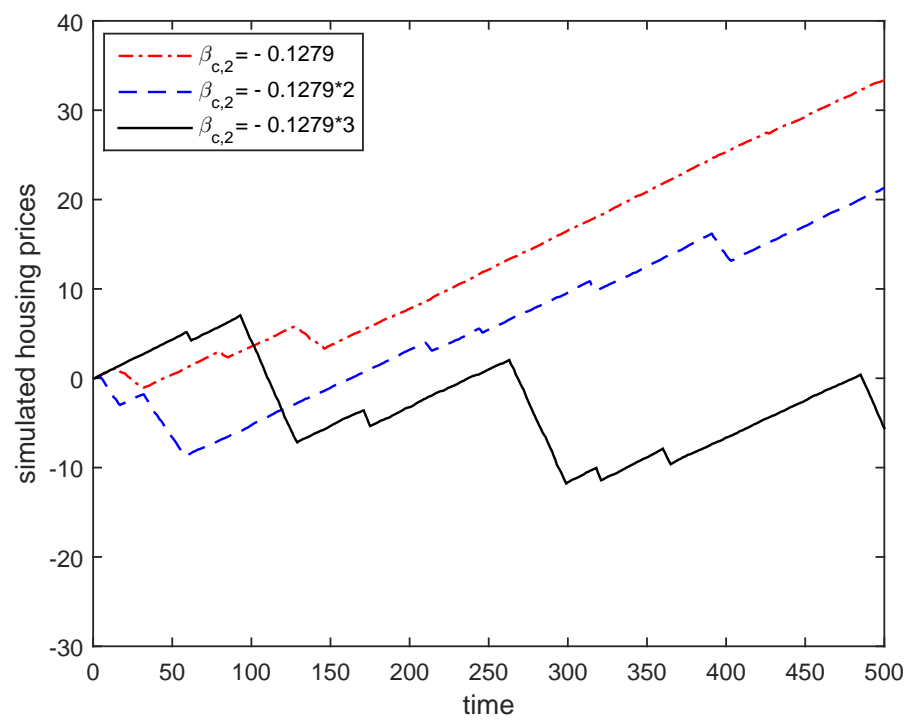

Figure 5.6: The effects of the chartists' beliefs parameter in the bust regime, $\beta_{c, 2}$, on the housing price dynamics

2015Q1 in the U.S. real estate market. Our estimation classifies the sample periods into two regimes, namely a boom regime and a bust regime, which match well the crisis and boom periods in real episodes. In addition, I not only confirm the co-existence of the three groups of investors, but also find within-group heterogeneity in the housing market. To be more specific, chartists switch between the bandwagon expectations and the contrarian expectations according to the market condition, and noise traders adjust their degree of reaction with a time-varying probability. Moreover, my simulation experiments show that a larger probability of staying in the boom (bust) regime, and a stronger bandwagon (contrarian) expectation of chartists could lead to the housing price to increase (decline) more rapidly. 


\section{Chapter 6}

\section{Conclusion and Future Work}

It is important to have a good understanding of bubbles in real estate markets, because the bursting of housing price bubbles could lead to not only financial instability and even financial crises, but also a severe negative impact on GDP and consumption. This thesis analyzes housing price bubbles in the U.S. real estate market using three different heterogeneous agent models (HAMs).

Using Freddie Mac housing price index from the United States, I classify the dynamics of housing prices on its rising trend into two patterns: an exponential pattern and a linear pattern. In an exponential bubble, housing prices were relatively stable through most of the 1990s and then, they began a rapid increase until it collapsed in the mid of 2006. On the contrary, a linear trend is a housing price trend that increases slowly in a linear pattern before it collapses in the mid-2006.

In order to examine whether the two housing price patterns can be formed in the absence of any external shocks, I then proceed to construct a HAM that consists of fundamentalists, chartists and naive agents to explore whether the interaction of agents with different beliefs could affect the dynamics of the housing prices and subsequently the formation of exponential bubbles and linear trends. Fundamentalists trade on mean-reversion, trend followers expect the observed historical price patterns to persist, and naive agents adopt naive expectations to forecast future prices. Agents switch between each other based on relative recent past performances. Nonlinear least squares (NLLS) is conducted to 
estimate the parameters of the model.

The estimated parameters confirm the existence of the behavioural heterogeneity in the U.S. housing market. Moreover, they suggest that interactions between heterogeneous agents can explain how exponential bubbles and linear trends were fueled up. In particular, exponential bubbles could be driven by the activation of trend followers while a linear growth in housing prices could be explained by constant fractions of fundamentalists, trend followers and naive agents. In addition, my simulation experiment suggests that an exponential bubble is more likely to occur when we have more frequent transition between trading strategies, stronger belief in the housing trend and smaller gross return on risk-free asset relative to houses.

Most studies in previous literature only discusses either the formation of housing price bubbles or the collapse of them separately. Chapter 4 builds a three-agent HAM with a market-correction-adjusted fitness measure framework to investigate the formations and the collapses of the two housing price patterns jointly. To form a better understanding of how the market switches from a boom regime towards a bust regime, my HAM adopts the market-correction-adjusted fitness measure framework. Investors consider two aspects when choosing their forecasting rules. On one hand, they will cluster to the strategies that performed better in the recent past, while on the other hand, they believe the further the price deviates from its fundamentals, the more likely the market is going to reverse.

Using monthly housing market data from two representative states, Arizona and Minnesota, from Jan 1975 to Mar 2015, I estimate the model with nonlinear least squares. Result 1 is that in contrast to the existing literature which studies either the formation of the collapse of the two patterns separately, I can explain the booms and the busts of an exponential bubble and a linear trend within the same framework. I show that (1) while the formation of an exponential bubble is primarily due to the dominance of trend followers, a linear trend can be explained by systematically constant proportions of each type of agents, and (2) the collapse of both an exponential bubble and a linear trend could be driven by the activations of fundamentalists. Result 2 is that the set up of market-correction-adjusted fitness measure improves the accuracy of forecasting the timing of market switches compared to the realized-profit fitness measure that is frequently 
applied in HAMs. My result 3 shows that the policy implication presents that stabilizing policies include an increase of the risk free interest rate, an increase of the property tax rate and a decrease of (the growth of) housing rents.

Chapter 5 proposes a simple Markov switching HAM made up of a real component and a speculative component consisting of fundamentalists, chartists and noise traders, to explore the within-group heterogeneity across different regimes. Fundamentalists trade on mean-reversion, chartists use either the trend following strategy or the contrarians strategy and noise traders' demand follows a normal distribution. The switches of market conditions follow a two-state Markov regime switching process. Within the Markovswitching framework, the beliefs of chartists and noise traders are modeled to be regimedependent.

I estimate the model using the quarterly FHFA housing price index data in the U.S. from 1975Q1 to 2015Q1. The regression results show that the model matches well with the boom and bust periods in the U.S. housing market. More interestingly, I not only confirm the co-existence of the three types of investors with different beliefs, but also find evidence of time-varying behavioural heterogeneity within-group. I show that chartists form trend following expectations in the boom periods while adopt contrarian strategies in the bust periods, and noise traders are much more sensitive to external news in the bust regime than in the boom regime.

However, many dimensions remain unexplored. To begin with, the HAMs in Chapters 3 and 4 have not taken into consideration the real demand and supply for housing which could potentially affect the dynamics of housing prices. The real demand for houses could influence housing price movements, because people buy houses not only for investment but also for living purposes. Additionally, the supply side of the market could affect the formation process of housing prices.

Furthermore, our Markov regime-switching HAM only include two states, a boom state and a bust state, but the business cycle at different stages of development cannot be captured only by boom regime and bust regime. Guidolin and Timmermann (2007 and 2008) show that the asset returns switch among four states, crash, slow growth, bull and recovery states, and that investors behave differently with these states. Nneji et al. (2013) 
suggest that investors' behaviour varies with three states, a bubble state, a steady state and a crash state in the U.S. housing market.

In addition, the HAMs put forward in this thesis have not taken into account a much broader range of factors, including government policy, transaction cost involved in buying and selling of properties and income constraints of buyers. Such factors that the housing price depends on could be considered in future research.

Finally, maybe an even more important future research direction is to conduct laboratory experiments and surveys to investigate the dynamic selection of expectation strategies. Branch (2004) estimates the dynamic three-agent HAM of Brock and Hommes (1997) using survey data on inflation expectations and shows that the HAM fits the survey data better than the corresponding homogeneous agent model. Hommes et al. (2005) conduct laboratory experiments with human subjects, in which individuals are asked to predict an asset price, with realized prices determined endogenously in the laboratory by the asset pricing model of Brock and Hommes (1998) with feedback from individual forecasts. This paper suggests that the asset price does not converge to its fundamental price in most of the time. Instead, the asset price oscillates around the fundamental price exhibiting temporary bubbles and long term mean-reversion. Adam (2005) presents a laboratory experiment, where participants are asked to forecast inflation, and the next period's output and inflation is the weighted sum of investors' expectations. His results show that output and inflation in the experimental monetary sticky price economy display considerable persistence and regular cyclical patterns. Recently, Bao and Hommes (2015) design an experimental housing market to study how the strength of the negative feedback affects market stability. Their results suggest that when the positive feedback through speculative demand is offset by the negative feedback of elastic housing supply the market stabilizes and prices converge to fundamental value. Although these recent studies contribute to investigating agents' expectations by conducting laboratory experiments and surveys, much more work needs to be done to study the dynamic selection of people's forecasting rules in real estate markets. 


\section{Appendix A}

\section{Computing the Nonlinear}

\section{Least Squares Estimator}

Minimizing the sum of squared residuals for a nonlinear regression is a standard problem in nonlinear optimization that can be solved by the method of Gauss-Newton. Employing the Gauss-Newton method for this works as follows:

Let $X_{t}=\left[\begin{array}{lll}x_{t-1} & x_{t-2} & x_{t-3}\end{array}\right]$ and $\theta=\left[\begin{array}{ccc}\Delta \phi_{2} & \Delta \phi_{3} & \beta^{*}\end{array}\right]$, the nonlinear regression model becomes $y_{t}=f\left(X_{t}, \theta\right)+\varepsilon_{t}$. To save some notation, I dropp the observation subscript, and the nonlinear regression model is $y=f(X, \theta)+\varepsilon$. A first-order Taylor approximation at $\theta^{0}$ yields:

$$
f(X, \theta) \approx f\left(X, \theta^{0}\right)+\sum_{k=1}^{K} \frac{\partial f\left(X, \theta^{0}\right)}{\partial \theta_{k}^{0}}\left(\theta_{k}-\theta_{k}^{0}\right)
$$

The form of the equation is called the linearized regression model. By collecting terms, this equation becomes

$$
f(X, \theta) \approx\left[f\left(X, \theta^{0}\right)-\sum_{k=1}^{K} \theta_{k}^{0}\left(\frac{\partial f\left(X, \theta^{0}\right)}{\partial \theta_{k}^{0}}\right)\right]+\sum_{k=1}^{K} \theta_{k}\left(\frac{\partial f\left(X, \theta^{0}\right)}{\partial \theta_{k}^{0}}\right) .
$$

Let $x_{k}^{0}$ equal the $k$ th partial derivative, $\partial f\left(X, \theta^{0}\right) / \partial \theta_{k}^{0}$. For a given value of $\theta^{0}, x_{k}^{0}$ is a 
function only of the data, not of the unknown parameters. So this equation becomes

$$
f(X, \theta) \approx\left[f^{0}-\sum_{k=1}^{K} x_{k}^{0} \theta_{k}^{0}\right]+\sum_{k=1}^{K} x_{k}^{0} \theta_{k}
$$

which may be written as

$$
f(X, \theta) \approx f^{0}-X^{0 \prime} \theta^{0}+X^{0 \prime} \theta
$$

which implies that

$$
y \approx f^{0}-X^{0 \prime} \theta^{0}+X^{0 \prime} \theta+\varepsilon .
$$

By placing the known terms on the left-hand side of the equation, a linear equation can be obtained

$$
y^{0}=y-f^{0}+X^{0 \prime} \theta^{0}=X^{0 \prime} \theta^{0}+\varepsilon^{0} .
$$

$\varepsilon^{0}$ is the sum of the true disturbance, $\varepsilon$, and the error in the first-order Taylor series approximation to the true regression, that is,

$$
\varepsilon^{0}=\varepsilon+\left[f(X, \theta)-\left\{f^{0}-\sum_{k=1}^{K} x_{k}^{0} \theta_{k}^{0}+\sum_{k=1}^{K} x_{k}^{0} \theta_{k}\right\}\right]
$$

With a value of $\theta^{0}$, one could compute $y^{0}$ and $X^{0}$ and then estimate the parameters of eq. (A.7) by linear least squares. 


\section{Appendix B}

\section{Robust Check: Neighbor States}

I explore whether the situations in neighbor states are similar to those in Arizona and Minnesota as a robust check. I look into the neighbor state of Arizona, California, and the neighbor state of Minnesota, Iowa. Note that from Figure 1.1, the housing price in California shows an exponential pattern while the housing price in Iowa presences a linear trend.

Table B.1 shows the estimation results. The significance of $\Delta \phi_{2}$ and $\Delta \phi_{3}$ suggests that there is significant difference between the belief parameter of Type-2 agents from Type-1 agents, and the belief parameter between the belief parameter of Type-3 agents from Type1 agents. The implied beliefs of fundamentalists, $\phi_{2}$ for the exponential bubble and the linear trend, lies between 0 and 1 . This indicates that Type-2 agents are fundamentalists who believe in mean-reversion and hence will expect the asset price to return back towards its fundamental values. In contrast, the implied beliefs parameter of trend followers, $\phi_{3}$, is larger than 1 for the exponential bubble and the linear trend, suggesting that Type-3 agents are trend following investors. The scaled intensity of choice, $\beta^{*}>0$, provides evidence that different types of investors are interacting between each other.

Figure B.1 shows the time series of the relative deviations between the actual housing prices from its fundamental prices, $x_{t}$, and estimated fractions of Type-1 agents $\left(n_{1, t}\right)$, Type- 2 agents $\left(n_{2, t}\right)$, and Type-3 agents $\left(n_{3, t}\right)$, for the exponential bubble in California. Similar to Arizona, the formation of the exponential bubble is driven mostly by the 
Table B.1: Estimation results for the three-agent HAM, 1975:1-2015:3

\begin{tabular}{lcccc}
\hline & \multicolumn{2}{c}{ Exponential (California) } & \multicolumn{2}{c}{ Linear (Iowa) } \\
\cline { 2 - 5 } & Estimate & $p$-value & Estimate & $p$-value \\
\hline Deviation of beliefs, $\Delta \phi_{2}$ & $-0.0319^{* * *}$ & 0.0000 & $-0.0474^{* * *}$ & 0.0001 \\
Deviation of beliefs, $\Delta \phi_{3}$ & $0.0350^{* * *}$ & 0.0000 & $0.0873^{* * *}$ & 0.0000 \\
Intensity of choice, $\beta^{*}$ & $13128.24^{* * *}$ & 0.0000 & $6991.41^{* *}$ & 0.0170 \\
Implied beliefs para., $\phi_{2}$ & 0.9681 & & 0.9526 & \\
Implied beliefs para., $\phi_{3}$ & 1.0350 & & 1.0873 & \\
\hline
\end{tabular}

dominance of the trend followers, while the burst of the exponential bubble could be due to the dominance of fundamentalists.

Figure B.2 plots the time series of $x_{t}$, and estimated fractions of Type- 1 agents, $n_{1, t}$, Type- 2 agents, $n_{2, t}$, and Type- 3 agents, $n_{3, t}$, for the linear trend in Iowa. These plots offer a possible explanation for a linear trend. These plots show a constant proportion of all types of agents in the market when the linear trend was formed. It suggests that the formation of a linear trend in Iowa could be explained by approximately constant proportions of each type of agents. The difference is that there is no crash in the linear trend.

Combining the findings from both Figure B.1 and Figure B.2, the situations in neighbor states are similar to those in the representative states, and our finding of behavioral heterogeneity seems robust when neighbor states are considered. 

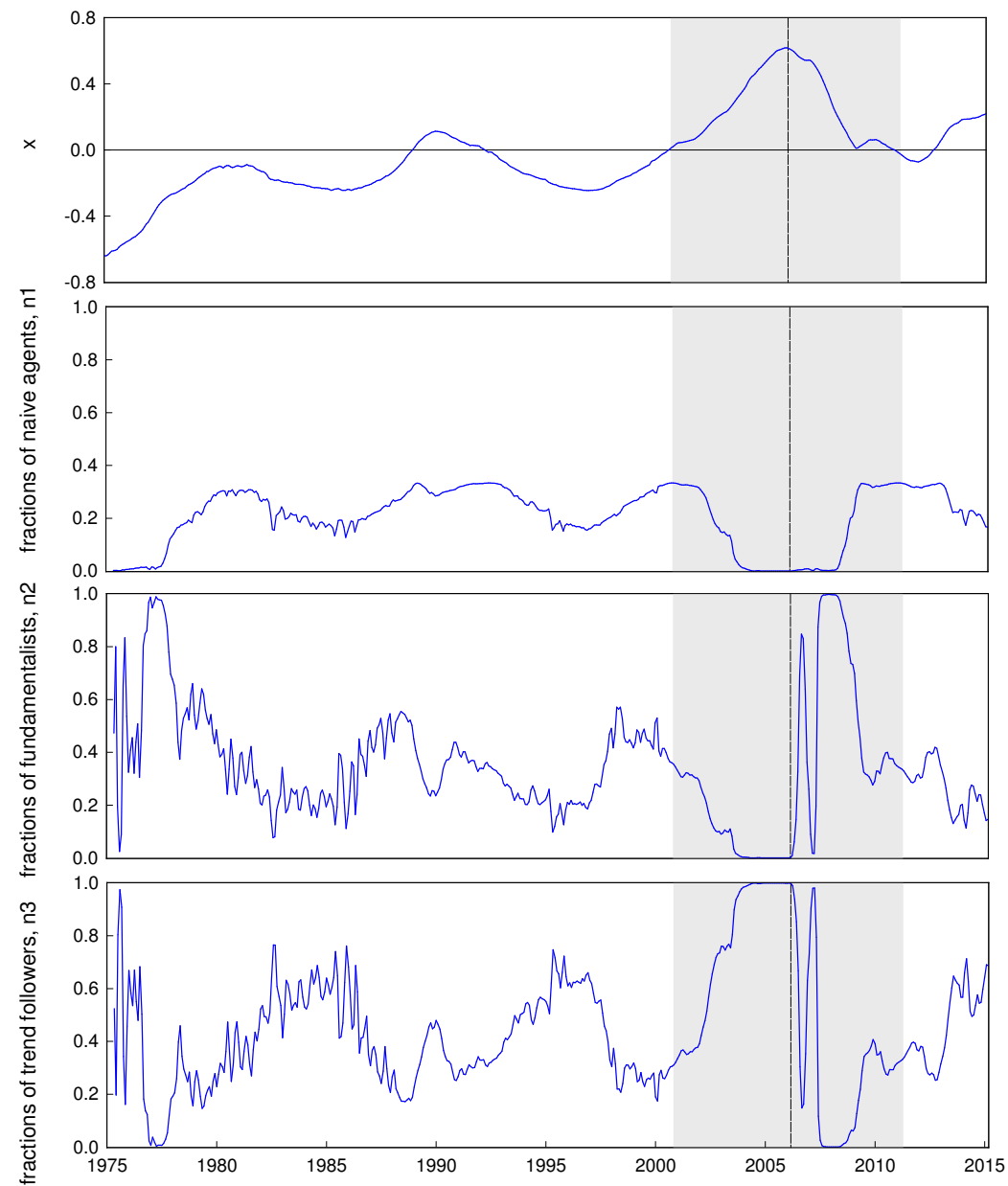

Figure B.1: Relative deviations and fractions of three types of agents in California's housing market 

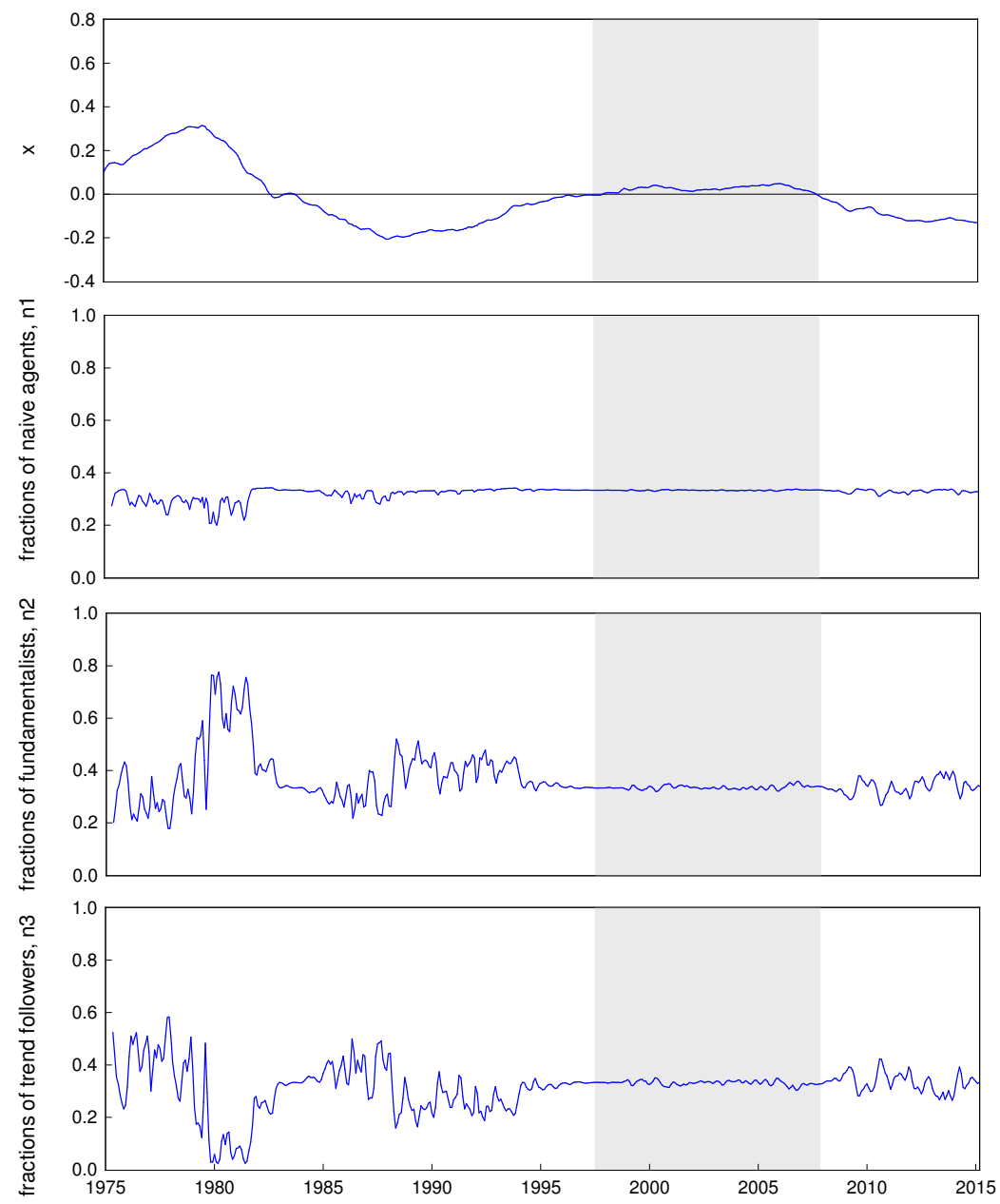

Figure B.2: Relative deviations and fractions of three types of agents in Iowa's housing market 


\section{Appendix C}

\section{Robust Check: Fundamental}

\section{Price is the Long-run Average}

\section{of the Housing Prices}

Different fundamental price can be used, for instance, the fundamental price is the longterm average. I use a long-term average fundamental price as a robust check, and my finding suggests that behavioral heterogeneity seems fairly robust when a long-term-average fundamental price is considered.

The estimated parameters $\left(\Delta \phi_{2}, \Delta \phi_{3}, \beta^{*}\right)$ and hence the implied beliefs parameters $\phi_{2}$ and $\phi_{3}$ are reported in Table C.1 ${ }^{1}$.

The significance of $\Delta \phi_{2}$ and $\Delta \phi_{3}$ suggests that there is significant difference between the belief parameter of Type-2 agents from Type-1 agents, and the belief parameter between the belief parameter of Type-3 agents from Type-1 agents.

Table C.1 supports the coexistence of fundamentalists and trend followers. The implied beliefs of fundamentalists, $\phi_{2}{ }^{2}$ for the exponential bubble and the linear trend, lies between

\footnotetext{
${ }^{1}$ It is not possible to calculate a valid $R^{2}$ for nonlinear regression so this value is an invalid goodnessof-fit statistic for my nonlinear HAM. $R^{2}$ is based on the underlying assumption that we are fitting a linear model. In nonlinear regression, $R^{2}$ is no longer between 0 and $100 \%$ and using $R^{2}$ to evaluate the fit of nonlinear models leads to incorrect conclusions.

${ }^{2}$ As discussed in Chapter 3 , the implied beliefs parameters $\phi_{2}$ and $\phi_{3}$ are close to 1 because I use
} 
Table C.1: Estimates for the model with a long-term-average fundamental price, 1975:1$\underline{2015: 3}$

\begin{tabular}{lcccc}
\hline & \multicolumn{2}{c}{ Exponential (Arizona) } & \multicolumn{2}{c}{ Linear (Minnesota) } \\
\cline { 2 - 5 } & Estimate & $p$-value & Estimate & $p$-value \\
\hline Deviation of beliefs, $\Delta \phi_{2}$ & $-0.0309^{* * *}$ & 0.0000 & $-0.0563^{* *}$ & 0.0758 \\
Deviation of beliefs, $\Delta \phi_{3}$ & $0.0349^{* * *}$ & 0.0000 & $0.0959^{* * *}$ & 0.0021 \\
Scaled intensity of choice, $\beta^{*}$ & $47978.40^{* * *}$ & 0.0019 & 3913.72 & 0.2766 \\
Implied beliefs parameter, $\phi_{2}$ & 0.9691 & & 0.9437 & \\
Implied beliefs parameter, $\phi_{3}$ & 1.0349 & & 1.0959 & \\
$R^{2}$ & 0.9981 & & 0.9987 & \\
$A I C$ & -6.8789 & -7.5774 & \\
\hline
\end{tabular}

0 and 1. This indicates that Type-2 agents are fundamentalists who believe in meanreversion and hence will expect the asset price to return back towards its fundamental values. In contrast, the implied beliefs parameter of trend followers, $\phi_{3}$, is 1.0349 for the exponential bubble and 1.0959 for the linear trend, suggesting that Type-3 agents are trend following investors. The scaled intensity of choice, $\beta^{*}>0$, provides evidence that different types of investors are interacting between each other. Note that, according to Boswijk et al (2007), the insignificance of the scaled intensity of choice for the linear trend would not affect the results.

Figure C.1 and C.2 shows the time series of the relative deviations between the actual housing prices from its fundamental prices, $x_{t}$, and estimated fractions of Type-1 agents $\left(n_{1, t}\right)$, Type-2 agents $\left(n_{2, t}\right)$, and Type-3 agents $\left(n_{3, t}\right)$, for the exponential bubble and linear trend. Similarly, these plots offer an explanation for the formation and the subsequent collapse of an exponential housing bubble and a linear trend. The formation of the exponential bubble is driven mostly by the dominance of the trend followers, while the burst of the exponential bubble could be due to the dominance of fundamentalists. Moreover, the formation of a linear trend in Minnesota could be explained by approximately constant proportions of each type of agents, while the collapse of the linear trend could be due to the dominance of fundamentalists.

This evidence suggests that my finding of behavioral heterogeneity seems fairly robust when a long-term-average fundamental price is considered.

monthly data to estimate the model. Market participants expect that the relative deviations between the housing prices and the fundamental housing prices would exhibit only small changes within one month. 

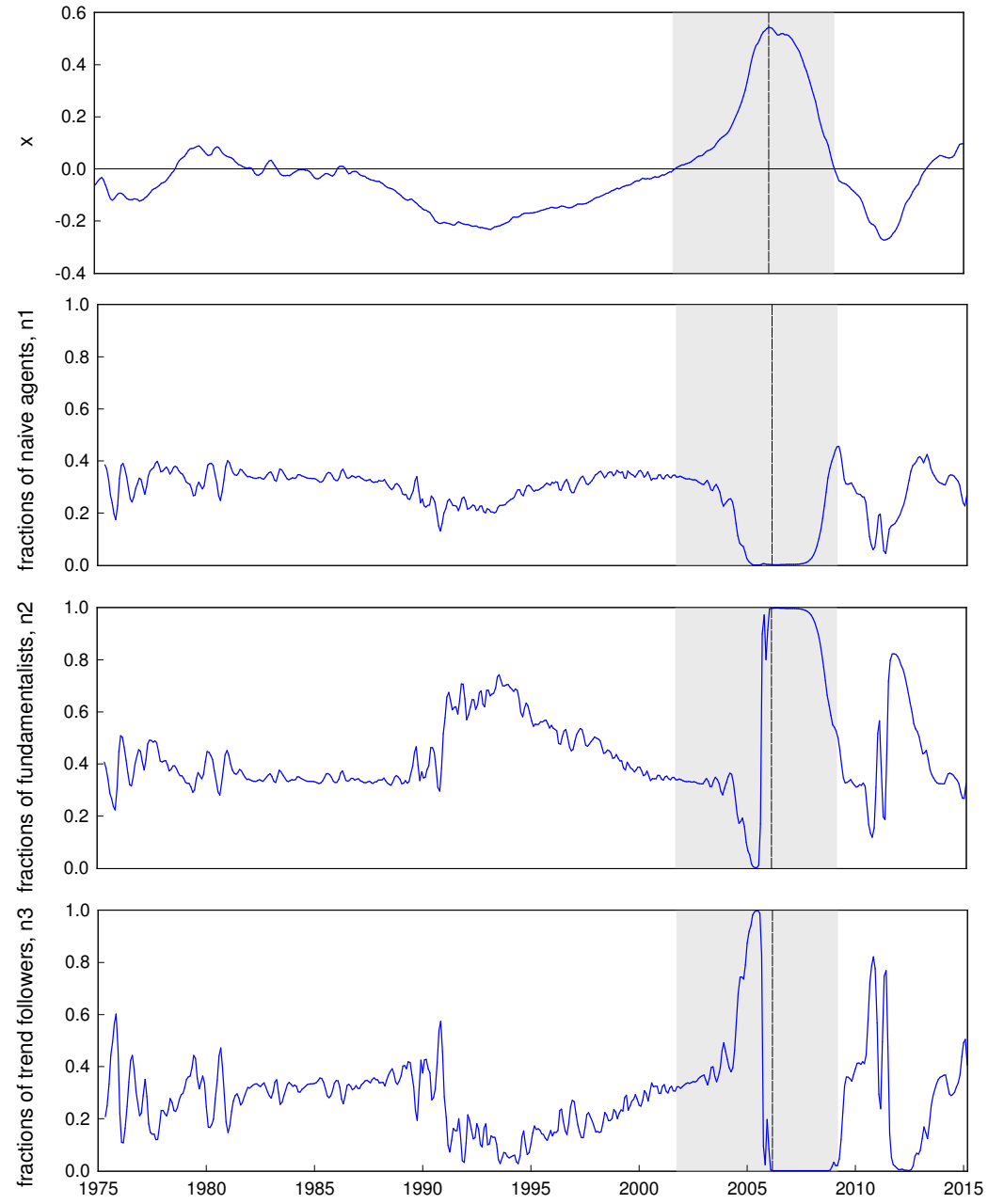

Figure C.1: Relative deviations and fractions of three types of agents in Arizona housing market using a long-term-average fundamental price 

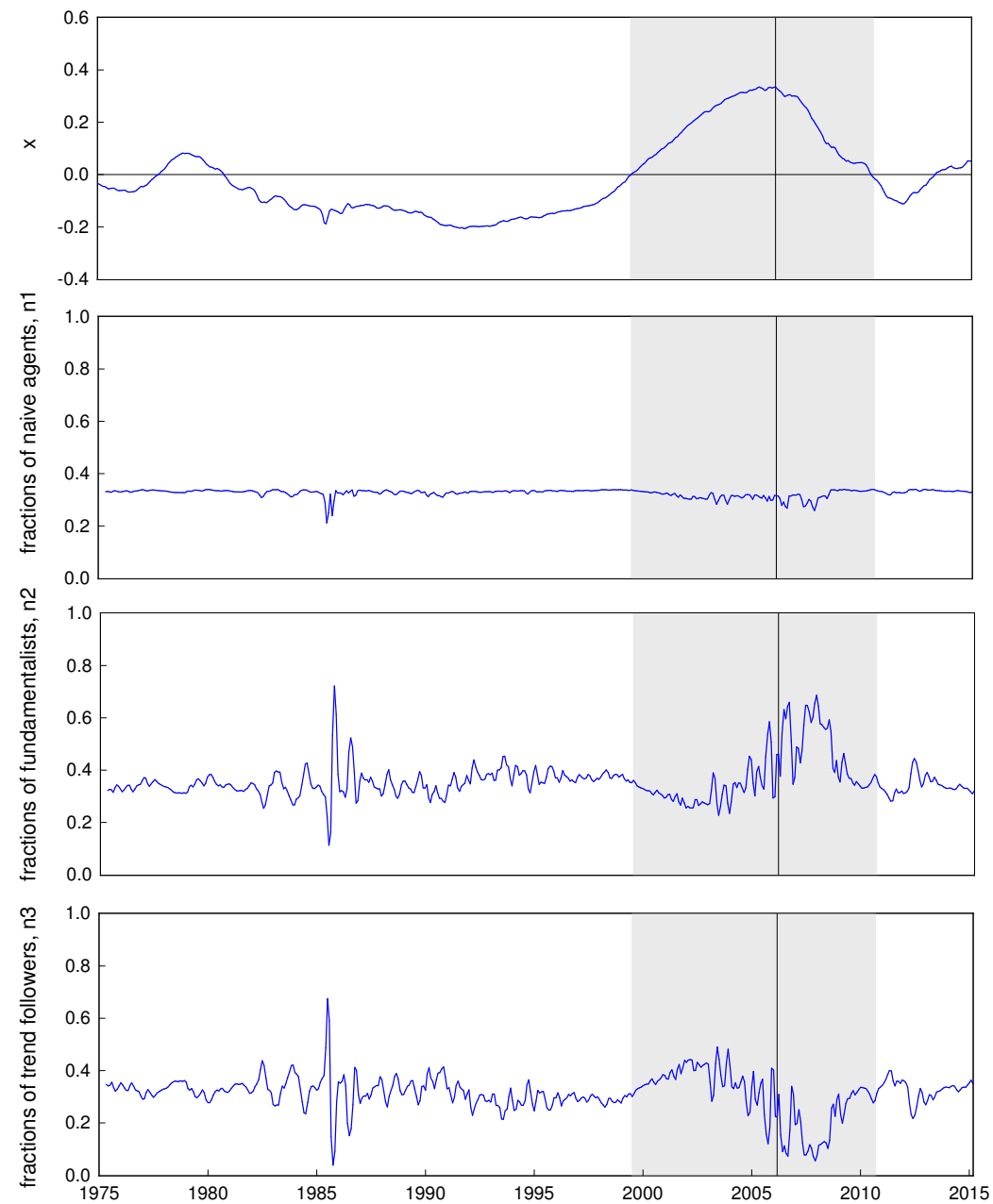

Figure C.2: Relative deviations and fractions of three types of agents in Minnesota housing market using a long-term-average fundamental price 


\section{Appendix D}

\section{A Modified Version of the}

\section{Markov Regime Switching}

\section{Model: Only Bringing in}

\section{Speculative Motives}

Besides the original model built in Chapter 5, I have added a simple and stylized heterogeneous agent model that does not bring in non-speculative motives. In other words, The model only contains fundamentalists, chartists and noise traders. Within the Markovswitching framework, chartists and noise traders are assumed to update their investing behavior based on market conditions.

Instead of assuming the demand of noise traders in period $t, D_{n, t}$, follows is $N\left(0, \sigma_{n, t}^{2}\right)$ distribution in Chapter 5 , I assume that $D_{n, t}$ follows $N\left(a_{t}, \sigma_{n, t}^{2}\right)$ distribution. The mean $a_{t}$ and the variance $\sigma_{n, t}^{2}$ are regime-dependent. As such, the demand of noise traders $D_{n, t}$ is given by

$$
D_{n, t} \sim \begin{cases}N\left(a_{1}, \sigma_{n, 1}^{2}\right), & s_{t}=1, \\ N\left(a_{2}, \sigma_{n, 2}^{2}\right), & s_{t}=2,\end{cases}
$$


where $a_{1} \neq a_{2}$ and $\sigma_{n, 1}^{2} \neq \sigma_{n, 2}^{2}$.

Price change, finally, is a function of excess demand:

$$
\begin{aligned}
p_{t+1}-p_{t} & =\gamma\left[\omega_{f} D_{f, t}+\omega_{c} D_{c, t}+\omega_{n} D_{n, t}\right] \\
& =\beta_{f} v_{t}\left(p_{t}^{*}-p_{t}\right)+\beta_{c, t}\left(p_{t}-p_{t}^{*}\right)+b_{t}+\varepsilon_{t},
\end{aligned}
$$

where $\beta_{f}=\gamma \omega_{f} \alpha_{f}, \beta_{c, t}=\gamma \omega_{c} \alpha_{c, t}, b_{t}=\gamma \omega_{n} a_{t}$ and the distribution of $\varepsilon_{t}$ follows:

$$
\varepsilon_{t} \sim \begin{cases}N\left(0, \sigma_{1}^{2}\right), & s_{t}=1, \\ N\left(0, \sigma_{2}^{2}\right), & s_{t}=2,\end{cases}
$$

where $\sigma_{1}^{2}=\gamma \omega_{n} \sigma_{n, 1}^{2}$ and $\sigma_{2}^{2}=\gamma \omega_{n} \sigma_{n, 2}^{2}$.

$\beta_{c, t}$ is proportional to the beliefs parameter of chartists, $\alpha_{c, t}$. So $\beta_{c, t}>0$ when the chartists form bandwagon expectation and $\beta_{c, t}<0$ when the chartists believe in trend reversal. The scaled beliefs parameter of chartists, $\beta_{c, t}$, is regime-dependent given by

$$
\beta_{c, t}= \begin{cases}\beta_{c, 1}, & s_{t}=1, \\ \beta_{c, 2}, & s_{t}=2\end{cases}
$$

in which $\beta_{c, 1}=\gamma \omega_{c} \alpha_{c, 1}$ and $\beta_{c, 2}=\gamma \omega_{c} \alpha_{c, 2}$.

I estimate the two-state Markov regime switching HAM using the same data set. The estimation results are shown as Table D.1. When $\varrho=1$, Regime 1 denotes the boom state and when $\varrho=2$, Regime 2 is the bust state. As mentioned previously, while the housing price during Regime 1 (boom state) is increasing with relatively low volatility, the housing price during regime 2 (bust state) is decreasing with relatively high volatility.

The estimation results provide evidence of within-group heterogeneity over time. To be more specific, the scaled beliefs parameter of chartists, $\beta_{c, 1}>0$, in the boom state and the scaled beliefs parameter $\beta_{c, 2}<0$ in the bust state. Note that although $\beta_{c, 2}$ is not significantly different from zero, these results can provide us some information. During the boom regime, most of the chartists are trend followers, believing that the 
Table D.1: Estimates for the regime switching HAM, 1975Q1-2015Q1

\begin{tabular}{lcc}
\hline Coefficient & Regime 1 (boom state) & Regime 2 (bust state) \\
\hline Chartists' beliefs param., $\beta_{c, \varrho}$ & $0.1060(0.0000)^{* * *}$ & $-0.0088(0.7944)$ \\
Std. dev., $\sigma_{\varrho}$ & $0.0197(0.0000)^{* * *}$ & $0.0419(0.0000)^{* * *}$ \\
Mean, $b_{\varrho}$ & $0.0279(0.0000)^{* * *}$ & $-0.0298(0.0000)^{* * *}$ \\
Fundamentalists' beliefs param., $\beta_{f}$ & $2.1011(0.0000)^{* * *}$ \\
Probability, $P_{1,1}$ & $0.9727(0.0000)^{* * *}$ \\
Probability, $P_{1,2}$ & $0.0898(0.0000)^{* * *}$ \\
\hline
\end{tabular}

Notes:

$(1) *{ }^{* *}$ and $* * *$ denote significance at $10 \%, 5 \%$ and $1 \%$, respectively.

(2) Numbers in the parentheses are $p$-values.

housing price is likely to deviate further from the fundamental housing price. It is in line with the economic intuition. The housing price during regime 1 (boom state) is increasing, and most chartists believe that the market price will deviate further away from the fundamental price. On the other hand, when the housing market is at its bust regime, contrarian expectations tend to dominate. It implies that, in the bust period when the housing price is declining, if the current housing price is above the fundamental housing price, most chartists believe that the market price will be below the fundamental housing price. These results are consistent with Chia et al. (2016) which find that contrarian expectations tend to dominate in the bust state while the trend following expectations are more overwhelmed in the boom state.

In addition, the standard deviation of noise traders in the boom state $\sigma_{1}^{2}$ is much smaller than that in the bust state $\sigma_{2}^{2}$, suggesting that noise traders are less sensitive to external news in the boom state than in the bust state. These results are in line with our assumption that the price is increasing with low volatility in the boom state, while market is depressed with declining price and high volatility in the bust state. Like the chartists, the different behaviour of the noise traders in different states provides evidence of time-varying behavioural heterogeneity within-group.

Moreover, the mean of the demand of noise traders in the boom state $b_{1}>0$ and the mean of the demand in the bust state $b_{2}<0$. It suggests that in the boom period, the noise traders tend to buy assets while in the bust period, they tend to sell.

Finally, the scaled beliefs parameter of fundamentalists $\beta_{f}>0$. It is in line with our model 
assumption that fundamentalists buy in house when the price is below the fundamental price and sell it out when price is above.

Overall, I find statistically significant results on the regime-dependence of $\beta_{c, \varrho}$ and $\sigma \varrho$, which indicate the existence of time-varying within-group heterogeneity. Chartists switch between the bandwagon expectations and the contrarian expectations according to the market conditions and noise traders adjust their demand and degree of reaction with a time-varying probability.

The classification of regimes is broadly in line with my previous estimation, as shown in Figure D.1. Although the dates of domestic economic instabilities and housing crises are not used in any way to estimate the parameters or the transition probabilities, the classified regimes also match well with the market booms and busts in the actual episodes. However, according to Figure D.2, the classification of the regimes in this model seems more accurate. Using my previous model, the classified boom periods are 1975-1979, 19832007 and 2012-2015. Using the model without non-speculative motives, the classified boom periods are 1975-1979, 1983-1989, 1991-2007 and 2012-2015. This classification seems more accurate as it detects the bust period from 1989 to 1991.

In conclusion, the Markov switching estimation results of this model also provide evidence on the co-existence of time-varying within-group heterogeneity and cross-group heterogeneity. Although the dates of domestic economic instabilities and housing crises are not used in any way to estimate the parameters or the transition probabilities, the classified regimes match well with the market booms and busts in the actual episodes. 


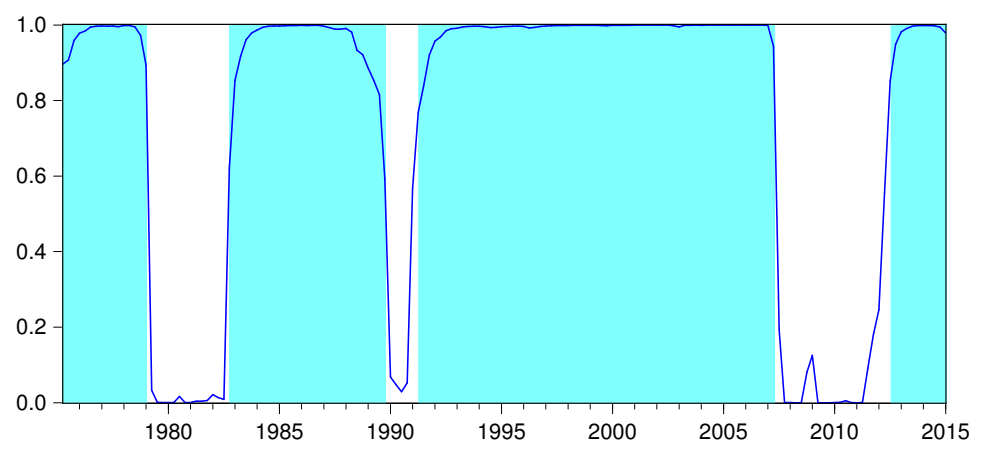

$P(S(t)=2)$ smoothed

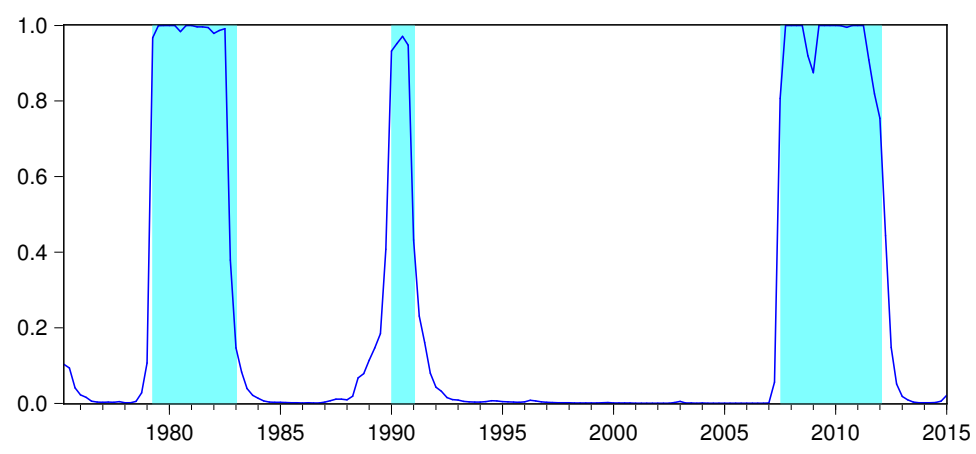

Figure D.1: Smoothed transition probability

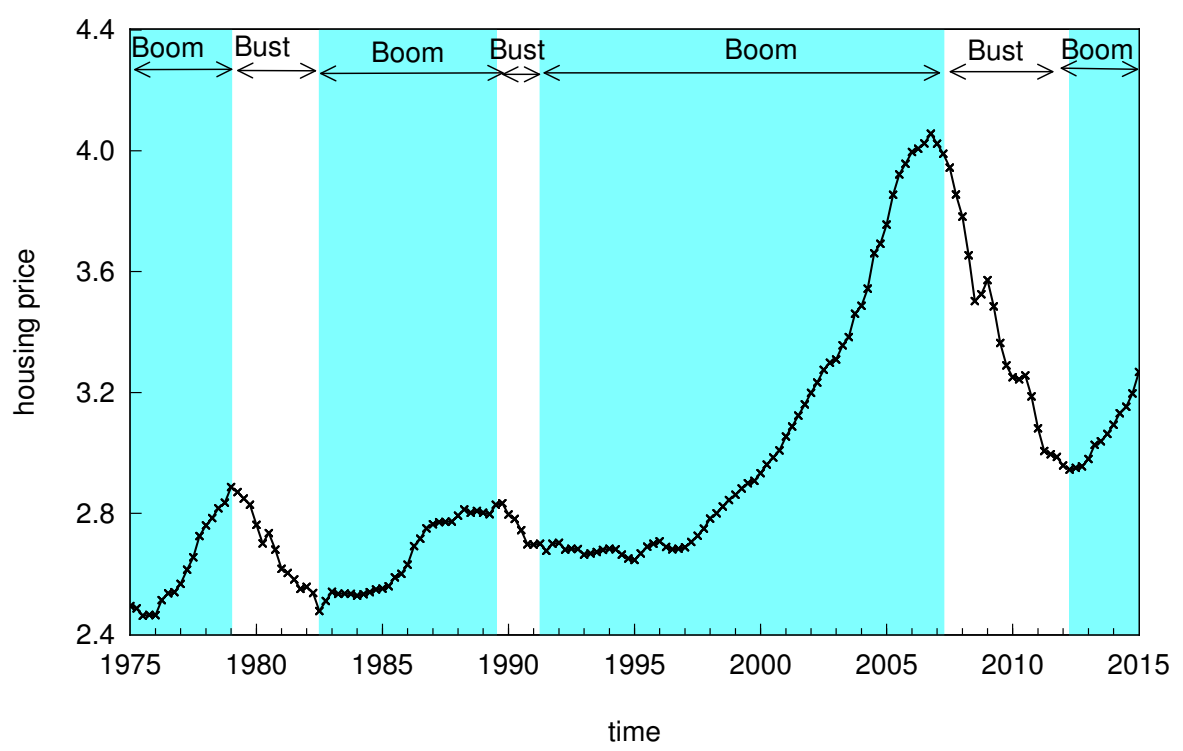

Figure D.2: Housing price index and classified boom regimes 


\section{Appendix E}

\section{Use Monthly data in the}

\section{regression in Chapter 5}

In this appendix, I explain why I use quarterly data instead of monthly data in the regression in Chapter 5. Because the estimated parameters using the monthly Freddie Mac housing price index are insignificant. The estimation results are shown as Table E.1. The beliefs parameter of chartists in Regime $1, \beta_{c, 1}$, is insignificant with $p$-value to be 1.0000 . This may be because I use monthly data to estimate the model. Market participants expect that the change in the relative deviations between the housing prices and the fundamental housing prices within a month is small so the model cannot distinguish a trend follower from a contrarian.

Table E.1: Estimates for regime switching model, 1975M1-2015M3.

\begin{tabular}{lcc}
\hline Coefficient & State 1 (boom) & State 2 (bust) \\
\hline Chartists' beliefs param., $\beta_{c, \varrho}$ & $-6.10 \mathrm{E}-08(1.0000)$ & $-0.0222(0.0025)^{* * *}$ \\
Std. dev., $\sigma_{\varrho}$ & $0.0019(0.0000)^{* * *}$ & $0.0090(0.0000)^{* * *}$ \\
Fundamentalists' beliefs param., $\beta_{f}$ & $-0.2089(0.0000)^{* * *}$ \\
Real excess demand param., $a$ & $0.0024(0.0425)^{* *}$ \\
Real excess demand param., $b$ & $-0.0022(0.2422)$ \\
\hline
\end{tabular}




\section{Bibliography}

[1] Adam, K. 2005. "Experimental evidence on the persistence of output and inflation" European Central Bank Working Paper: January 2005.

[2] Allen, H., and Taylor, M. 1990. "Charts, Noise and Fundamentals in the London Foreign Exchange Market." The Economic Journal 100: 49-59.

[3] Bao, T., and Hommes, C. H. 2015. "When Speculators Meet Constructors: Positive and Negative Feedback in Experimental Housing Markets." CeNDEF Working paper 15-10 University of Amsterdam

[4] Battiston, S., Farmer, J. D., Flache, A., Garlaschelli, D., Haldane, A. G., Heesterbeek, H., Hommes, C. H., Jaeger, C., May, R. and Scheffer, M. 2016. "Complexity theory and financial regulation. Economic policy needs interdisciplinary network analysis and behavioral modeling." Science 351(6275): 818-819.

[5] Bucks, B., Kennikell, A., and Moore, K. 2006. "Recent changes in U.S. family finances: evidence from the 2001 and 2004 survey of consumer finances." Federal Reserve Bulletin 92: A1-A38.

[6] Branch, W. 2004. "The theory of rationally heterogeneous expectations: evidence from survey data on inflation expectations" Economic Journal 114: 592-621.

[7] Branch, W., and Evans, G. 2006. "Intrinsic heterogeneity in expectation formation." Journal of Economic Theory 127: 264-295.

[8] Bolt, W., Demertzis, M., Diks, C. G. H., Hommes, C. H., and Marco, L. 2014. "Identifying booms and busts in house prices under heterogeneous expectations." De Nederlandsche Bank Working Paper: No. 450. 
[9] Boswijk, H. P., Hommes, C. H., and Manzan, S. 2007. "Behavioral heterogeneity in stock prices" Journal of Economic Dynamics and Control 31: 1938-1970.

[10] Brock, W. A., and Hommes, C. H. 1997. "A rational rout to randomness." Econometrica 65: 1059-1095.

[11] Brock, W. A., and Hommes, C. H. 1998. "Heterogeneous beliefs and routes to chaos in a simple asset pricing model." Journal of Economic Dynamics and Control 22: $1235-1274$

[12] Case, K. E., and Shiller, R. J. 2003. "Is there a bubble in the housing market?" Brookings Papers on Economic Activity 2: 299-362.

[13] Cheung, Y., and Chinn, M. 2011. "Currency traders and exchange rate dynamics: A survey of the US market." Journal of International Money and Finance 20(4): $439-471$.

[14] Chia, W., Zheng, H., and Li, M. 2014. "Behavioral heterogeneity in Australian housing market." Australian Conference for Economists.

[15] Chia, W., Li, M., and Zheng, H. 2014. "Regime switching models in the foreign exchange market." in Nonlinear economic dynamics and financial modelling : essays in honour of Carl Chiarella.

[16] Chiarella, C., Dieci, R., and He, X. 2009. "Heterogeneity, market mechanisms and asset price dynamics." in Hens, T., Schenk-Hoppe, K.R. (Eds.), Handbook of Financial Markets: Dynamics and Evolution.

[17] Chiarella, C., and He, X. 2002. "Heterogeneous beliefs, risk and learning in a simple asset pricing model." Computational Economics 19: 95-132.

[18] Chiarella, C., and He, X. 2003. "Dynamics of beliefs and learning under aL-processesthe heterogeneous case." Journal of Economic Dynamics and Control 27: 503-531.

[19] Chiarella, C., He, X., Huang, W., and Zheng, H. 2012. "Estimating behavioural heterogeneity under regime switching." Journal of Economic Behavior \& Organization 83: $446-460$. 
[20] Day, R., and Huang, W., 1990. "Bulls, bears and market sheep." Journal of Economic Behavior \&3 Organization 14: 299-329.

[21] De Grauwe, P. 2008. "DSGE-modelling: when agents are imperfectly informed." European Central Bank Working Paper: No. 897.

[22] De Jong, E., Verschoor, W., and Zwinkels, R. 2010. "Heterogeneity of agents and exchange rate dynamics: evidence from the EMS." Journal of International Money and Finance 29(8): 1652-1669.

[23] De Long, J., Shleifer, A., Summers, L., and Waldmann, R. 1990. "Noise trader risk in financial markets." Journal of political economy 98(4): 703-738.

[24] Dieci, R., and Westerhoff, F., 2012. "A simple model of a speculative housing market." Journal of Evolutionary Economics 22(2): 303-329.

[25] Dieci, R., and Westerhoff, F., 2013. "Modeling house price dynamics with heterogeneous speculators." Global Analysis of Dynamic Models in Economics and Finance: $35-61$.

[26] Dieci, R., and Westerhoff, F., 2016. "Heterogeneous expectations, boom-bust housing cycles, and supply conditions: A nonlinear economic dynamics approach." Journal of Economic Dynamics and Control 71: 21-44.

[27] Eichholtz, P., Huisman, R., and Zwinkels, R. 2015. "Fundamentals or trends? A long-term perspective on house prices." Applied Economics 47(10): 1050-1059.

[28] Ellen, S., and Zwinkels, R. 2010. "Oil price dynamics: A behavioral finance approach with heterogeneous agents." Energy Economics 32: 1427-1434.

[29] Fama, E. 1970. "Efficient capital markets: a review of theory and empirical work." The Journal of Finance 25(2): 28-30.

[30] Franke, R., and Westerhoff, F. 2011. "Estimation of a structural stochastic volatility model of asset pricing." Computational Economics 38: 53-83.

[31] Franke, R., and Westerhoff, F. 2012. "Structural stochastic volatility in asset pricing dynamics: Estimation and model contest." Journal of Economic Dynamics and Control 36: 1193-1211. 
[32] Frankel, J., and Froot, K. 1986. "Chartists, fundamentalists, and trading in the foreign exchange market." Papers and proceedings of the hundred and second annual meeting of the American Economic Association: The American economic review $80(2): 181-185$.

[33] Frankel, J., and Froot, K. 1987. "Using survey data to test standard propositions regarding exchange rate expectations." The American economic review 77(1): 133153.

[34] Frijns, B., and Thorsten, L., and Zwinkels, R. 2010. "Behavioral heterogeneity in the option market." Journal of Economic Dynamics and Control 34(11): 2273-2287.

[35] Gali, J., and Gertler, M. 1999. "Inflation dynamics: A structural econometric analysis." Journal of Monetary Economics 44: 195-222.

[36] Gallin, J. 2006. "The long-run relationship between house prices and income: evidence from local housing markets." Real Estate Economics 34(3): 417-438.

[37] Gehrig, T., and Menkhoff, L. 2004. "The use of flow analysis in foreign exchange: Exploratory evidence." Journal of International Money and Finance 23(4): 573-594.

[38] Gilli, M., and Winker, P. 2003. "A global optimization heuristic for estimating agent based models." Computational Statistics and Data Analysis 42(3): 299-312.

[39] Guidolin, M., and Timmermann, A. 2007. "Asset allocation under multivariate regime switching." Journal of Economic Dynamics and Control 31: 3503-3544.

[40] Guidolin, M., and Timmermann, A. 2008. "International asset allocation under regime switching, skew, and kurtosis preferences." Review of Financial Studies 21: $889-935$.

[41] Hamilton, J. 1994. Time Series Analysis. Princeton University Press.

[42] He, X., and Li, Y. 2007. "Power-law behaviour, heterogeneity, and trend chasing." Journal of Economic Dynamics and Control 31: 3396-3426.

[43] He, X., and Westerhoff, F. 2005. "Commodity markets, price limiters and speculative price dynamics." Journal of Economic Dynamics and Control 29: 1577-1596. 
[44] Hendershott, P., Hendershott, R., and Shilling, J. 2010. "The mortgage finance bubble: causes and corrections." Journal of Housing Research 19: 1-16.

[45] Himmelberg, C., Mayer, C., and Sinai, T. 2005. "Assessing high house prices: bubbles, fundamentals, and misperceptions." Journal of Economic Perspectives 19(4): $67-92$

[46] Hommes, C. H. 2006. "Heterogeneous agent models in economics and finance." Chap. 23 in Handbook of Computational Economics.

[47] Hommes, C. H. 2011. "The heterogeneous expectations hypothesis: Some evidence from the lab." Journal of Economic Dynamics and Control 35: 1-24.

[48] Hommes, C. H. and in't Veld, D. 2014. "Booms, busts and behavioral heterogeneity in stock prices." Technical Report. University of Amsterdam. CeNDEF Working Paper.

[49] Hommes, C. H., Sonnemans, J., Tuinstra, J., and van de Velden, H. 2005. "Coordination of expectations in asset pricing experiments." Review of Financial Studies 18: $955-980$.

[50] Huang, W., and Zheng, H. 2012. "Financial crises and regime dependent dynamics." Journal of Economic Behavior \& Organization 82: 445-461.

[51] Huang, W., Zheng, H., and Chia, W. 2010. "Financial crises and interacting heterogeneous agents." Journal of Economic Dynamics and Control 34: 1105-1122.

[52] Kim, C., Nelson, C. 1999. State space models with regime switching: classical and Gibbs sampling approaches with applications. MIT Press.

[53] Kouwenberg, R., and Zwinkels, R. 2014. "Forecasting the US housing market." International Journal of Forecasting 30: 415-425.

[54] Kouwenberg, R., and Zwinkels, R. 2015. "Endogenous price bubbles in a multi-agent system of the housing market." PloS one 10(6): e0129070.

[55] Krugman, P. 2009. The Return of Depression Economics. New York: Norton.

[56] Leamer, E. 2007. "Housing IS the business cycle." Technical Report. NBER. Working paper: 13428 . 
[57] Lof, M. 2014. "Rational speculators, contrarians, and excess volatility" Management Science: 1889-1901.

[58] Massaro, D. 2013. "Heterogeneous expectations in monetary DSGE models." Journal of Economic Dynamics and Control 37(3): 680-692.

[59] McCarthy, J., and Peach, R. 2004. "Are home prices the next bubble?" Federal Reserve Bank of New York Economic Policy Review 10(3): 1-17.

[60] McDonald, J., and Stokes, H. 2013. "Monetary Policy and the Housing Bubble." Journal of Real Estate Finance and Economics 46: 437-451.

[61] Menkhoff, L., and Taylor, M. 2007. "The obstinate passion of foreign exchange professionals: Technical analysis." Journal of Economic Literature 45(4): 936-972.

[62] Mikhed, V., and Zemcik, P. 2007. "Testing for bubbles in housing markets: a panel data approach." CERGE-EI Working Paper: 338.

[63] Mikhed, V., and Zemcik, P. 2009. "Testing for bubbles in housing markets: a panel data approach." Journal of Real Estate Finance and Economics 38: 366-386.

[64] Nneji, O., Brooks, C., and Ward, C. 2013. "Intrinsic and rational speculative bubbles in the US housing market: 1960-2011." Journal of Real Estate Research 35(2): 121151.

[65] Perlin, M. 2015. "MS regress the MATLAB package for Markov regime switching models." Available at SSRN: http://ssrn.com/abstract=1714016.

[66] Piazzesi, M., and Schneider, M. 2009. "Momentum traders in the housing market: survey evidence and a search model" The American Economic Review 99(2): 406411.

[67] Roubini, N., and Mihm, S. 2010 Crisis economics. New York: Penguin.

[68] Schwartz, A. 2009. "Origins of the financial market crisis of 2008." Cato Journal 29: $19-23$.

[69] Shiller, R. 2005. Irrational Exuberance. Princeton: Princeton University Press.

[70] Shiller, R. 2009. The subprime solution. Princeton: Princeton University Press. 
[71] Simon, H. 1957. Models of Man, Social and Rational: Mathematical Essays on Rational Human Behavior in a Social Setting. New York: Wiley.

[72] Smith, M., and Smith, G. 2006. "Bubble, bubble, wheres the housing bubble?" Brookings Papers on Economic Activity 1: 1-50.

[73] Sommervoll, D., Borgersen, T., and Wennemo, T. 2010. "Endogenous housing market cycles." Journal of Banking and Finance 34(3): 557-567.

[74] Spiess, A., and Neumeyer, N. 2010. "An evaluation of $R^{2}$ as an inadequate measure for nonlinear models in pharmacological and biochemical research: a Monte Carlo approach." BMC Pharmacology 10: 6.

[75] Stiglitz, J. 1990. "Symposium on bubbles." Journal of Economic Perspectives 4(2): $13-18$.

[76] Takeshi, A. 1983. "Nonlinear Regression Models." Chap. 6 in Handbook of Econometrics. Amsterdam: Elsevier B.V.

[77] Taylor, J. 2007. "Housing and monetary policy." NBER Working Paper: No. 13682.

[78] Taylor, J. 2010. "Getting Back on Track: Macroeconomic policy lessons from the financial crisis." Federal Reserve Bank of St. Louis Review: 165-176.

[79] Terasvirta, T. 1994. "Specification, estimation,and evaluation of smooth transition autoregressive models." Journal of the American Statistical Association 89(425): 208-218.

[80] Uhlig, H. 2010. "A model of a systemic bank run." Journal of Monetary Economics 57: 78-96.

[81] Westerhoff, F., and Reitz, S. 2005. "Commodity price dynamics and the nonlinear market impact of technical traders: empirical evidence for the US corn market." Physica A: Statistical Mechanics and its Applications 349: 641-648.

[82] Zhou, W., and Sornette, D. 2006. "Is there a real-estate bubble in the US?" Physica A 361: 297-308. 